\title{
Nutrient Limitation Dynamics of a Coastal Cape Cod Pond: Seasonal Trends in Alkaline Phosphatase Activity
}

\author{
By \\ Christie Lynn Haupert \\ B.S., University of Minnesota, Duluth, 1998 \\ Submitted in partial fulfillment of the requirements for the degree of \\ Master of Science \\ at the \\ MASSACHUSETTS INSTITUTE OF TECHNOLOGY \\ and the \\ WOODS HOLE OCEANOGRAPHIC INSTITUTION
}

November 13, 2000

(C) 2000 Christie Lynn Haupert

All rights reserved.

The author hereby grants to MIT and WHOI permission to reproduce paper and electronic copies of this thesis in whole or in part and to distribute them publicly.

Signature of Author

Joint Program in Oceanography

Massachusetts Institute of Technology

And Woods Hole Oceanographic Institution

November 13, 2000

Certified by

Dr. Kathleen C. Ruttenberg

Associate Scientist, Marine Chemistry and Geochemistry

Thesis Supervisor

Accepted by

Dr. Margaret K. Tivey

Chair, Joint Committee for Chemical Oceanography

Massachusetts Institute of Technology/

Woods Hole Oceanographic Institution 


\title{
Nutrient Limitation Dynamics of a Coastal Cape Cod Pond: Seasonal Trends in Alkaline Phosphatase Activity
}

\author{
By \\ Christie Lynn Haupert
Submitted to the Department of Earth, Atmospheric, and Planetary Sciences
Massachusetts Institute of Technology
and
Department of Marine Chemistry and Geochemistry
Woods Hole Oceanographic Institution

November 2000

in partial fulfillment of the requirements

for the degree of Master of Science

\begin{abstract}
A bi-weekly seasonal study was conducted in Ashumet Pond (Cape Cod, Massachusetts). The Redfield Ratio (106C:16N:1P) and alkaline phosphatase activity (APA) were utilized in tandem as nutrient deficiency indicators (NDIs) for phytoplankton. The study objective was to evaluate the limiting nutrient status of the pond throughout the growing season.

The development of a high throughput method for fluorometrically measuring APA allowed for a large quantity of pond-water samples to be analyzed. The new method utilized a cytofluor, a fluorescence multi-well plate reader, which increased sample throughput by $75 \%$ compared to a standard filter fluorometer method. The detection limit, capability to measure APA at different time intervals, and performance at sea were tested. APA measurements made using the cytofluor were comparable to those made using a standard filter fluorometer, thus indicating that the cytofluor is a suitable and preferred replacement to the fluorometer for APA measurements.

The presence of alkaline phosphatase, an inducible phospho-hydrolytic enzyme, is commonly used as an NDI diagnostic for phosphate limitation. A nutrient enrichment incubation re-affirmed the use of APA as a robust indicator of phosphate limitation in phytoplankton. APA data indicate that the system experienced episodic periods of phosphate-deficiency, implying that the limiting nutrient regime was not static, but was changeable throughout the growing season. Seasonal trends in dissolved N:P and particulate C:P ratios often contradict the APA results, however, suggesting that the Redfield Ratio is an unreliable indicator of the overall nutrient limitation regime of the pond. The observed discrepancies between $\mathrm{C}: \mathrm{N}: \mathrm{P}$ and APA can be reconciled by taking into account seasonal changes in species composition, which played an important role in driving seasonal APA trends.
\end{abstract}




\section{Acknowledgements}

Life is funny. We go through it struggling to become individuals, to find our own way, and yet, in order to do that we must rely on the wisdom and kindness of others. This thesis would not have been what it is without the effort and support of a number of people. First, I'd like to recognize Kathleen Ruttenberg. Her careful thought, her watchful eye and her ability to delegate made our advisor-student relationship one I'll forever look back on with fondness. Thank you for honing my scientific skills, especially my writing style. The members of my committee must also be recognized-Karin Rengefors, Brian Howes and Craig Taylor-who supported me and set me straight more times than I can count. Thank you. To the members of the Ashumet Pond sampling, thanks for a job well done. To Alex Williamson and Nicole Keon, many thanks, for without the two of you I'd probably still have a freezer full of Ashumet Pond samples. Special thanks to Andy Solow for taking hours out of his weekends to enlighten me on the mystical world of statistics. To all the basement dwellers of McLean, thanks for the life down there. The members of the Ruttenberg lab group meetings also deserve recognition-Kirsten Laarkamp, Nicole Colassaco, Nana Ogawa, Kate Doyle (dishwasher extraordinaire), Sonya Dhyrman, and Karin Rengefors-for the hours they spent listening to me think out loud. Karin, I've enjoyed our dialogue over the past two years and wish you the very best in Sweden.

This thesis wasn't only supported by the wisdom and knowledge of colleagues, for without my friends and family I wouldn't have learned as much as I did. Thank you all for the laughter, especially Ana Lima-you will forever hold a special place in my heart. To Horace-thank you for helping me escape the daily grind, your love and support kept the light at the end of the tunnel shining bright. Obrigado, Querrido.

To my mom and dad-thank you for giving me the tools to stand on my own, for allowing me to stumble and fall, and for helping me dust myself off afterwards. For encouraging me to follow my heart and to make sure I laugh every step along the way. But more importantly, thank you for your honesty and insight into what life is really all about:

$$
\text { BEING TRUE TO YOURSELF! }
$$

My thoughts and prayers are with the two of you everyday. I love you.

And for all of those who have enjoyed my Minnesota accent over the years, I just have one thing to say: Am I glad to be done?....(-) "YOU BETCHA!" :)

Funding was provided by: Air Force/University of Massachusetts; Dartmouth (WHOI grant\#1503770) and a WHOI Educational Fellowship. 
Dedicated to those who dared to dance. 


\section{Table of Contents}

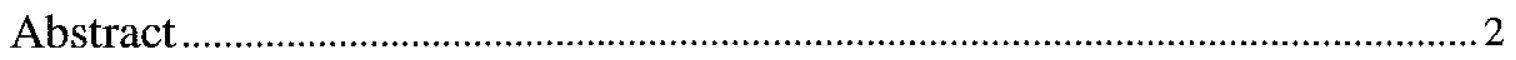

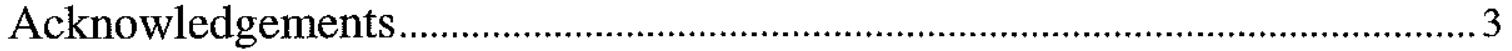

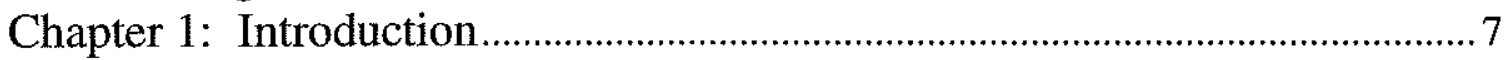

Chapter 2: Nutrient Deficiency Indicators ......................................................... 10

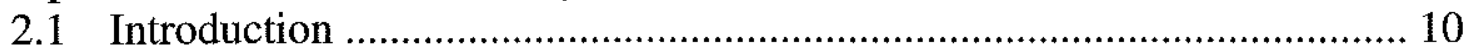

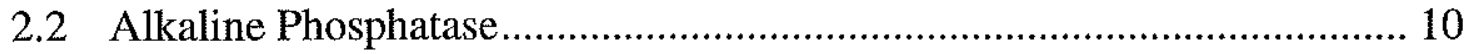

2.2.1 What is an Enzyme?.............................................................................. 11

2.2.2 The Hydrolysis Reaction Mechanism ........................................................ 13

2.2.3 Structural Characteristics …………………….......................................... 14

2.2.4 Location, Location, Regulation ................................................................ 15

2.2.5 Phosphorus- versus Phosphate-Deficiency ………………………………... 17

2.2.6 Reporting Alkaline Phosphatase Activity ………....................................... 18

2.2.7 Alkaline Phosphatase Activity as an Indicator of Phosphate-Deficiency .....21

2.3 Other Common Indicators of Nutrient Deficiency Used for This Study .. 22

2.3.1 Dissolved Inorganic Nutrient Ratios ............................................................2 23

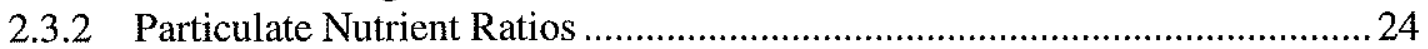

2.3.3 The Reliability of Dissolved and Particulate Nutrient Ratios ....................... 26

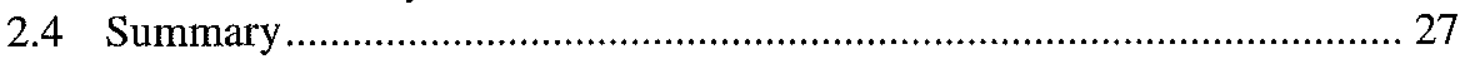

Chapter 3: Alkaline Phosphatase Activity Measurements................................ 32

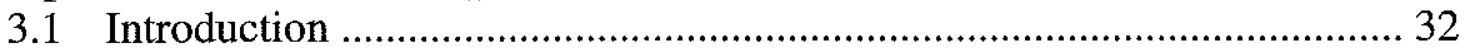

3.2 Theory of Enzyme Kinetics \& Application to Alkaline Phosphatase ....... 32

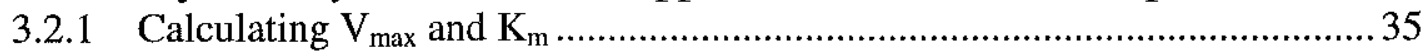

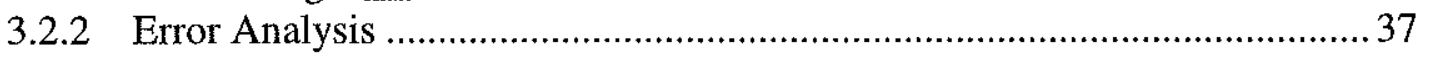

3.3 Measurement of Alkaline Phosphatase Activity ….................................. 38

3.3.1 Analytical Methods ................................................................................ 40

3.3.1.1 Basic Theory of Fluorescence …….................................................... 41

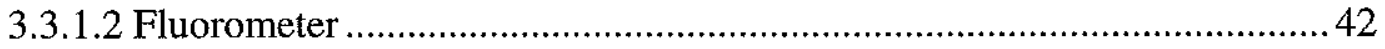

Detection Limit ............................................................................... 43

3.3.1.3 Cytofluor ........................................................................................ 44

Detection Limit ................................................................................ 47

Capabilities of the Cytofluor at Two Different Time Intervals.................. 48

3.3.1.4 Effect of Long-Term Freezing on Alkaline Phosphatase Activity........... 49

3.3.1.5 Cytofluor-Fluorometer Direct Comparison................................................ 51

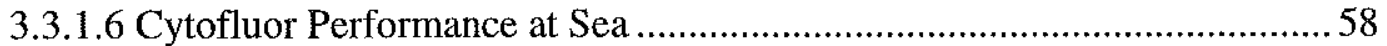

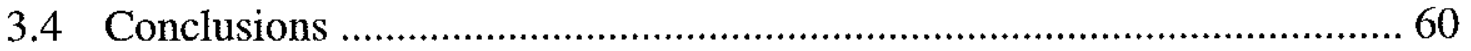

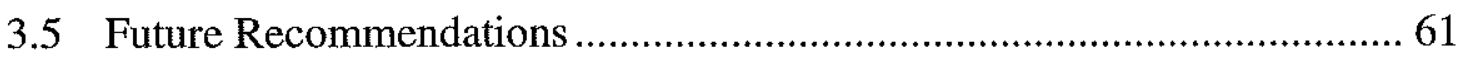


Chapter 4: Nutrient Limitation Dynamics Of Ashumet Pond: Reliability Of Nutrient Deficiency Indicators............................................................................... 73

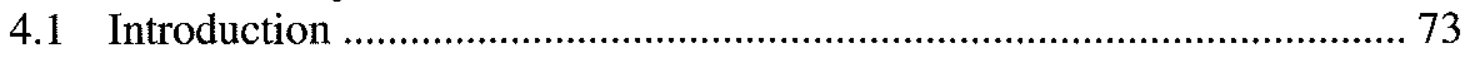

4.2 Background \& Context of Study .......................................................... 74

4.2.1 Description of Study Site .......................................................................... 74

4.2.2 MMR, Sewage Treatment Plant, and Sewage Groundwater Plume .............. 75

4.3 Sample Collection \& Analysis .................................................................... 77

4.3.1 SMAST Water Sampling Plan/Collection and Nutrient Analyses.................77

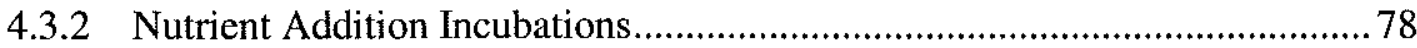

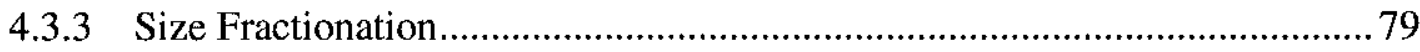

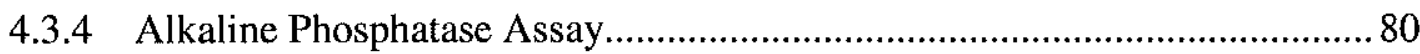

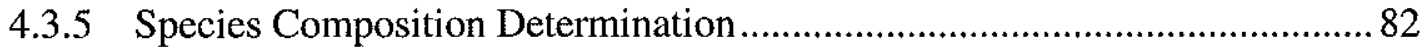

4.4 Summer Stratification: Temperature \& Dissolved Oxygen Profiles.......... 82

4.4.1 Seasonal Development of Temperature and Dissolved Oxygen ..................... 83

4.5 Nutrient Cycles \& Nutrient Deficiency Indicators ..................................... 87

4.5.1 The Phosphorus Cycle................................................................................8 87

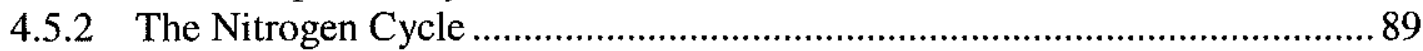

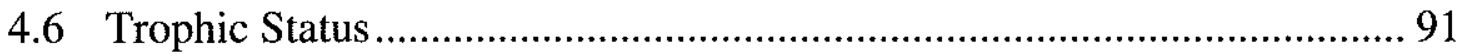

4.7 Nutrient Deficiency Indicators: Alkaline Phosphatase \& Nutrient Ratios 93

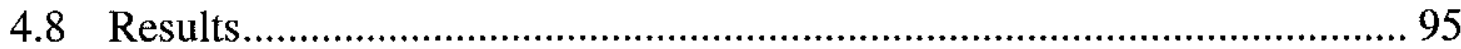

4.8.1 Nutrient Addition Experiments .................................................................99

4.8.2 Pond-Wide Lateral Homogeneity \& Vertical Patchiness................................ 99

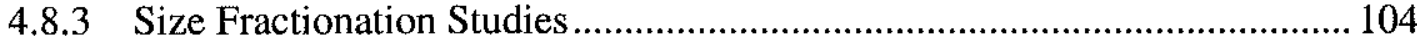

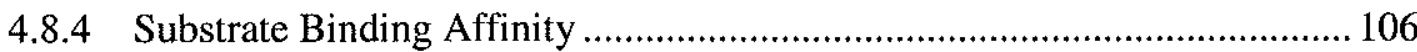

4.8.5 Comparison of Nutrient Deficiency Indicators ............................................. 107

4.8.6 Influence of Species Composition.................................................................. 109

4.8.7 Dissolved Inorganic-P Threshold for Alkaline Phosphatase Activity ........ 112

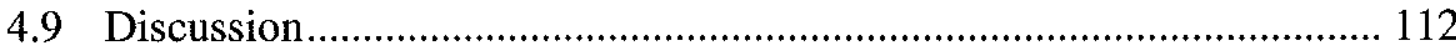

4.9.1 Influence of Species Composition and Nutrient Distribution on APA ....... 112

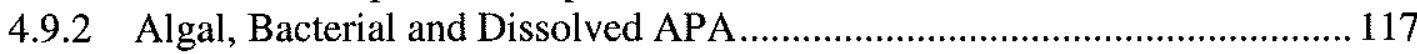

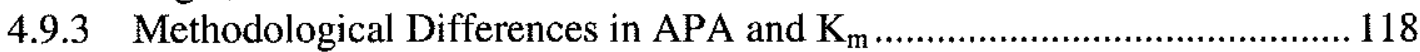

4.9.4 Discrepancies Between C:N:P and APA as Nutrient Deficiency Indicators

4.9.5 Phosphate Threshold for Alkaline Phosphatase Activity ............................ 122

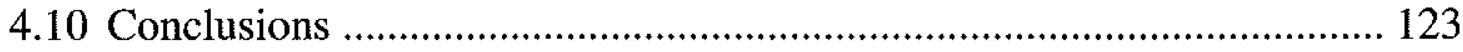

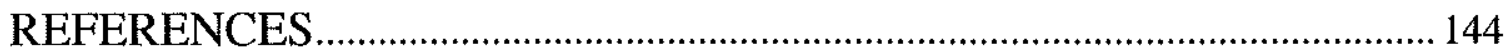




\section{Chapter 1}

\section{INTRODUCTION}

A sewage-contaminated groundwater plume is impacting Ashumet Pond, a kettle pond on Cape Cod, Massachusetts. In order to determine if the nutrient-laden groundwater will cause eutrophication in Ashumet Pond, the current limiting nutrient status of the pond over the growing season was assessed. A bi-weekly seasonal study utilized the Redfield Ratio (106C:16N:1P) and alkaline phosphatase activity (APA) in tandem as nutrient deficiency indicators for phytoplankton.

The nutrient deficiency indicators used in this study are: (i) alkaline phosphatase, (ii) dissolved nutrient ratios, and (iii) particulate nutrient ratios. The general characteristics of these three nutrient deficiency indicators are described in Chapter 2 and will be briefly described here. Alkaline phosphatase is a phospho-hydrolytic enzyme, that hydrolyzes the phosphate head group off of phosphomonoesters. It is either located on the cell-surface or it is excreted directly into the water column. It is an inducible enzyme that is produced by phytoplankton and bacteria under phosphate-deficient conditions (McComb, 1979). Therefore, since phytoplankton and bacteria can regulate the synthesis of alkaline phosphatase, detecting of the presence of the enzyme indicates that the phyto- and bacterio-plankton taxa are limited by the availability of bioavailable inorganic phosphorus. 
Phytoplankton and bacteria require the same biochemical building blocks in roughly the same proportions. Therefore, nutrient ratios, such as the dissolved inorganic nitrogen to phosphorus ratio (DIN:DIP) and the particulate organic carbon to phosphorus ratio (POC:PP), can be used as nutrient deficiency indicators due to the average $\mathrm{C}: \mathrm{N}: \mathrm{P}$ composition of phytoplankton (Redfield, 1958). The limiting nutrient status is determined by evaluating deviations in the in-situ DIN:DIP and POC:PP ratios from the average C:N:P composition of 106C: 16N: 1P (Redfield, 1958). Therefore, if the DIN:DIP ratio of the system is greater than $16: 1$ and the POC:PP ratio is greater than 106:1, the system is defined to be P-limited. There are weaknesses to each nutrient ratio, however, that undermine the use of these as effective nutrient deficiency indicators, such as luxury consumption of $\mathrm{N}$ and $\mathrm{P}$ and detrital influences.

The methodology used for alkaline phosphatase activity measurements is described in Chapter 3. The presence of alkaline phosphatase is typically determined by measuring the catalytic activity of the enzyme. Alkaline phosphatase activity (APA) was determined by fluorometrically measuring the increase of a fluorescent hydrolysis product (MUF) from the addition of an artificial fluorogenic substrate (MUF-P) during a 30-minute time course. To adequately characterize Ashumet Pond, it was necessary to analyze a large quantity of samples. However, the standard instrument employed in fluorometric assays, a standard filter fluorometer, required a very time-intensive method. Therefore, a high throughput method was developed for fluorometrically measuring APA. The new method utilized a fluorescence multi-well plate reader, or cytofluor, which increased sample throughput by $75 \%$ as compared to using a standard filter 
fluorometer method. The cytofluor was tested for detection limit, capability to measure APA at different time intervals, and performance at sea. The detection limit was determined to be adequate for the levels of APA in Ashumet Pond, and the time interval spanning fluorescence measurements was shown to be inconsequential in measuring APA. The cytofluor was shown to be a suitable and preferred replacement to the fluorometer for APA measurements through the use of a head-to-head direct comparison. The cytofluor was a reliable instrument under rough sea conditions.

In Chapter 4, the limiting nutrient status of Ashumet Pond is evaluated using trends in APA, DIN:DIP and POC:PP. The three nutrient deficiency indicators used in this study were scrutinized to evaluate how accurate and robust they proved to be. Alkaline phosphatase emerged as the least ambiguous of the three nutrient deficiency indicators tested. A nutrient enrichment incubation re-affirmed the use of APA as a robust indicator of phosphate limitation in phytoplankton. APA data indicated that the system experienced episodic periods of phosphate-deficiency, implying that the limiting nutrient regime was not static throughout the growing season. Seasonal trends in dissolved N:P and particulate C:P ratios often contradicted the APA results, as well as each other, however, suggesting that the Redfield Ratio was an inaccurate indicator of the overall nutrient limitation regime of the pond. Seasonal changes in species composition played an important role in driving seasonal APA trends. The correlation between APA and species composition stresses the importance of high frequency sampling in tandem with species composition analysis in order to accurately characterize the nutrient limitation regime of aquatic systems. 


\section{Chapter 2}

\section{NUTRIENT DEFICIENCY INDICATORS}

\section{$2.1 \quad$ Introduction}

Algal and bacterial cells have physiological properties that respond similarly under nutrient deficient conditions. These responses are directly related to the nutritional status of an aquatic system and are, therefore, used as nutrient deficiency indicators. Commonly used nutrient deficiency indicators include: (i) production of enzymes known to alleviate nutrient deficiency, (ii) the dissolved nutrient inventories and ratios of the aquatic system, and (iii) the elemental composition of biogenic particulate material within an aquatic system. Each of these three indicators are used in this study to understand the nutrient limitation status of a freshwater pond.

\subsection{Alkaline Phosphatase}

When phosphate concentrations are in excess relative to phytoplankton cellular requirements within an aquatic system, phytoplankton and bacteria readily assimilate orthophosphate, which is the simplest form of dissolved inorganic phosphorus (DIP), to maintain cellular phosphorus requirements (Cembella et al., 1984). However, under depleted orthophosphate concentrations, the dissolved organic phosphorus (DOP) pool can be utilized (Berman, 1988; Bjorkman and Karl, 1994). Utilization of DOP by algal and bacterial cells occurs via DOP hydrolysis using alkaline phosphatase, a non- 
constitutive cell-surface enzyme (Healey and Hendzel, 1980). The presence/absence of alkaline phosphatase is, therefore, an indicator of the nutritional status of the aquatic system with respect to orthophosphate concentrations.

\subsubsection{What is an Enzyme?}

Most chemical reactions require catalysts in order to proceed (Oxtoby and Nachtrieb, 1990). The group of biological catalysts, known as enzymes, mediate the biochemical reactions that regulate all living organisms. Enzymes are high molecular weight proteins synthesized by cells to catalyze specific reactions. They are superior to non-enzymatic chemical catalysts in many ways, as summarized by Voet and Voet (1995):

1. A reaction catalyzed by an enzyme will have a much higher reaction rate (i.e., the reaction occurs much faster) than one catalyzed by a non-enzymatic chemical catalyst.

2. Enzymatic reactions can occur under mild reaction conditions, often times much lower than $100^{\circ} \mathrm{C}$ and at neutral $\mathrm{pH}$. These conditions characterize many natural systems. In contrast, chemical catalysts often require extreme temperature and pH conditions.

3. Enzymes have specificity for certain substrates or reactants. A particular enzyme only catalyzes a specific reaction, eliminating side reactions and enhancing the overall yield. Chemical catalysts do not display such specificity, and are, therefore, less efficient. 
Each enzyme has a specific structural conformation at the substrate binding site (i.e., active site). The active site is geometrically complementary to the shape of the substrate. Binding of the substrate to the active site (Figure 2.1) occurs through non-covalent forces, such as van der Waals, electrostatic, hydrogen-bonding, and hydrophobic interactions. The amino acid residues within the active site are also arranged specifically to interact electronically with the substrate. Therefore, molecules that differ from the substrate in shape and functional group distribution will be unable to bind to the active site (i.e., the enzyme-substrate complex does not form).

4. Enzymes have the capacity for regulation. They can be regulated by the presence/absence of substances other than the substrate. There are three classes of enzyme regulation: (i) constitutive, (ii) repressible, and (iii) inducible. A constitutive enzyme is one that is made at more or less a constant rate under all environmental conditions (this is analogous to a chemical catalyst). Repressible and inducible enzymes have mechanisms that turn on and off enzyme synthesis. In the case of a repressible enzyme, production ceases in the presence of the repressor, (e.g., the reaction product). Therefore, it is the absence of the repressor that stimulates synthesis. The mirror image is true for an inducible enzyme, for which the presence of an activator protein (some protein other than the substrate) stimulates enzyme synthesis.

Enzymes play an important role in mediating the pathways that control the formation and breakdown of life's essential building blocks. For example, alkaline phosphatase, one of 
the nutrient deficiency indicators used in this study, functions at the cellular level within the planktonic community of natural aquatic systems. Algal and bacterial cells utilize alkaline phosphatase to mediate the breakdown of dissolved phosphomonoesters into bioavailable forms of phosphorus. Synthesis of the enzyme is regulated by the presence of orthophosphate. Therefore, in situations when orthophosphate becomes depleted, alkaline phosphatase is produced. The enzymatic characteristics of alkaline phosphatase make it ideally suited as an indicator of phosphate limitation in natural waters. In this study alkaline phosphatase is used to understand the nutrient limitation status of a freshwater pond.

\subsubsection{The Hydrolysis Reaction Mechanism}

Alkaline phosphatase is a phosphomonoesterase that catalyzes the hydrolysis of monoesters of phosphoric acid, or phosphomonoesters (PMEs), hydrolytically cleaving orthophosphate from the organic moiety of the PME. The hydrolysis reaction mechanism, summarized by Jansson et al. (1988), proceeds according to the following four steps. These steps are illustrated graphically in Figure 2.2:

1. The enzyme non-covalently bonds to the substrate (PME), forming an enzyme-substrate complex.

2. The orthophosphate moiety of the PME covalently bonds to the enzyme, forming a phosphoryl-enzyme complex and releasing organic carbon in the form of an alcohol.

3. The phosphoryl-enzyme complex combines with water and becomes noncovalently bonded. 
4. Orthophosphate is released and the protonated enzyme is regenerated. Alkaline phosphatase is not substrate specific, as indicated in the schematic of the reaction mechanism (Figure 2.2). A mono phosphate-head group is the sole requirement; the nature of the organic moiety (e.g., the R-group) does not play a primary role in enzyme affinity. Therefore a variety of phosphomonoesters, theoretically, can be hydrolytically cleaved by a single phosphomonoesterase. In practice, however, it has been demonstrated that some phosphomonoester substrates are more readily hydrolyzed than others (Mccomb et al., 1979). Such observed variability in substrate hydrolysis implies that the R-group may influence enzyme affinity for specific substrates by interfering with the conformational nature of the active site.

\subsubsection{Structural Characteristics}

A common name for phosphomonoesterases is phosphatase. There are two major divisions of phosphatases, alkaline and acid. Alkaline phosphatases are the most frequently studied of the phosphomonoesterases in natural waters. The catalytic activity of the alkaline phosphatases (i.e., speed at which hydrolysis of the PME occurs) functions optimally at $\mathrm{pH}>7$; conditions typical to most freshwater environments. Acid phosphatases have also been investigated, however, conditions which favor activity of acid phosphatases (i.e., express highest activity between $\mathrm{pH} 4$ and $\mathrm{pH} 6$ ) are not common in most freshwater systems and are believed to be less important for in-situ phosphorus mineralization (Jansson et al., 1988).

Alkaline phosphatases are, generally, zinc containing, dimeric enzymes (i.e., two identical sub-units) that have molecular weights between 70,000-180,000 (see McComb 
et al., 1979 for summary). The active site for an alkaline phosphatase isolated from $E$. coli is shown in Figure 2.3. As phosphate binds to the active site (either in the form of orthophosphate or a PME), it interacts with a metal triplet ( $t w o \mathrm{Zn}^{2+}$ and one $\mathrm{Mg}^{2+}$ ), an amino acid sequence of aspartic acid (Asp101), serine (Ser102), and alanine (Ala103), their ligands, and other amino acids in the immediate vicinity (Figure 2.3) (Kim and Wyckoff, 1991). The phosphate is coordinated directly to both $\mathrm{Zn}^{2+}$ moieties. It is also tightly held by an amino group (Arg156) that is hydrogen bonded to Asp101, and further hydrogen bonded to a water molecule that is coordinated to $\mathrm{Mg}^{2+}$. The active site of this E. coli alkaline phosphatase has been matched to other mammalian and bacterial alkaline phosphatases, and it appears that they all have the same 3-dimensional active site core. Most modifications in structure occur away from the active site region (Kim and Wyckoff, 1991). The structural evidence presented here supports the claim that alkaline phosphatases are uniform in morphology throughout nature. In addition, the enzymes are consistent in function due to the non-specific nature of the enzyme for PMEs, as depicted in the hydrolysis reaction mechanism (Figure 2.2).

\subsubsection{Location, Location, Regulation}

Studies of marine (Kuenzler and Perras, 1965; Rivkin and Swift, 1980) and freshwater algal cultures (Healey and Hendzel, 1979), and bacterial cultures (Whitton et al., 1991) have indicated that alkaline phosphatase is mostly cell-surface bound and/or excreted (secreted) into the surrounding water. The location of alkaline phosphatase at the cell surface is an important characteristic for it's role as a nutrient deficiency indicator. Alkaline phosphatase is positioned on the outside of the cell, either on the cell 
wall or in the periplasmic space between the cell wall and the plasma membrane, or it is directly excreted into the surrounding water. Alkaline phosphatase can readily access the dissolved organic phosphorus (DOP) pool of the surrounding medium, thus enabling it to hydrolyze DOP and restock cellular phosphate stores.

The surface-associated nature of the enzyme is also important from a regulation standpoint. Alkaline phosphatase is considered to be non-constitutive, i.e., repressed in the presence of orthophosphate (Cembella et al., 1984). Competitive inhibition of alkaline phosphatase is controlled by the concentration of orthophosphate in the surrounding medium (Mccomb et al., 1979). Orthophosphate competitively binds to the active site forming a stable complex that prohibits the formation of the enzyme-substrate complex, thus shutting down the catalytic activity of the enzyme. Just as the presence of orthophosphate inhibits enzyme production, the absence of orthophosphate stimulates enzyme synthesis, i.e., de-repression occurs. The terms de-repression and induction are used synonymously in the published literature to indicate that in the absence of orthophosphate, synthesis of alkaline phosphatase occurs. However, the repression/derepression cycle undergone by alkaline phosphatase is distinct from that of an inducible enzyme, for which production is stimulated in the presence of an activator substrate. Although the mechanism controlling alkaline phosphatase production is distinct from a strictly inducible enzyme, the fact that it is a cell-surface de-repressible/inducible enzyme makes alkaline phosphatase an inherently good indicator of phosphate-deficiency.

The presence of constitutive surface-associated alkaline phosphatase activity (APA) in a natural water system has not been conclusively documented. Jamet et al. 
(1997) speculated about the presence of constitutive APA when they were unable to establish an inverse relationship between dissolved inorganic phosphorus (DIP) and APA during a study of a lake in France. However, the study focused primarily on DIP concentrations. They were unable to conclusively document the presence of constitutive activity because they were unable to rule out the possibility that internal-P concentrations were regulating the production of the enzyme (see section 2.1.5). Jamet et al., also, did not analyze the species composition of the system, which, as this study will show, can be an important factor in understanding the dynamic nature of APA. Consequently, they were unable to refute the de-repressible nature of the enzyme. Dyhrman and Palenik (1999) documented the presence of constitutive intracellular alkaline phosphatases in cultured diatoms using a fluorescent tag (ELF-97) that interacts with alkaline phosphatases, however, they were unable to document the presence of constitutive surface-associated APA. On the contrary, the inducible nature of surface-associated alkaline phosphatase was conclusively documented by their study.

\subsubsection{Phosphorus- versus Phosphate-Deficiency}

Terminology to describe the nutritional status of a phyto- and bacterio-plankton population can at times be confusing. For the purposes of this study, P-

limitation/stress/deficiency will be used synonymously, and will all be defined as the environmental condition in which the total dissolved phosphorus (TDP) content (including orthophosphate plus DOP) of the supporting medium becomes so low that phytoplankton growth rate is severely diminished. Under these conditions, phosphorus is the limiting nutrient. 
Organisms able to produce alkaline phosphatase, have an alternative way to obtain P, via DOP hydrolysis. Therefore, even when orthophosphate becomes depleted from the environment, organisms able to produce alkaline phosphatase will not be $\mathrm{P}$ limited, but may be phosphate-deficient. Phosphate-deficiency is defined as the condition in which extracellular orthophosphate concentrations drop to levels at which cells can no longer maintain intracellular surplus-P. Phytoplankton have the ability to store surplus-P in the form of polyphosphates (polymers of orthophosphate) (Rubin et al., 1977; Reynolds, 1984). The mechanism by which surplus-P storage occurs is defined as luxury uptake. Luxury uptake of nitrogen exists within some phytoplankton taxa, as well (e.g., McCarthy 1980). Internal storage of surplus-P as polyphosphate occurs when orthophosphate is abundant in the surrounding water. When these internal cellular-P stores become depleted, alkaline phosphatase synthesis is triggered (Fitzgerald and Nelson, 1966; Pettersson, 1980; Cembella et al., 1984). According to this definition, the presence of APA signifies phosphate-deficiency. This study will deal primarily with detecting phosphate-deficiency, rather than P-limitation. However, if an auto- and heterotrophic plankton community is phosphate-deficient, it indicates that there is not enough $\mathbf{P}$ for sufficient normal growth and therefore, cells must expend more energy to maintain equivalent growth.

\subsubsection{Reporting Alkaline Phosphatase Activity}

Alkaline phosphatase activity (APA) is usually reported as the maximum velocity (i.e., maximum catalytic rate) at which the enzyme can hydrolyze PMEs. Velocity measurements are typically made by saturating the enzyme's active site with a PME so 
that enzyme catalysis will proceed at its maximum rate. APA is usually reported in units of $\mu \mathrm{mol} \mathrm{L} \mathrm{L}^{-1} \mathrm{~min}^{-1}$. Specific APA, or specific activity, is determined by normalizing APA to a biomass indicator, such as chlorophyll-a (Pettersson, 1980) or ATP (Healey and Hendzel, 1980). Specific APA has been used as an indicator of how a population behaves at the cellular level with respect to phosphate-deficiency (Kuenzler and Perras, 1965; Fitzgerald and Nelson, 1966; Perry, 1972). However, this usage is valid only if the entire population synthesizes alkaline phosphatase. For example, if all of the cells within a population were producing alkaline phosphatase, and both enzyme activity and chlorophyll-a were determined, specific APA would reflect the number of enzymes produced by each cell. Under these conditions, specific APA would be a robust indicator of the severity of phosphate-deficiency being experienced by the cells. If the population is producing many enzymes per cell, it is assumed that the cells are extremely phosphate starved. All studies that report specific activity are based on the assumption that all cells within a mixed phytoplankton population produce alkaline phosphatase at the same time and at the same level. Support for this assumption has been derived from the work of Healey and Hendzel (1979), who demonstrated that five algal species in culture responded with fairly similar APA under phosphate-deficient conditions. However, most work of this kind has focused on APA of unialgal cultures (e.g., Rivkin and Swift, 1980), and the possibility of species specific variability in APA within a mixed phytoplankton population has not been widely investigated. Thus, the assumption that all cells within a mixed phytoplankton population produce alkaline phosphatase at the same time and at the same level under phosphate-deficient conditions has not rigorously been validated. 
The assumption that specific APA can be used to describe the nutritional status of a mixed phytoplankton populations has been viewed with skepticism by some. According to Chróst and Overbeck (1987), differences in alkaline phosphatase production between microbial species must be considered when reporting APA of a mixed population. As T. Berman (1970) so eloquently stated, "when dealing with mixed populations of alkaline phosphatase and phytoplankton in the environment, specific activities serve no relevant purpose." These views have recently been supported through the use of a powerful new species-specific technique that determines the presence of APA at the single cell level (Gonzalez-Gil et al., 1998). This new technique, commonly called Enzyme Labeled Fluorescence, or ELF, involves fluorometrically tagging cellbound alkaline phosphatase, followed by species identification using an epifluorescence microscope. Use of ELF in a nutrient enrichment experiment conducted with Ashumet Pond surface water samples has demonstrated species-specific differences in APA through the course of the incubation (Rengefors et al., 2000). Under progressively more severe phosphate depletion, Rengefors et al. (2000) report that several chlorophyte taxa were driven to phosphate-deficiency as evidenced by the presence of ELF-alkaline phosphatase on their cell-surface. Two other species of the chlorophyte taxa and cyanobacterial species, however, did not produced APA (i.e., no ELF labeling occurred) during the 5-day incubation time-course. This study unequivocally indicates that all phytoplankton taxa do not produce APA at the same time or level under phosphate deficient conditions. Because the ELF assay results reported by Rengefors et al. (2000) for Ashumet Pond suggest the occurrence of species specific differences in the response 
of Ashumet Pond phytoplankton to phosphate-deficiency, specific APA values will not be used in this study. Rather, APA values will be reported without normalizing to biomass. The APA data presented in this study has not been normalized to biomass. Thus, reported APA data characterize the overall amount of enzyme activity in the water sample and does not, therefore, permit any inference to be made about the extent to which the overall community or a sub-population within the community is phosphatedeficient.

\subsubsection{Alkaline Phosphatase Activity as an Indicator of Phosphate-Deficiency}

In 1965, Kuenzler and Perras formulated the idea that APA can be used as an indicator of phosphate-deficiency of algae in culture. This initial work was followed by Fitzgerald and Nelson (1966), who reported that APA can be used as a phosphatedeficiency indicator in mixed populations from natural freshwater systems. Numerous other studies have successfully used APA to indicate the nutritional-P status of aquatic systems (e.g., Berman, 1970; Pettersson, 1980; Chróst and Overbeck, 1987; Whitton, 1991; Istvanovics et al., 1992; Hantke et al., 1996). However, debate continues as to the usefulness/reliability of this assay. There are uncertainties that must be kept in mind when using alkaline phosphatase as an indicator of phosphate-deficiency (see Cembella et al., 1984; Jansson et al., 1988 for summary). A summary of both the strengths and potential weaknesses of the APA assay as an index of phosphate-deficiency is provided in Table 2.1. Inverse correlations between APA and parameters such as phosphate concentration and total cellular phosphorus (Table 2.1), have been successfully used to indicate the efficaciousness of APA as a phosphate-deficiency indicator. However, 
factors such as APA contribution from zooplankton, constitutive APA, species-specific differences in APA, and differences in methodology, complicate the interpretation of APA data. As a consequence, alkaline phosphatase activity is best used in conjunction with other nutrient deficiency indicators (e.g., Jansson et al., 1988; Vincent, 1981).

The approach adopted by this study is to use multiple nutrient deficiency indicators in order to build the most robust case possible for the presence/absence of phosphate-deficiency. Specifically, seasonal pond-wide APA data will be supported by results from two nutrient enrichment experiments, species composition data and other nutrient deficiency indicators (discussed in the following section).

\subsection{Other Common Indicators of Nutrient Deficiency Used for This Study}

The absolute minimum cellular requirements of macronutrients (e.g., carbon (C), nitrogen $(\mathrm{N})$, phosphorus $(\mathrm{P})$ ) occur in relatively fixed proportions among freshwater algae (Reynolds, 1984). This empirical observation is consistent with the fact that most living cells perform the same basic functions and, therefore, require the same biochemical building blocks in roughly the same proportions. Within marine systems it has been determined that the C:N:P ratio of oceanic phytoplankton communities on average consists of 106C: 16N: 1P. This ratio is known as the Redfield Ratio (Redfield, 1958). Although the Redfield Ratio has not been empirically tested in freshwater systems, it is often used in comparison with the in-situ dissolved and particulate nutrient ratios of 
Table 2.1: Strengths and Potential Weaknesses of Alkaline Phosphatase Activity as a Phosphate-Deficiency Indicator. APase, APA and PME are defined as alkaline phosphatase, alkaline phosphatase activity and phosphomonoester, respectively.

\begin{tabular}{|l|}
\hline \multicolumn{1}{|c|}{ Observations Consistent with Phosphate-Deficiency } \\
\hline APA is inversely correlated with phosphate concentration. \\
\hline APA is inversely correlated with total phosphorus. \\
\hline APA is inversely correlated with total cellular phosphorus. \\
\hline $\begin{array}{l}\text { APA is inversely correlated with cellular surplus } \\
\text { phosphorus. }\end{array}$ \\
\hline APA is inversely correlated with phosphate uptake rate. \\
\hline $\begin{array}{l}\text { Cellular APA is inversely correlated with total cellular } \\
\text { phosphorus. }\end{array}$ \\
\hline
\end{tabular}

\footnotetext{
${ }^{1}$ after Jansson et al. (1988)

${ }^{2}$ Jamet et al. (1997)

${ }^{3}$ Rengefors et al. (unpublished)

${ }^{4} J a n s s o n$ and Pettersson (1978)

${ }^{5}$ Wilkins (1972)
}

\begin{tabular}{|l|}
\hline \multicolumn{1}{|c|}{$\begin{array}{c}\text { Factors interfering with the use of APA as a phosphate- } \\
\text { deficiency indicator }\end{array}$} \\
\hline The contribution from zooplankton APase is not well known. \\
\hline $\begin{array}{l}\text { The possible presence of constitutive APA can complicate the } \\
\text { use of the presence of APA as a definitive marker for } \\
\text { phosphate-deficient conditions. }\end{array}$ \\
\hline $\begin{array}{l}\text { Species-specific differences in APA can complicate } \\
\text { interpretation of the degree to which a mixed population is } \\
\text { limited. }\end{array}$ \\
\hline $\begin{array}{l}\text { The use of a variety of different methods for determining APA } \\
\text { complicates comparisons across studies. }\end{array}$ \\
\hline $\begin{array}{l}\text { APA in the dissolved phase has the potential to be mobile } \\
\text { throughout the water column and can therefore influence total } \\
\text { APA measurements through space/time. }\end{array}$ \\
\hline $\begin{array}{l}\text { Increased APA can be induced by conditions other than low } \\
\text { phosphate supply. For example, APase in } E \text {. coli were induced } \\
\text { by starvation for nucleotides rather than starvation for } \\
\text { phosphate. }\end{array}$ \\
\hline $\begin{array}{l}\text { External APA sources, such as riverine input, may interfere } \\
\text { with accurately attributing APA to in-situ production. }\end{array}$ \\
\hline
\end{tabular}


lacustrine systems in order to evaluate the nutrient status of freshwater systems (Hecky and Kilham, 1988). The constancy of macronutrients within different phytoplankton assemblages, and the similarity between the algal cells and the surrounding water, form the basis for the use of certain physiological properties as nutrient deficiency indicators. The elemental C:N:P ratios of both the dissolved and particulate pools in aquatic systems are commonly used to indicate the nutritional status of the in-situ phytoplankton community. These indicators provide a means for determining whether nutrient deficiency is important in the resident phytoplankton populations, and possibly to what extent the deficiency exists (Healey and Hendzel, 1980). The nutrient deficiency indicators employed in this study are defined in subsequent sections.

\subsubsection{Dissolved Inorganic Nutrient Ratios}

One of the conceptually simplest and most widely used of the nutrient deficiency indicators is the molar ratio of dissolved inorganic $\mathrm{N}$ (DIN) to dissolved inorganic $\mathrm{P}$ (DIP), or DIN:DIP. Using the Redfield ratio of $16 \mathrm{~N}: 1 \mathrm{P}$ to reflect the optimal nutritional state of the phytoplankton population, $\mathrm{N}$ - or P-limitation can be assessed from deviations in the measured DIN:DIP ratio from the Redfield Ratio. A DIN:DIP ratio above 16:1 implies that the microbial population is P-limited, while a ratio less than $16: 1$ indicates $\mathrm{N}$-limitation. There are some uncertainties associated with this approach, however. For example, phytoplankton are able to vary their internal N:P supply by utilizing luxury uptake mechanisms (i.e., consumption of excess nutrients in excess of growth requirements) (McCarthy, 1980; Reynolds, 1984). Therefore, if phytoplankton can store excess $N$ and $P$, the DIN:DIP ratio of the water need not coincide with the particulate N:P 
ratio, and therefore, may not reflect the nutritional status of the resident organisms. A specific example of this is Asterionella, a diatom. It can amass enough internally storedP to yield four full divisions in P-free medium (see Reynolds, 1984 for summary).

Despite this potential complication, the DIN:DIP ratio in aquatic environments has often proven to be an effective indicator of nutrient deficiency. For example, DIN:DIP ratios have been used as nutrient deficiency indicators in summer epilimnion studies in the US (AFCEE, 2000) and throughout Canada (see Hecky and Kilham, 1988 for summary). Recent evidence from total dissolved N:P ratios within the North Pacific Gyre (Karl, 1999) and DIN:DIP ratios from the Eel River Shelf (Ruttenberg et al., 1998; Monaghan and Ruttenberg, 1999) have been used to argue for the potential for P-limitation in the ocean.

\subsubsection{Particulate Nutrient Ratios}

The validity of various physiological indicators of nutrient deficiency derived from the elemental composition and elemental ratios of particulate matter in aquatic systems was evaluated by Healey and Hendzel (1980). They concluded that not only can particulate nutrient ratios diagnose nutrient deficiency, they can also indicate the degree to which the population is deficient. Through the use of culture studies, boundary conditions for the degree of limitation within phytoplankton cultures were distinguished (Healey and Hendzel, 1979; Vincent, 1981). A C:P ratio greater than 258:1 and a N:P ratio greater than 44:1 denote severe P-deficiency, where as a $\mathrm{C}: \mathrm{P}$ and a N:P ratio less 129:1 and 22:1, respectively, indicate no P-deficiency. Between these regions lies the boundary for moderate P-deficiency. Elevated deviations from the boundary conditions 
in particulate $\mathrm{C}: \mathrm{P}$ and $\mathrm{N}: \mathrm{P}$ ratios can be diagnostic of $\mathrm{P}$-limitation, where as $\mathrm{N}$-limitation is reflected in particulate $\mathrm{C}: \mathrm{P}$ and $\mathrm{N}: \mathrm{P}$ ratios less than $258: 1$ and $44: 1$, respectively (Hecky and Kilham, 1988). Although, the particulate nutrient ratios used by Healey and Hendzel (1980) are more descriptive concerning the nutrient limitation status of an aquatic system, they are not significantly different from the $106 \mathrm{C}: 1 \mathrm{P}$ and $16 \mathrm{~N}: 1 \mathrm{P}$ ratio of the Redfield Ratio. It is therefore common practice for studies to focus primarily on dissolved nutrients and to determine the nutrient limitation status of the natural population based on the Redfield Ratio.

However, there are differences between the boundary conditions established for freshwater algae by Healey and Hendzel (1980) and the Redfield Ratio. Therefore, in order to validate the use of the Redfield Ratio in lacustrine systems, the particulate C:N:P ratio of 50 different lakes was investigated (Hecky et al., 1993). Hecky et al. (1993) concluded that particulate matter in lakes varies significantly from the Redfield ratio and that the average particulate $\mathrm{C}: \mathrm{N}: \mathrm{P}$ ratio in different lakes varies as a function of climatic regime. The results of this study may not be conclusive, however, since the approach taken assumed all particulate matter was biogenic in nature, with negligible amount of detrital material. Hecky et al. (1993) assert there was little difference between detrital material and living particles in lakes, and that in most lakes with residence times in excess of months, particulate composition ratios will reflect the general availability of $\mathrm{N}$ and $\mathrm{P}$ for growth and not for terrestrial matter. However, terrestrial soils and vegetation are rich in $\mathrm{C}$ and $\mathrm{N}$ with high $\mathrm{C}: \mathrm{N}, \mathrm{N}: \mathrm{P}$ and $\mathrm{C}: \mathrm{P}$ ratios (Wetzel, 1975). Therefore, if detrital material, whether from riverine or atmospheric inputs, is present in considerable 
quantities, it will significantly influence the particulate nutrient ratio, and must be taken into account.

Ashumet Pond, the system investigated for this study, had no riverine input, as groundwater was the major input term. Therefore, an assumption was made that the pond has minimal inputs of detrital matter, and thus, the ratios established by Redfield (1958) and Healey and Hendzel (1980) will be compared to the stiociometry of Ashumet Pond. Both particulate and dissolved nutrient ratios will be referenced to the Redfield Ratio.

\subsubsection{The Reliability of Dissolved and Particulate Nutrient Ratios}

The weaknesses of dissolved and particulate nutrient ratios raise questions as to the reliability of each ratio as a nutrient deficiency indicator. Dissolved nutrient ratios only reflect the bioavailable component of the water column, and realistically may not accurately reflect the nutrient status of the phyto- and bacterio-plankton populations within the system. This is particularly true if luxury $\mathrm{P}$ or $\mathrm{N}$ consumption has occurred, because this results in a decoupling of the dissolved and particulate nutrient ratios. Particulate nutrient ratios, although conceptually reflective of the cellular nutrient status of the phyto- and bacterio-plankton, cannot distinguish between living and dead seston. For example, if the planktonic populations are dying off, the particulate $\mathrm{C}: \mathrm{N}: \mathrm{P}$ ratios will be heavily influenced by the $\mathrm{C}: \mathrm{N}: \mathrm{P}$ of the dead seston and will therefore be misleading as to the status of the living system.

Therefore, when using nutrient ratios, either dissolved or particulate, to determine the nutrient limitation status of a system, care must be taken in data interpretation. The use of APA in conjunction with dissolved and particulate nutrient ratios has afforded this 
study unique insight into the reliability of each indicator's ability to gauge the seasonal nutrient limitation regime of Ashumet Pond.

\subsection{Summary}

Nutrient deficiency indicators are used to determine the nutrient limitation status of aquatic systems. The nutrient deficiency indicators used in this study are: (i) alkaline phosphatase, (ii) dissolved inorganic nutrient ratios, and (iii) particulate nutrient ratios. Algae and bacteria synthesize alkaline phosphatase in order to maintain cellular-P requirements when experiencing phosphate-deficiency. Alkaline phosphatase is a derepressible, cell surface enzyme that hydrolyzes phosphomonotesters, producing bioavailable orthophosphate. Alkaline phosphatase synthesis is regulated by the concentration of dissolved inorganic phosphorus. The characteristics of alkaline phosphatase, such as its surface-associated or extracellular location and its repression in the presence of phosphate, enable it to be used as an indicator of phosphate-deficiency.

Under nutrient replete conditions, the elemental composition of algae and bacteria is nearly constant. Deviations from nutrient ratios normal under replete conditions are indicative of either nutrient-deficiency or surplus storage. Using alkaline phosphatase in tandem with dissolved and particulate nutrient ratios, the reliability of each nutrient deficiency indicator to describe the seasonal evolution of the nutrient limitation status of Ashumet Pond, was gauged. 

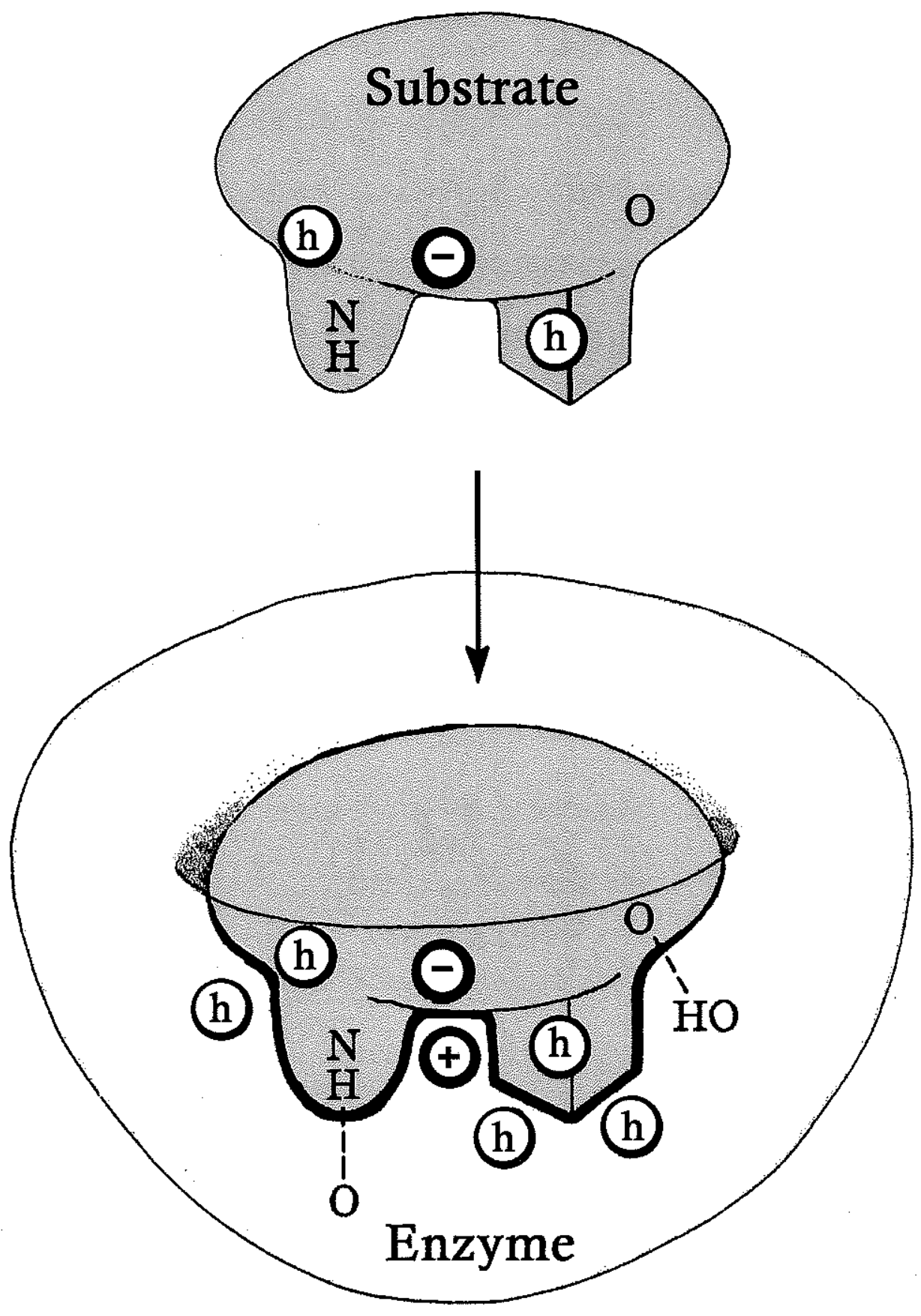

Figure 2.1: An enzyme-substrate complex illustrating both the geometrical and electronical complementarity between enzyme and substrate. Hydrophobic bonds are represented by an $h$ in a circle and dashed lines represent hydrogen bonds (taken from Voet and Voet, 1995). 


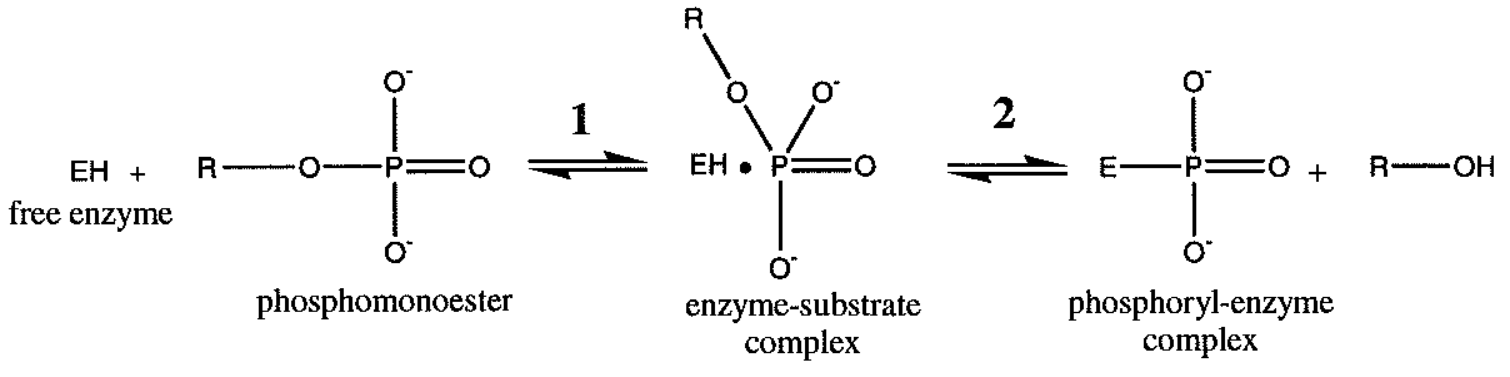<smiles>[O-]P([O-])(O)=[OH+]</smiles><smiles>CCP(=O)([O-])O</smiles><smiles>C=CCCC</smiles><smiles>O=P([O-])([O-])O</smiles>

orthophosphate

Figure 2.2: Reaction Mechanism for Alkaline Phosphatase. 1) The free enzyme forms a noncovalent bond ( $\bullet$ ) with the phosphomonoester creating the enzyme-substrate complex. 2) Hydrolysis of the phosphomonoester occurs as the enzyme releases a proton and covalently complexes to orthophosphate, the R-group (which denotes any non-specific organic carbon moiety) is released in the form of an alcohol. 3) Interaction with water protonates the enzyme breaking the covalent bond. 4) The free enzyme is regenerated upon release of orthophosphate. 


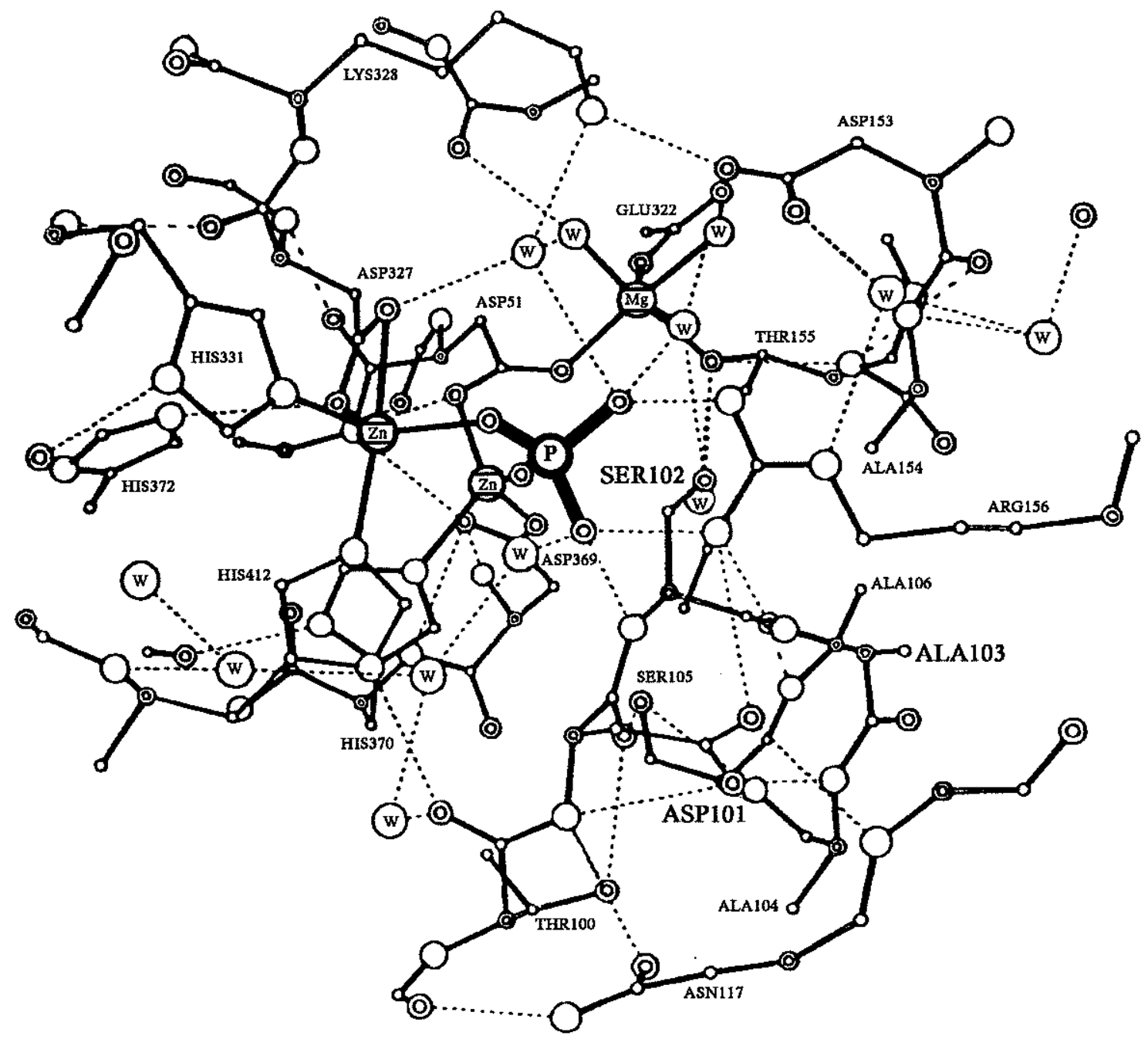

Figure 2.3: Active site region of an alkaline phosphatase isolated from $E$. coli. The region includes all the atoms within $10 \AA$ of the phosphorus atom. Water molecules are labeled as W. Hydrogen bonds are shown as broken lines (taken from Kim and Wyckoff, 1991). 


\section{Chapter 3}

\section{ALKALINE PHOSPHATASE ACTIVITY MEASUREMENTS}

\subsection{Introduction}

In order to use alkaline phosphatase as an effective phosphate-deficiency indicator, the presence of the enzyme must be documented and its activity determined. The presence of alkaline phosphatase is typically determined by measuring the catalytic activity of the enzyme. The activity of an enzyme is the kinetic rate at which the catalyzed reaction proceeds, in this case the rate at which alkaline phosphatase hydrolyzes phosphosmonoesters (PMEs). The formation of the hydrolysis product is measured over time, and the activity of the enzyme is determined. By studying the kinetics of alkaline phosphatase-catalyzed reactions, the maximum velocity of the enzyme, the relative amount of enzyme present, and the substrate binding affinity of the enzyme are determined.

\subsection{Theory of Enzyme Kinetics \& Application to Alkaline Phosphatase}

An enzyme is specific for certain substrates. The interplay between binding of the substrate to the enzyme, and hydrolysis of the substrate into the product, controls the rate at which the enzymatic reaction will proceed. The rate of an enzymatic reaction can be determined using the Michaelis-Menten equation. This equation and the theory behind it were first proposed by Leonor Michaelis and Maude Menten in the early part of the $20^{\text {th }}$ 
century. According to Michaelis-Menten theory, an enzyme binds to a substrate, forming an enzyme-substrate complex, with concomitant product formation and enzyme regeneration. This sequence of reactions is depicted in the following general equation:

$$
\mathrm{E}+\mathrm{S} \longleftrightarrow \mathrm{ES} \longrightarrow \mathrm{P}+\mathrm{E}
$$

where E, S, ES, and P, symbolize the unbound enzyme, substrate, enzyme-substrate complex, and product, respectively. According to this model, $\mathrm{S}$ can be elevated to high enough concentrations that all $\mathrm{E}$ is converted into $\mathrm{ES}$, forcing the second step (formation of the product) to become the rate limiting step. When the enzyme is thus saturated with respect to substrate, the overall reaction rate is insensitive to further increases in substrate concentration (Voet and Voet, 1995). Under enzyme-saturated conditions, direct measurement of the maximal rate of product formation $\left(\mathrm{V}_{\max }\right)$ can be determined and is therefore proportional to the concentration of total enzyme.

Michaelis and Menten determined the rate of product formation by making two assumptions. First, the enzyme-substrate complex was assumed to be in equilibrium with the free enzyme and substrate, and second, it was assumed that the reaction occurred at steady state (Voet and Voet, 1995). The final expression was solved for the initial velocity $\left(v_{0}\right)$, or catalytic rate, of the enzyme in terms of substrate concentration, maximal velocity $\left(\mathrm{V}_{\max }\right)$, and a constant $\left(\mathrm{K}_{\mathrm{m}}\right.$, known as the Michaelis constant $)$. The expression is known as the Michaelis-Menten equation and is the basic equation of enzyme kinetics:

$$
\mathrm{v}_{\mathrm{o}}=\frac{\mathrm{V}_{\max }}{\mathrm{K}_{\mathrm{m}}+[\mathrm{S}]}
$$

This equation describes a rectangular hyperbola, known as a saturation curve, as illustrated in Figure 3.1. The initial velocity increases with substrate concentration until 
it asymptotically approaches the maximal velocity of the reaction, $\mathrm{V}_{\max }$, at high substrate concentrations.

$\mathrm{V}_{\max }$ occurs at high substrate concentrations, when the enzyme is saturated (Figure 3.1), and is by definition directly proportional to the concentration of enzyme present. Determining $\mathrm{V}_{\max }$ of the enzyme in question is preferred over measuring an arbitrary velocity lower on the saturation curve. The primary reason for this preference is that it allows for the determination of enzyme activities under the same, enzymesaturated, conditions. This permits direct comparisons to be made between different studies.

$\mathrm{K}_{\mathrm{m}}$, the Michaelis constant, is defined as the substrate concentration at which the reaction is at half maximal velocity (Figure 3.1). This constant is an indicator of the affinity of the enzyme for the substrate. If $\mathrm{K}_{\mathrm{m}}$ is small, then the enzyme has a greater affinity for the substrate and achieves maximal catalytic efficiency $\left(\mathrm{V}_{\max }\right)$ at lower substrate concentrations.

The reaction mechanism for alkaline phosphatase operates according to the general Michaelis-Menten reaction mechanism, equation 1 (Jansson et al., 1988). The rate limiting step is thought to be hydrolysis of the phosphomonoester (PME) to produce orthophosphate and an alcohol (Berman, 1970), step two in the reaction mechanism described in section 2.2.2. Therefore, the Michaelis-Menten equation can be used to measure the catalytic rate of alkaline phosphatase by calculating $\mathrm{V}_{\max }$, and it can describe the affinity of alkaline phosphatase for PMEs through the determination of $\mathrm{K}_{\mathrm{m}}$. 


\subsubsection{Calculating $V_{\max }$ and $K_{m}$}

There are several methods for determining the values of the parameters of the Michaelis-Menten equation. At very high concentrations of substrate, the initial velocity asymptotically approaches $V_{\max }$, as plotted on a saturation curve (Figure 3.1). However, in practice, it is difficult to extrapolate $V_{\max }$ from a saturation curve. Non-linear computer programs have been written that can directly calculate $\mathrm{V}_{\max }$ using the Michealis-Menten equation by performing iterative calculations of $\mathrm{V}_{\max }$. These programs require an initial estimate of $\mathrm{K}_{\mathrm{m}}$, which introduces some uncertainty in the resultant $\mathrm{V}_{\max }$ value. However, the ease of these programs makes them a good candidate for determining Michealis-Menten kinetic parameters.

An alternative method for simultaneous determination of $\mathrm{V}_{\max }$ and $\mathrm{K}_{\mathrm{m}}$, which requires no initial estimates of parameters, is a linear transformation such as a doublereciprocal plot, better known as a Line-Weaver Burk plot (Voet and Voet, 1995). The Line-Weaver Burk plot uses the reciprocal of the Michaelis-Menten equation:

$$
1 / \mathrm{v}_{\mathrm{o}}=\left(\mathrm{K}_{\mathrm{m}} / \mathrm{V}_{\max }\right) 1 /[\mathrm{S}]+1 / \mathrm{V}_{\max }
$$

This is a linear equation in $1 / v_{o}$ and $1 /[S]$ with the slope of the line equal to $K_{m} / V_{\max }$, the $\mathrm{y}$-intercept equal to $1 / \mathrm{V}_{\max }$, and the $\mathrm{x}$-intercept equal to $-1 / \mathrm{K}_{\mathrm{m}}$ (Figure 3.2). Care must be taken to ensure that the range of $S$ concentrations will adequately constrain the slope generated by a Line-Weaver Burk plot. For example, this treatment is not well-suited to experiments using relatively high substrate concentrations, as they will not be able to adequately constrain the line because the data points will be crowded toward the y-axis. A disadvantage to reciprocal plots, such as the Line-Weaver Burk plot is that small errors 
in $v_{0}$, calculated from low concentrations of substrate, will often lead to large errors in $1 / \mathrm{v}_{\mathrm{o}}$ and, thus, increase the error in $\mathrm{V}_{\max }$ and $\mathrm{K}_{\mathrm{m}}$.

Line-Weaver Burk plots were used in this study, in conjunction with the commercially available non-linear regression program, GraphPad Prism ${ }^{(1)}$ (GraphPad 2000 ), to calculate $\mathrm{V}_{\max }$. In order to constrain the Line-Weaver Burk line and avoid crowding of points from higher substrate concentrations an even distribution of substrate concentrations was used. A typical Line-Weaver Burk plot from an Ashumet Pond bulk water sample (Figure 3.2) illustrates that the line is well constrained. The standard deviation (over triplicates) indicated by the error bars shows that larger errors were not always focused on the data point generated from the highest substrate concentration, rather, the size of the error bars varied in a non-systematic way across the range of substrate used. The fact that the error did not increase systematically with decreasing substrate concentration (as increasing $1 / \mathrm{S}$ ) indicates that, for natural water samples, the error may dependent be more on natural variability within the water sample itself rather than the linear transformation. The same data used to construct the Line-Weaver Burk plot were used to generate a saturation curve employing the GraphPad Prism ${ }^{(1)}$ program. By entering velocity values determined in triplicate from different substrate concentrations, and the substrate concentrations themselves into the program, a direct estimate $V_{\max }$ and $\mathrm{K}_{\mathrm{m}}$ values within a $95 \%$ confidence interval were produced. A typical Michealis-Menten saturation curve generated using GraphPad Prism ${ }^{\circledR}$ is shown in Figure 3.3 . 


\subsubsection{Error Analysis}

Determining the uncertainty associated with the estimates of $\mathrm{V}_{\max }$ and $\mathrm{K}_{\mathrm{m}}$ using a Line-Weaver Burk plot is not a straight forward process. When initially constructing a Line-Weaver Burk, the inverse of the initial velocity values $\left(1 / v_{0}\right)$ are plotted against 1/[S]. This initial transformation complicates the error analysis because the standard deviation (over triplicates) must be inverted as well. The final value reported by a LineWeaver Burk plot is $1 / \mathrm{V}_{\max }$ (the $\mathrm{y}$-intercept), rather than $\mathrm{V}_{\max }$. Therefore, the error determined in $1 / \mathrm{V}_{\max }$ must be inverted to determine the final uncertainty in $\mathrm{V}_{\max }$. $A$ direct estimate of the uncertainty in $\mathrm{V}_{\max }$ cannot be directly made from a Line-Weaver Burk plot. To combat this problem, a statistical computer program using a statistical treatment known as the bootstrap method was prepared to estimate $V_{\max }$ and the $95 \%$ confidence interval surrounding the estimate (Solow, 2000). The bootstrap operates by creating a predetermined number of data sets by sampling the original data set, then uses the sampled data sets to estimate $\mathrm{V}_{\max }$ and $\mathrm{K}_{\mathrm{m}}$, and determines a $95 \%$ confidence region around the $\mathrm{V}_{\max }$ and $\mathrm{K}_{\mathrm{m}}$ estimates. The bootstrap method has been shown to work for estimating the uncertainty associated with calibration curves (Jones et al., 1996) and it worked well for the purposes of this study. One complicating characteristic of the bootstrap method was that it is unable to handle outliers. Therefore the data had to be meticulously scrutinized before performing the bootstrap which proved to be very time consuming and was therefore, undesirable.

Estimates of the uncertainty in $\mathrm{V}_{\max }$ using GraphPad Prism ${ }^{(1)}$ and those calculated using the bootstrap method were very similar. Both statistical analyses reported virtually 
the same $V_{\max }$ estimate as well as virtually identical $95 \%$ confidence regions, however, the estimate generated by GraphPad Prism ${ }^{\circledR}$ was more conservative than the bootstrap method (Table 3.1). Based on the similarity of these results, the GraphPad Prism ${ }^{\circledR}$ method of calculation was used in preference to the Line-Weaver Burk transformation due to the ease, quickness and reliability of the GraphPad Prism ${ }^{\circledR}$ program. All values of $\mathrm{V}_{\max }$ reported for this study were calculated using GraphPad Prism ${ }^{1}$.

Table 3.1: Comparison between $V_{\max }$ point estimates and $95 \%$ confidence intervals (95\% C.I.) calculated using the Bootstrap method vs. GraphPad Prism" ${ }^{\circledast 2}$ "denotes the sample was a replicate measured after long-term storage.

\begin{tabular}{|c|c|c|c|c|c|c|}
\hline \multirow[b]{2}{*}{ Site } & \multirow[b]{2}{*}{ Depth } & \multirow[b]{2}{*}{ Date } & \multicolumn{4}{|c|}{$V_{\max }\left(n M P \min ^{-1}\right)$} \\
\hline & & & Bootstrap & $95 \%$ C.I. & GraphPad Prism $^{(8)}$ & $95 \%$ C.I. \\
\hline \multirow{3}{*}{$\begin{array}{l}\text { Deep } \\
\text { Basin }\end{array}$} & \multirow{2}{*}{$2 \mathrm{~m}$} & July-7 & 1.96 & $1.91-2.01$ & 2.01 & $1.89-2.13$ \\
\hline & & July-20 & 0.86 & $0.80-0.92$ & 0.91 & $0.84-0.98$ \\
\hline & $4 \mathrm{~m}$ & Aug-9 & 0.52 & $0.48-0.56$ & 0.52 & $0.47-0.57$ \\
\hline \multirow{2}{*}{$\begin{array}{l}\text { South } \\
\text { Basin }\end{array}$} & \multirow{2}{*}{$2 \mathrm{~m}$} & July-7 & 1.73 & $1.63-1.82$ & 1.77 & $1.64-1.90$ \\
\hline & & July- $7^{*}$ & 1.81 & $1.76-1.86$ & 1.83 & $1.74-1.91$ \\
\hline
\end{tabular}

\subsection{Measurement of Alkaline Phosphatase Activity}

Assay conditions greatly affect enzymatic parameters (Pettersson and Jansson, 1978), and thus, determining the maximal catalytic rate at which alkaline phosphatase can operate $\left(\mathrm{V}_{\max }\right)$ is imperative for comparing results between studies. $\mathrm{V}_{\max }$ is not a measure of the actual in-situ velocity, but rather the potential maximal in-situ velocity.

Unfortunately, there are a wide variety of methods used to determine $\mathrm{V}_{\max }$ making it difficult to compare results from different investigations.

In this study, the maximal in-situ activity of alkaline phosphatase was determined by fluorometrically measuring the increase of the fluorescent hydrolysis product from the 
addition of an artificial fluorogenic substrate over a 30 minute time course. The $\mathrm{pH}$ of the samples were unaltered from their natural state, so as not to stimulate or diminish any active enzymes. Some studies optimize the $\mathrm{pH}$ of their natural water sample to maximize the fluorescence of the substrate (e.g., Healey and Hendzel, 1979; Rose and Axler, 1998), which may result in activating or de-activating certain pools of enzymatic activity (Chrost and Krambeck, 1986). To further avoid stimulating enzymatic activity that would otherwise be dormant, this study employed low concentrations of substrate, $0-10 \mu \mathrm{M}$ (after Hantke et al., 1996). These levels attempted to approximate in-situ DOP levels, which ranged from 0.02 to $1.36 \mu \mathrm{M}$ during the period over which the study was conducted (AFCEE 2000). By using low substrate concentrations, alkaline phosphatase was not saturated by the artificial fluorogenic substrate. Therefore, $\mathrm{V}_{\max }$ was not directly measured, but was rather calculated from the Michealis-Menten equation using the GraphPad Prism ${ }^{\circledR}$ program.

The artificial substrate used was 4-methylumbelliferyl phosphate (MUF-P) (Figure 3.4). There is a broad consensus that MUF-P is the optimal substrate for determination of phosphatase activity in lake waters, due to the sensitivity and reliability of the assay under various conditions (Pettersson and Jansson, 1978). MUF-P has been proven a successful substrate in numerous studies (e.g., Pettersson, 1980; Chrost and Overbeck, 1987; Hantke et al., 1996). MUF-P is a fluorogenic substrate. As alkaline phosphatase cleaves the phosphate moiety from MUF-P, it releases a fluorescent product, 4-methylumbelliferone (MUF) (Figure 3.4). For every one MUF-P hydrolyzed, one 
MUF is liberated. Therefore, fluorescence is directly proportional to the concentration of MUF and is a direct measure of the enzymatic activity.

\subsubsection{Analytical Methods}

The analytical method most commonly used to measure the MUF-P/MUF reaction is fluorometry, a sensitive luminescent technique. A standard filter-fluorometer can be used to measure the increase of fluorescence over the time course of an enzymehydrolysis experiment. As this study shows, however, monitoring enzyme kinetics with a standard filter-fluorometer is a very time consuming process. A new analytical approach was explored in this study, utilizing a fluorescence multi-well plate reader, with the objective of decreasing analysis time. As will be described in this chapter, the cytofluor (the trade name for the fluorescence multi-well plate reader manufactured by Applied Biosystems) greatly increases sample through-put without compromising the integrity of the analyses.

When dealing with natural aquatic samples, heterogeneities, such as differences in cell density and size of detrital matter, will exist. Utilizing a sensitive method to detect slight variations between samples is therefore essential when trying to determine thresholds, to substantiate minimum limits, and to understand patchiness. Levels of alkaline phosphatase within a natural system may vary depending on the extent of phosphate-deficiency and the algal and bacterial species within the water column. It is, therefore, important to have a sensitive method than can confidently detect slight differences between alkaline phosphatase activity levels. 


\subsubsection{Basic Theory of Fluorescence}

The main analytical technique employed in this study was the analysis of molecular fluorescence. Molecular fluorescence occurs as radiation is given off when a molecule, with an electron in an excited electronic singlet state, relaxes back to its ground state configuration (Figure 3.5) (Skoog and Leary, 1992). Under natural conditions, a molecule exists in the ground state electronic configuration (step 1 in Figure 3.5). As the molecule absorbs a photon of radiation at a specific frequency, one of a pair of electrons is excited to a higher energy level, and in the case of fluorescence, does not undergo a change in spin (step 2 in Figure 3.5). As this electron relaxes back to its ground state level, a photon of radiation, at a slightly greater wavelength than that which excited it, is released as fluorescence (step 3 in Figure 3.5). The average lifetime of a fluorescent excited species is on order of $10^{-5}$ to $10^{-8}$ seconds. If the relaxation by fluorescent emission occurs more rapidly than relaxation by a radiationless, or thermal, process, such as internal or external conversion, fluorescence will occur.

The structural characteristics of a molecule significantly influence whether or not it will be fluorogenic. The most intense and useful fluorescence is found in compounds containing aromatic functional groups, such as those having a benzene ring fused to a heterocyclic nucleus (Skoog and Leary, 1992). The structure of MUF (Figure 3.4) contains such characteristic structure. The only difference between MUF and MUF-P is the phosphate moiety bonded to the aromatic ring. The presence of this phosphate functional group disrupts the electronic transition levels of the molecule causing it not to exhibit fluorescence. Once the phosphate group is cleaved, in this case by the action of 
the phosphohydrolytic enzyme alkaline phosphatase, the residual MUF molecule is free to fluoresce.

\subsubsection{Fluorometer}

The fluorometer employed in this study was a Turner Designs Model 10-AU Field and Laboratory Fluorometer, a simple filter fluorometer. Filter fluorometers provide a relatively simple way of performing quantitative fluorescence analyses. A fluorometer uses filters to restrict the wavelengths of the excitation and emitted radiation. A schematic for the fluorometer is shown in Figure 3.6. Light from a tungsten lamp is passed through an excitation filter that transmits light of a diagnostic wavelength; the excitation wavelength for MUF is $360 \mathrm{~nm}$. The light passes through the sample, exciting the fluorogenic species (MUF), which emits light proportional to the concentration of the fluorescent material present and proportional to the intensity of the exciting light. The emitted light, in this case $460 \mathrm{~nm}$, passes through an emission filter to exclude any scattered exciting light at wavelengths other than $460 \mathrm{~nm}$ from reaching the phototmultiplier detector.

Some current APA assays employ the use of a spectrophotometer (Rose and Axler, 1998; Dyhrman and Palenik, 1997). However, the spectrophotometric method is not as sensitive as a fluorometric assay. In the case of spectrophotometry, the amount of light transmitted through the sample is measured and subtracted from the light transmitted through a blank ( $100 \%$ transmittance), in order to determine how much light was absorbed, and thus how much analyte is present. In contrast, the fluorometer is a direct measure of the light emitted from the fluorescent analyte, and thus a direct measure 
of the light absorbed from the excitation radiation. Trying to spectrophotometrically measure a very dilute sample would require the subtraction of two very similar numbers, resulting in a large error. In contrast, a dilute sample can be directly measured fluorometrically, thereby minimizing the margin of error.

A limiting feature of the fluorometric assay using a standard filter fluorometer is the time requirement for each sample assayed. It is not an automated method, and is very time- and labor-intensive, requiring up to 4 continuous hours per sample analyzed. In order to adequately characterize a natural aquatic system, it is necessary to analyze many samples. In this study over 600 pond samples were collected that needed to be analyzed in a period of a few months. Therefore, a method was sought that would provide more rapid sample-throughput. The high throughput method that was developed for this thesis employed the use of a cytofluor, a fluorescence multi-well plate reader.

\section{Detection Limit}

Debate exists about what a detection limit is and how it should be defined (Mactaggart and Farwell, 1998). Often a detection limit is determined strictly by statistical variability of blanks or an instrumental baseline. The most common application is the 3-sigma method, in which a suite of blanks are measured, the standard deviation (sigma) is calculated, and anything greater than 3 times sigma is assumed to be significant. To confidently determine the lowest concentration of sample distinguishable from the blank, however, it is more useful to test standard solutions because the variability of samples with nonzero analyte is usually greater than that of the blank (Mactaggart and Farwell, 1998). 
The detection limit for the Turner Designs Model 10-AU Fluorometer was determined using a standard curve derived from measuring standard solutions. A serial dilution of triplicate standard solutions was performed on six Ashumet Pond bulk water samples. Standards were made from bulk water samples so that the matrix of the standard would match that of the sample unknown. Each standard was measured to determine if, within the standard deviation of triplicates, it was statistically significant from the blank. The lowest standard that was statistically significant from the blank was defined as the detection limit for the alkaline phosphatase assay. The fluorometer was able to distinguish MUF concentrations confidently at $2.5 \mathrm{nM}$ for all samples tested (Figure 3.7-a and -b). In some instances, depending on the sample matrix, the fluorometer detection limit was even lower than $2.5 \mathrm{nM}$ (Figure 3.7-b).

\subsubsection{Cytofluor}

A cytofluor is a fluorescence multi-well plate reader, that operates according to the same principles as a fluorometer but has the automated capability of analyzing samples distributed in a multi-well plate. The sample distribution can range from $48-384$ wells in a plate, and a plate can be scanned and fluorescence measured for each plate within one minute. In contrast, a standard filter fluorometer will require at least 20 minutes to analyze the same suite of samples. A 96-well cytoplate was employed for all APA analyses in this study. The fluorescence plate reader operated in this study was an Applied Biosystems Cytofluor 4000/TC (temperature controlled), hereafter referred to as a cytofluor. The temperature control option allows isothermal measurements to be made at any temperature above ambient, up to $45^{\circ} \mathrm{C}$. The cytofluor operates on a smaller scale 
to the fluorometer, as well. Volumes required for the cytofluor, $0.300 \mathrm{~mL}$ per sample per well, are an order of magnitude smaller than those required for the fluorometer, $3 \mathrm{~mL}$ per sample per cuvette. As with the fluorometer, light is passed through an excitation filter, exciting the fluorescent material in the wells, and the emitted light passes through a filter to a photomultiplier tube. However, the mechanics behind the operating system are different. A sensitive fiber-optic probe scans the plate from the bottom of the plate, stopping at each well for a fraction of a second, to quantify the fluorescence. The fluorescence measurement is also made from the bottom of the plate. The plate remains stationary during the scanning of each row, and then moves down to the next row. The entire measurement takes place within the fiber-optic probe itself. In fluorometric assays, the path-length of the sample is important. The path-length is the thickness of the sample that the excitation and emission wavelengths must travel through. It is imperative that the path-length remains constant throughout the entire measurement. The optic probe is centered at the bottom of each well, therefore as long as there is no movement of the sample in the well itself, the reading will be stable and accurate. The ramifications for sample movement of surface tension within individual wells during an at-sea trial will be addressed later.

The cytofluor system is automated and is programmable for (i) number of cycles, (ii) number of reads per well, and (iii) time lapse between cycles. The number of cycles is how many times the entire plate is read, whereas the number of reads per well is how many times the fiber optic probe reads the well before moving on to the next well during one cycle. The time lapse between cycles is the interval of rest between measurements of 
the entire plate. For example, the kinetic parameters calculated for this study were based on a 30 minute hydrolysis time course. A sample split was spiked with one substrate concentration, the start of the reaction (i.e., time at which sample was spiked with MUFP) was recorded. The next substrate concentration was added to another sample split and time was recorded again, until all six substrate concentrations had been added to sample splits, therefore, the measurement time for each substrate was staggered. The time at which the cytofluor measured the first reading was also noted. Once the plate was put into the cytofluor, the program used for this study took one reading per well for six cycles with a five minute time interval between cycles. The raw data is then exported to a spreadsheet, where data manipulation takes place. The system offers greater flexibility for sample analysis, relative to a standard filter fluorometer, making it easier to run replicate samples, while at the same time significantly reducing total analysis time. The time frame for analyzing one sample by the cytofluor is reduced by $75 \%$ from the time required using a standard filter fluorometer.

Since this is a novel apparatus for alkaline phosphatase measurements, the capabilities of the instrument were tested to ensure that the results obtained by the cytofluor were comparable to those obtained by a standard fluorometer. The sensitivity of the cytofluor was evaluated by determining the detection limit. The effect of reaction time on APA measurements was determined by testing the cytofluor at 5 and 10 minute time intervals. In order to determine the reliability of the cytofluor measurements, a direct comparison between the fluorometer and the cytofluor was preformed, in which an identical set of samples was analyzed by each instrument, and the final results compared. 
Finally, the performance of the cytofluor at sea was evaluated, to determine if it can be useful for real-time APA determinations in the field.

\section{Detection Limit}

The detection limit for the cytofluor was determined in a similar manner as that for the fluorometer; a serial dilution of standard solutions using Ashumet Pond bulk water was performed. The cytofluor detection limit was higher by a factor of 10-20 than the detection limit for the fluorometer, ranging between 15-20 nM MUF (Figure 3.8-a and -b). The distinction in detection limit between the two methods stems from the differences in volume required per sample analyzed. Recall, the cytofluor reads sample volumes an order of magnitude smaller than the fluorometer. Any small differences between replicates in the wells will influence the fluorescence measurement.

The difference in detection limits between the cytofluor and the fluorometer, with the fluorometer 10 times more sensitive, indicates that the fluorometer has the capability of detecting extremely low levels of APA. However, the cytofluor confidently measured the APA levels of interest for this study $\left(>0.5 \mathrm{nM} \mathrm{Pmin}{ }^{-1}\right)$. Most published studies utilizing the MUF-P assay were performed with MUF-P concentrations ranging between $10 \mu \mathrm{M}$ to $1 \mathrm{mM}$ MUF-P ( e.g., Pettersson, 1980; Chrost and Overbeck, 1987), significantly greater than that used by this study (MUF-P concentrations between $0.5 \mu \mathrm{M}$ and $10 \mu \mathrm{M})$. This suggests that APA levels observed in a variety of different aquatic systems can be detected perfectly well by the cytofluor. 


\section{Capabilities of the Cytofluor at Two Different Time Intervals}

The rationale for this experiment was to determine whether a shorter cycle time for the cytofluor than that needed for the fluorometer would affect the resultant $V_{\max }$. With the fluorometer it manually takes 10 minutes to measure a triplicate set of substrate concentrations, however, since the cytofluor is an automated system, the time interval between readings could be decreased to 5 minutes, thereby reducing the total analysis time. Therefore, to determine the effect reaction time has on APA measurements, the cytofluor was tested at 5 and 10 minute interval cycles. The reaction to measure APA proceeds as alkaline phosphatase hydrolyzes MUF-P into the fluorescent product MUF, increasing the concentration of MUF over time. The hydrolysis is considered to occur at a uniform rate, such that the increase in MUF should be monotonic, and the velocity of the reaction should remain constant. Therefore, time elapsed between fluorescence measurements should be inconsequential. Theoretically then, the same $\mathrm{V}_{\max }$ value, reported as APA, should be obtained whether the experiment is conducted at 5 or 10 minute intervals. Fourteen Ashumet Pond bulk water samples were analyzed for APA during a 60 minute cycle with $6 \times 10$ minute intervals, followed immediately by a 30 minute cycle consisting of $6 \times 5$ minute intervals. $V_{\max }$ was calculated for each cycle and compared (Table 3.2).

APA measured at both time intervals was very consistent, varying on average $20 \%$. There is a tight fit along the 1:1 axis between APA calculated from the 5 minute interval cycles versus that using data from the 10 minute interval cycles (Figure 3.9). The outlier was due to an unexplained phenomenon. The tight correlation between the 
two time intervals substantiates the idea that the calculated APA of the enzymatic reaction is not altered by changing the time interval between measurements.

Table 3.2: Alkaline phosphatase (APA) measured at 5 and 10 minute time intervals using the cytofluor. Average \% Difference $=22 \%$. Sample designation represents sample site followed by depth (m) (FC = Fisherman's Cove, $\mathrm{SB}=$ South Basin, DB = Deep Basin).

APA (nM P min-1) for the Cytofluor

\begin{tabular}{|c|c|c|c|c|c|c|c|}
\hline Sample & Date & 5 min interval & $+/-$ & $10 \mathrm{~min}$ interval & $+/-$ & Average & \% Difference \\
\hline FC. 0 & Aug-9 & 0.83 & 0.14 & 0.54 & 0.06 & 0.68 & 42 \\
\hline FC. 2 & Jul-20 & 1.09 & 0.42 & 0.70 & 0.07 & 0.89 & 44 \\
\hline SB.0 & $\begin{array}{c}\text { Aug-9 } \\
\text { Jul-7 }\end{array}$ & $\begin{array}{l}0.45 \\
2.47\end{array}$ & $\begin{array}{l}0.15 \\
0.19\end{array}$ & $\begin{array}{l}0.35 \\
2.96\end{array}$ & $\begin{array}{l}0.10 \\
0.15\end{array}$ & $\begin{array}{l}0.40 \\
2.72\end{array}$ & $\begin{array}{l}26 \\
18\end{array}$ \\
\hline SB.2 & Jul-7 & 1.77 & 0.13 & 1.83 & 0.08 & 1.80 & 3 \\
\hline SB.4 & May-10 & 4.29 & 0.15 & 4.21 & 0.11 & 4.25 & 2 \\
\hline DB. 2 & $\begin{array}{c}\text { Jul-7 } \\
\text { Jul-20 }\end{array}$ & $\begin{array}{l}2.01 \\
1.07\end{array}$ & $\begin{array}{l}0.12 \\
0.10\end{array}$ & $\begin{array}{l}2.24 \\
0.98\end{array}$ & $\begin{array}{l}0.10 \\
0.07\end{array}$ & $\begin{array}{l}2.12 \\
1.02\end{array}$ & $\begin{array}{c}11 \\
9\end{array}$ \\
\hline DB.4 & $\begin{array}{c}\text { May-10 } \\
\text { Jul-7 } \\
\text { Jul-20 } \\
\text { Aug-9 }\end{array}$ & $\begin{array}{l}2.23 \\
2.69 \\
0.67 \\
0.68\end{array}$ & $\begin{array}{l}0.21 \\
0.45 \\
0.09 \\
0.19\end{array}$ & $\begin{array}{l}2.73 \\
2.62 \\
0.80 \\
0.52\end{array}$ & $\begin{array}{l}0.19 \\
0.23 \\
0.05 \\
0.05\end{array}$ & $\begin{array}{l}2.48 \\
2.66 \\
0.73 \\
0.60\end{array}$ & $\begin{array}{c}20 \\
3 \\
18 \\
26\end{array}$ \\
\hline DB.6 & Jul-7 & 1.34 & 0.15 & 1.08 & 0.13 & 1.21 & 21 \\
\hline WR.int & Jul-20 & 1.55 & 0.23 & 3.22 & 0.45 & 2.38 & 70 \\
\hline
\end{tabular}

\subsubsection{Effect of Long-Term Freezing on Alkaline Phosphatase Activity}

The effect of long-term freezing on enzymatic parameters has not been widely investigated. The effect of frozen storage was evaluated in this study by comparing data 
generated on the same samples 2-4 months after collection and again after 6-8 months total frozen storage time. When trying to understand the complexities of a natural aquatic system, samples must be collected regularly in order to adequately characterize the entire system. This strategy results in a compilation of hundreds of samples collected over a short time period. Unfortunately, it is not always possible to analyze all of the samples immediately and therefore, they must be properly stored so as not to disturb the integrity of the sample. For this study around 600 samples were collected within an 8 month period. The chosen method of sample storage was freezing. The water samples were stored at $-30^{\circ} \mathrm{C}$ from the time of collection until the samples were initially analyzed for APA (between 2-4 months), at which time they were re-frozen for a maximum of four more months and then re-analyzed.

Table 3.3 presents the APA values for the initial bulk water samples, representing 2-4 months of storage time, and the APA recorded for the re-run samples, representing 68 months total storage time. The act of re-freezing and re-thawing frozen samples had little effect on APA of Ashumet Pond samples (Figure 3.10). Outliers occurred at high APA, however, there were no significant differences in the samples causing the outlying APA, and therefore, an explanation for their cause is unavailable. Regardless of the outlying samples, this experiment demonstrated that bulk water samples can undergo long term storage without any degradation of alkaline phosphatase. However, none of the samples analyzed were tested before the sample was initially frozen, therefore, the effect of 0-2 months storage cannot be determined at this time. 
Table 3.3: Differences in APA on the same samples after freezing. Original column represents total storage time of 2-4 months and Re-run column represents the same samples as orginials, re-frozen and re-thawed having a total storage time of 6-8 months. Sample designation represents sample site followed by depth $(\mathrm{m})(\mathrm{FC}=$ Fisherman's Cove, $\mathrm{SB}=$ South Basin, $\mathrm{DB}=$ Deep Basin).

\begin{tabular}{|c|c|c|c|c|c|c|}
\hline \multirow[b]{2}{*}{ Sample } & \multirow[b]{2}{*}{ Date } & \multicolumn{4}{|c|}{ APA $\left(n M P \min ^{-1}\right)$} & \multirow[b]{2}{*}{ \% Difference } \\
\hline & & Original & $+1-$ & Re-run & $+/-$ & \\
\hline FC. 0 & Aug-9 & 0.85 & 0.10 & 0.68 & 0.10 & 22 \\
\hline FC. 2 & Jul-20 & 1.08 & 0.10 & 0.89 & 0.24 & 19 \\
\hline SB.0 & $\begin{array}{c}\text { Aug-9 } \\
\text { Jul-7 }\end{array}$ & $\begin{array}{l}0.34 \\
2.50\end{array}$ & $\begin{array}{l}0.08 \\
0.13\end{array}$ & $\begin{array}{l}0.40 \\
2.72\end{array}$ & $\begin{array}{l}0.12 \\
0.17\end{array}$ & $\begin{array}{c}18 \\
9\end{array}$ \\
\hline SB. 2 & Jul-7 & 3.03 & 0.18 & 1.80 & 0.10 & 51 \\
\hline DB. 2 & $\begin{array}{c}\text { Jul-7 } \\
\text { Jul-20 }\end{array}$ & $\begin{array}{l}2.50 \\
0.91\end{array}$ & $\begin{array}{l}0.16 \\
0.07\end{array}$ & $\begin{array}{l}2.12 \\
1.02\end{array}$ & $\begin{array}{l}0.11 \\
0.09\end{array}$ & $\begin{array}{l}16 \\
12\end{array}$ \\
\hline DB.4 & $\begin{array}{c}\text { Jul-7 } \\
\text { Jul-20 } \\
\text { Aug-9 } \\
\end{array}$ & $\begin{array}{l}2.19 \\
0.44 \\
0.43 \\
\end{array}$ & $\begin{array}{l}0.16 \\
0.06 \\
0.06 \\
\end{array}$ & $\begin{array}{l}2.66 \\
0.73 \\
0.60 \\
\end{array}$ & $\begin{array}{l}0.34 \\
0.07 \\
0.12\end{array}$ & $\begin{array}{l}19 \\
49 \\
33 \\
\end{array}$ \\
\hline DB.6 & Jul-7 & 1.31 & 0.09 & 1.21 & 0.14 & 8 \\
\hline
\end{tabular}

\subsubsection{Cytofluor-Fluorometer Direct Comparison}

The features of the cytofluor, particularly it's automated capability, make using the cytofluor preferred over the fluorometer. However, the method developed for measuring APA using the cytofluor is a novel one and therefore needed to be validated. In order to determine if the cytofluor is a viable alternative to the fluorometer for measuring APA, the alkaline phosphatase activities of twelve Ashumet Pond bulk water samples were measured in triplicate on the cytofluor and fluorometer, simultaneously, and the $V_{\max }$ values from each instrument were compared (Table 3.4). Samples were 
chosen to cover a range of APAs found within Ashumet Pond. The samples were measured at either 5 or 10 minute intervals on the cytofluor and at approximately 10 minute intervals on the fluorometer. A previous experiment (see section 3.3.1.3) indicated 5 and 10 minute interval data from the cytofluor are interchangeable/comparable. Each sample was standardized to calibration standards made from the same sample matrix.

On average, the APA determined by each instrument was offset by $30 \%$ (Table 3.4). The fact that this offset was systematic and that there was a tight correlation between the values obtained by the two instruments (Figure 3.11) indicates that the cytofluor can be confidently used to measure APA in natural water samples. The APA calculated from samples run on the fluorometer were greater than those measured on the cytofluor (Figure 3.11). Figure 3.11, also, illustrates the tight 1:1.13 correlation between cytofluor and fluorometer derived APA between 0.9-2.0 nM P $\min ^{-1}$, and more variance in the correlation when APA was greater than $2.0 \mathrm{nM} \mathrm{P} \mathrm{min}^{-1}$. There is no obvious explanation for the outliers occurring at APA $>2.0 \mathrm{nM} \mathrm{P} \min ^{-1}$ (Figure 3.11). After comparing various parameters such as chlorophyll-a content, weather conditions and nutrient levels, no reasonable explanation could account for the variability in high APA values. It is therefore recommended that standards of commercial alkaline phosphatase be tested to better constrain the 1:1 relationship between the fluorometer and cytofluor at low and high APA values.

In an attempt to explain the offset in APA measured by the cytofluor and that measured by the fluorometer, three possibilities were investigated: (i) temperature effect, 
Table 3.4: A comparison of alkaline phosphatase activity (APA) measured on the fluorometer and cytofluor. Sample designation represents sample site followed by depth $(\mathrm{m})(\mathrm{FC}=$ Fisherman's Cove, $\mathrm{SB}=$ South Basin, $\mathrm{DB}=$ Deep Basin). $\% \mathrm{E}$ is the relative \% error for each APA value. Average \% Difference $=32 \%$.

\begin{tabular}{|c|c|c|c|c|c|c|c|c|c|}
\hline \multirow[b]{2}{*}{ Sample } & \multirow[b]{2}{*}{ Date } & \multicolumn{7}{|c|}{ APA (nM P $\left.\min ^{-1}\right)$} & \multirow[b]{2}{*}{$\%$ Difference } \\
\hline & & Fluorometer & $+/-$ & $\% \mathrm{E}$ & Cytofluor & $+1-$ & $\% \mathrm{E}$ & Mean & \\
\hline \multirow{3}{*}{ DB.0 } & Jun-22 & 2.60 & 0.34 & 13 & 2.06 & 0.19 & 9 & 2.33 & 23 \\
\hline & Jul-7 & 1.81 & 0.12 & 7 & 1.43 & 0.12 & 8 & 1.62 & 23 \\
\hline & Aug-9 & 1.60 & 0.11 & 7 & 1.22 & 0.08 & 7 & 1.41 & 27 \\
\hline DB. 2 & Jul-20 & 0.78 & 0.07 & 9 & 0.91 & 0.07 & 8 & 0.85 & 16 \\
\hline DB.4 & May-10 & 4.61 & 0.24 & 5 & 2.48 & 0.19 & 8 & 3.55 & 60 \\
\hline DB.6 & Jul-7 & 1.72 & 0.08 & 5 & 1.21 & 0.13 & 11 & 1.46 & 35 \\
\hline SB.0 & Jun-22 & 1.74 & 0.21 & 12 & 1.67 & 0.15 & 9 & 1.71 & 4 \\
\hline SB.2 & Jul-7 & 2.26 & 0.22 & 10 & 1.80 & 0.08 & 4 & 2.03 & 23 \\
\hline & Jul-20 & 1.52 & 0.11 & 7 & 1.00 & 0.14 & 14 & 1.26 & 42 \\
\hline SB.4 & Jul-20 & 2.34 & 0.06 & 3 & 1.45 & 0.11 & 8 & 1.89 & 47 \\
\hline FC. 2 & Jul-7 & 2.28 & 0.11 & 5 & 3.22 & 0.28 & 9 & 2.75 & 34 \\
\hline WR.int & Jul-20 & 4.18 & 0.10 & 2 & 2.38 & 0.44 & 18 & 3.28 & 55 \\
\hline Mean & & 2.29 & 0.15 & 7 & 1.74 & 0.17 & 9 & 1.32 & 32 \\
\hline
\end{tabular}

(ii) cellular size exclusion, and (iii) inherent instrumental differences. Temperature is a parameter that effects fluorescence; they are inversely proportional to each other. As temperature increases, fluorescence decreases. The increased thermal energy in the system allows the electron in an excited state to relax back into its ground state configuration without emitting fluorescence. Therefore, it is important to maintain 
isothermal conditions throughout a fluorescence experiment. Although every attempt was made to maintain constant temperature between the instruments, a temperature difference still occurred. Samples run on the cytofluor, which has a built in temperature control capability, were analyzed at $5{ }^{\circ} \mathrm{C}$ above room temperature $\left(30^{\circ} \mathrm{C}\right)$; the operating conditions recommended by the manufacturer. This was in contrast to the fluorometer, which has no temperature control capacity. Samples were analyzed by the fluorometer at room temperature $\left(25^{\circ} \mathrm{C}\right)$. Maintaining temperatures elevated above room temperature for the fluorometer was very difficult due to the lack of a temperature controlled water bath and therefore samples were run at room temperature. To insure no fluctuations in temperature occurred during the fluorometer experiment, the samples were kept in a room temperature water bath.

Temperature alone can not account for the $30 \%$ offset between the two instruments, however. A study conducted to test the capability of the cytofluor while at sea (discussed in the next section) compared the fluorescence readings of the cytofluor measured at two temperatures: $23{ }^{\circ} \mathrm{C}$ and $31{ }^{\circ} \mathrm{C}$. The fluorescence varied by $7 \%$ between the two experiments, thereby indicating that although it is important to maintain isothermal conditions throughout an experiment, temperature variations on order of a few degrees will not influence the precision of the overall instrument reading.

Another possible explanation for the offset is the volume requirements for analysis by the cytofluor and the fluorometer. Natural heterogeneities of phytoplankton cells in natural water samples could be a more significant source of uncertainty within the cytofluor system. As previously discussed, the cytofluor requires an order of magnitude 
less volume than the fluorometer. The cytofluor requires $0.300 \mathrm{~mL}$ of sample per well, whereas the fluorometer handles $3.0 \mathrm{~mL}$ of sample per cuvette. The transfer of sample to the sample wells and the cuvettes was completed through the use of a pipette. The pipette tip size used for the samples run on the cytofluor was an Eppendorf ${ }^{\mathrm{TM}} 0-1000 \mu \mathrm{L}$, with an orifice dimension of $1 \mathrm{~mm}$. Samples run on the fluorometer were pipetted with an Eppendorf ${ }^{\mathrm{m}} 500-5000 \mu \mathrm{L}$ pipette tip, with an opening of $2 \mathrm{~mm}$ in diameter. The difference in pipette tip orifices could result in size exclusion of phytoplankton cells due to differences in cell size. Different species of phytoplankton have different structural characteristics, such as cell density and cell size. For example, the phytoplankton species dominating the samples used in this experiment were: (i) Asternionella sp., a diatom, (ii) Oscillatoria sp., a cyanobacterium, and (iii) Aphanizomenon sp., a cyanobacterium. The cell structure of Asternionella $s p$. can be visualized as eight cuboids, whereas the cellular structure of Oscillatoria sp. and Aphanizomenon $s p$. is cylindrical as each species form colonies (Reynolds, 1984). If the size of the phytoplankton in the water sample is larger than the orifice of the pipette tip, then size exclusion of cells can occur for the cytofluor samples, and a bias develop in the APA measurement. If cellular size exclusion was occurring in the samples used by the cytofluor and not the fluorometer, then lower APA would be measured by the cytofluor.

However, size exclusion of cells probably did not occur on a wide scale during the cytofluor or the fluorometer measurement. The maximum axial dimensions of Asternionella sp., Oscillatoria sp. and Aphanizomenon sp. have been determined to be 70,1000 , and $125 \mu \mathrm{m}$ respectively (Reynolds, 1984). The smallest opening on the 
pipette tip used was for the cytofluor and spanned $1 \mathrm{~mm}(1000 \mu \mathrm{m})$ and that used for the fluorometer was twice as wide. Therefore, the pipette tip would not have excluded any of the dominant phytoplankton species in the pond samples; even size exclusion of the colonies formed by Oscillatoria sp. would not occur because it would have fit through the pipette tip. Therefore, the bias between the two instruments cannot be directly attributed to size exclusion of cells.

An alternative explanation for the offset in APA measured by the two instruments may be attributed to inherent instrumental differences. Although the cytofluor and the fluorometer operate under the same principles of fluorescence, the mechanistic way in which each instrument obtains a fluorescence reading differs. The cuvette used in the fluorometer has a longer path-length and is exposed to the exciting light for a longer period of time than the sample wells used in the cytofluor. The cytofluor measures the fluorescence in a sample well for a fraction of a second. Therefore, it is recommended that a careful investigation be conducted to determine if the offset could be attributed to inherent instrumental analytical capabilities.

The offset in APA generated by the two instruments does not, however, discredit the cytofluor as a viable alternative to the fluorometer. The fact that the offset is systematic merely indicates that a correction may be needed when comparing APA measured by each instrument. The presence of a tight $1: 1.13$ correlation between APA determined using the cytofluor and that using the fluorometer validates the use of the cytofluor for APA measurements. 
In order to determine the significance the offset has on overall APA values, the samples measured on the cytofluor for this experiment were corrected for the 1.13 offset (Table 3.5). Correcting APA values measured on the cytofluor reduced the difference between instruments from $30 \%$ to $15 \%$. Therefore, it is advisable that when comparing APA values derived from the fluorometer to those derived from the cytofluor, a correction should be made.

Table 3.5: Comparison of APA values after being corrected for offset. Cytofluor (corrected) APA values were corrected for the 1.13 ofiset and then compared to the fluorometer APA values. Rel \% E is the relative \% error between the fluorometer and cytofluor (corrected) APA values. Average \% difference between two instruments was decreased to $15 \%$ from $32 \%$ before correction.

\begin{tabular}{|c|c|c|c|c|c|}
\hline \multirow[b]{2}{*}{ Sample } & \multirow[b]{2}{*}{ Date } & \multicolumn{3}{|c|}{ APA $\left(n M P \min ^{-1}\right)$} & \multirow[b]{2}{*}{$\operatorname{Rel} \% \mathbf{E}$} \\
\hline & & Fluorometer & $\begin{array}{c}\text { Cytofluor } \\
\text { (corrected) }\end{array}$ & Average & \\
\hline DB.0 & $\begin{array}{c}\text { 22-Jun } \\
\text { 7-Jul } \\
\text { 9-Aug }\end{array}$ & $\begin{array}{l}2.60 \\
1.81 \\
1.60 \\
\end{array}$ & $\begin{array}{l}2.33 \\
1.62 \\
1.38 \\
\end{array}$ & $\begin{array}{l}2.46 \\
1.71 \\
1.49 \\
\end{array}$ & $\begin{array}{l}11 \\
11 \\
15 \\
\end{array}$ \\
\hline DB.2 & 20-Jul & 0.78 & 1.03 & 0.90 & 27 \\
\hline DB.4 & 10-May & 4.61 & 2.80 & 3.71 & 49 \\
\hline DB.6 & 7-Jul & 1.72 & 1.37 & 1.54 & 23 \\
\hline SB.0 & 22-Jun & 1.74 & 1.89 & 1.81 & 8 \\
\hline SB.2 & $\begin{array}{c}7-\mathrm{Jul} \\
20-\mathrm{Jul}\end{array}$ & $\begin{array}{l}2.26 \\
1.52\end{array}$ & $\begin{array}{l}2.03 \\
1.13\end{array}$ & $\begin{array}{l}2.15 \\
1.33\end{array}$ & $\begin{array}{l}11 \\
29\end{array}$ \\
\hline SB.4 & 20-Jul & 2.34 & 1.64 & 1.99 & 35 \\
\hline FC.2 & 7-Jul & 2.28 & 3.64 & 2.96 & 46 \\
\hline WR.int & 20-Jul & 4.18 & 2.69 & 3.43 & 43 \\
\hline Mean & & 2.29 & 1.97 & 2.13 & 15 \\
\hline
\end{tabular}




\subsubsection{Cytofluor Performance at Sea}

In the realm of aquatic science, it is necessary for scientists to partake in research cruises on-board research vessels in order to investigate remote aquatic environments. In order to have real-time data, it is therefore desirable to have equipment that can stand up to harsh conditions while in the field (i.e., at sea). One of the cytofluor's optimal features is it's automated capability to analyze large quantities of samples in a short span of time. Therefore, the capability of the cytofluor under harsh field conditions was tested. The performance of the cytofluor was tested during a sea trial under various sea-state conditions, while steaming at 11 knots onboard the $54 \mathrm{~m}$ long $\mathrm{R} / \mathrm{V}$ Oceanus. The stability of the fluorescence measurements made by the cytofluor was evaluated using a 96-well cytoplate and a 48-well sterile polystyrene plate at sea-states ranging from $0-4 \mathrm{~m}$ seas. The volume capacity of a well in the 48 -well plate was greater than that of the $96-$ well plate, with a maximum well capacity of $0.700-\mathrm{mL}$ and $0.400-\mathrm{mL}$ for the 48 - and 96 well plates, respectively. Fluorescein $(1 \mu \mathrm{M})$, a fluorescent dye, was placed in each well of each plate. Each well of the 48 - and 96 -well plate was spiked with $0.400 \mathrm{~mL}$ and $0.300 \mathrm{~mL}$ fluorescein, respectively. The plates were run in the cytofluor at one minute intervals for 6 cycles, with one reading per well per cycle. The sea-state was determined by crew members, who would look out from the bridge and, using their experience and wisdom, estimate the sea-state. A $4 \mathrm{~m}$ sea-state onboard the Oceanus is the most severe state in which an operator could function. However, the level of ship motion at these respective sea-states will be dependent on ship size. 
The results are summarized as follows: (i) the 96-well cytoplate had excellent precision between raw fluorescence values measured at 3 different sea states, 1-2 m seas, 2-3 m seas, 3-4 m seas (Figure 3.12-a), whereas (ii) the precision between raw fluorescence values measured using the 48-well plate was poor (Figure 3.12-b). The 96well cytoplate was run at two different temperatures to determine the effect temperature would have on the measurement. Figure 3.12-a indicates that increased temperature decreased the raw fluorescence value measured by the cytofluor, but did not change the precision between sea states. A temperature difference of $8{ }^{\circ} \mathrm{C}$ only had a $7 \%$ change in fluorescence on the cytofluor, thereby indicating that although temperature can influence fluorescence readings, a small change in temperature will not dramatically change the overall resultant fluorescence.

Results for the 48-well polystyrene plate show greater scatter among data points, with no correlation between sea-state or temperature (Figure 3.12-b). The lack of precision is probably due to reduced surface tension in each well of the 48-well plate. The well of the 48 -well plate has a larger surface area than the 96-well plate, reducing the surface tension and thus, allowing more movement of sample in a well. Fluorescence measurements are dependent on the path length of the medium of which it is measuring. If the path length is oscillating from the movement caused by a moving ship, as is the case with the 48-well plate, an accurate reading cannot be measured, and reliable results will not be produced. Therefore, the cytofluor experiments performed at sea clearly indicate that the 96-well plate can be used with confidence while on a moving vessel, whereas the 48-well plate is not recommended for APA analyses performed in the field. 


\subsection{Conclusions}

Alkaline phosphatase activity was determined in Ashumet Pond water samples using a fluorometric method in which an artificial substrate, MUF-P, was added to a sample and the increase in subsequent formation of fluorescent hydrolysis product, MUF, was measured over time. On the order of 600 samples were collected for this study, and in order to increase sample throughput, a method for determining APA utilizing an automated system known as a cytofluor was developed. The method detection limit of the cytofluor, as well as the performance of the cytofluor at different time intervals was investigated. The detection limit was determined to be 15-20 nM MUF, and it was determined that the cytofluor measured equivalent APA at 5 and 10 minute time intervals. The effect of freezing/thawing and long term storage was investigated and it was determined that long term freezing has a minimal effect on degradation of APA. The adequacy of the cytofluor method was tested for APA measurements through the use of a head-to-head comparison with a standard filter fluorometer (commonly used for fluorometric enzymatic assays). APA measured using the cytofluor was offset from APA using the fluorometer, with the values derived from the cytofluor systematically lower than the fluorometer derived values. This systematic offset could not be attributed to temperature or cell size, and was therefore thought to be due to inherent differences between the instruments. A tight 1:1.13 correlation between cytofluor and fluorometer derived APA existed for APA values between 0.9-2 $\mathrm{nM} \mathrm{P} \min ^{-1}$, whereas the correlation between APA values greater than $2.0 \mathrm{nM} \mathrm{P} \mathrm{m^{-1 }}$ exhibited greater variance. Accounting 
for the variability in the correlation between the APA measured by each instrument, the cytofluor was determined to be a valid alternative method for determining APA in natural waters.

\subsection{Future Recommendations}

It is recommended that more analyses using standards be completed for the cytofluor-fluorometer direct comparison to better constrain the adequacy of the cytofluor in measuring APA values greater than $2.0 \mathrm{nM} \mathrm{P} \mathrm{min}^{-1}$ and less than $0.5 \mathrm{nM} \mathrm{min} \min ^{-1}$. It is also recommended that a careful investigation be undertaken into how differences in the cytofluor's and the fluorometer's internal mechanisms may cause an offset in APA. 
Figure 3.1: Michaelis-Menten saturation plot. Initial velocity $\left(\mathrm{v}_{0}\right)$ plotted against substrate concentration [S]. $K_{m}$ denotes the Michaelis constant, $V_{\max }$ denotes the maximal enzymatic velocity.

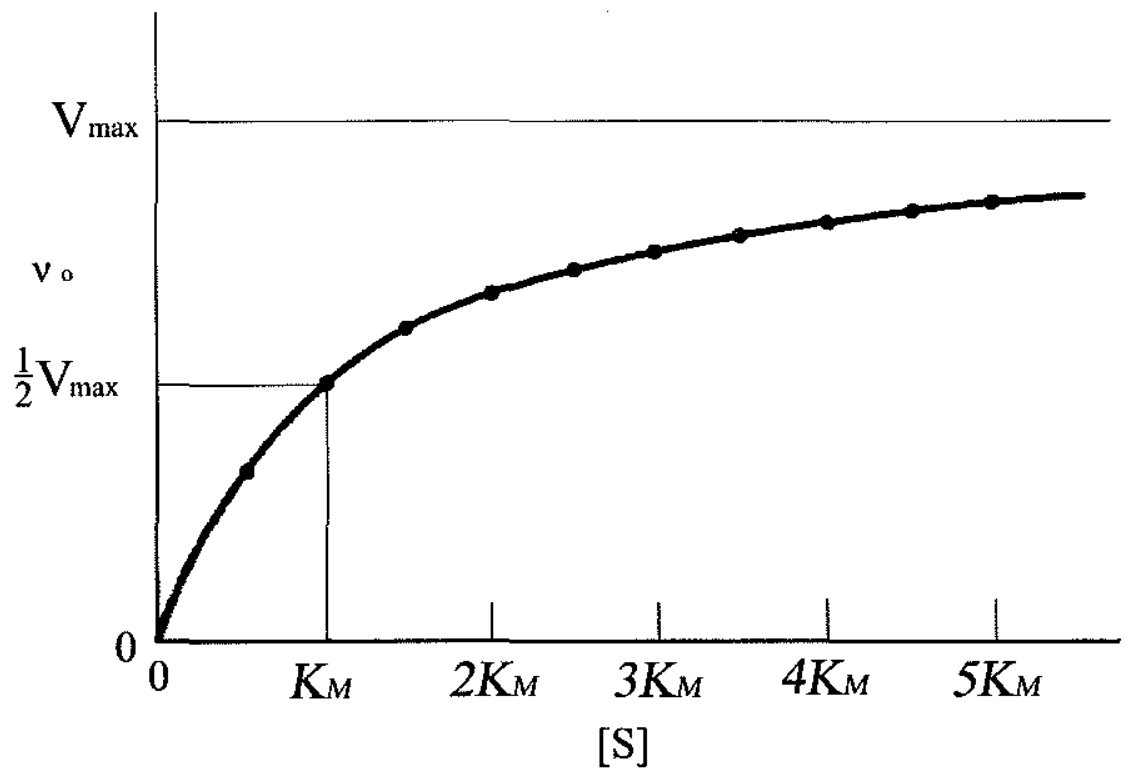

Figure 3.2: A typical LineWeaver-Burk Plot for Ashumet Pond. This linear transformation represents the double reciprocal plot used to calculate $V_{\max }$ and $K_{m}$ values. $1 / V_{\max }$ is equivalent to the $y$-intercept, and $-1 / K_{m}$ is equivalent to the $x$-intercept. The sample represented in this figure was taken at Deep Basin $0 \mathrm{~m}$ on April 29, 1999.

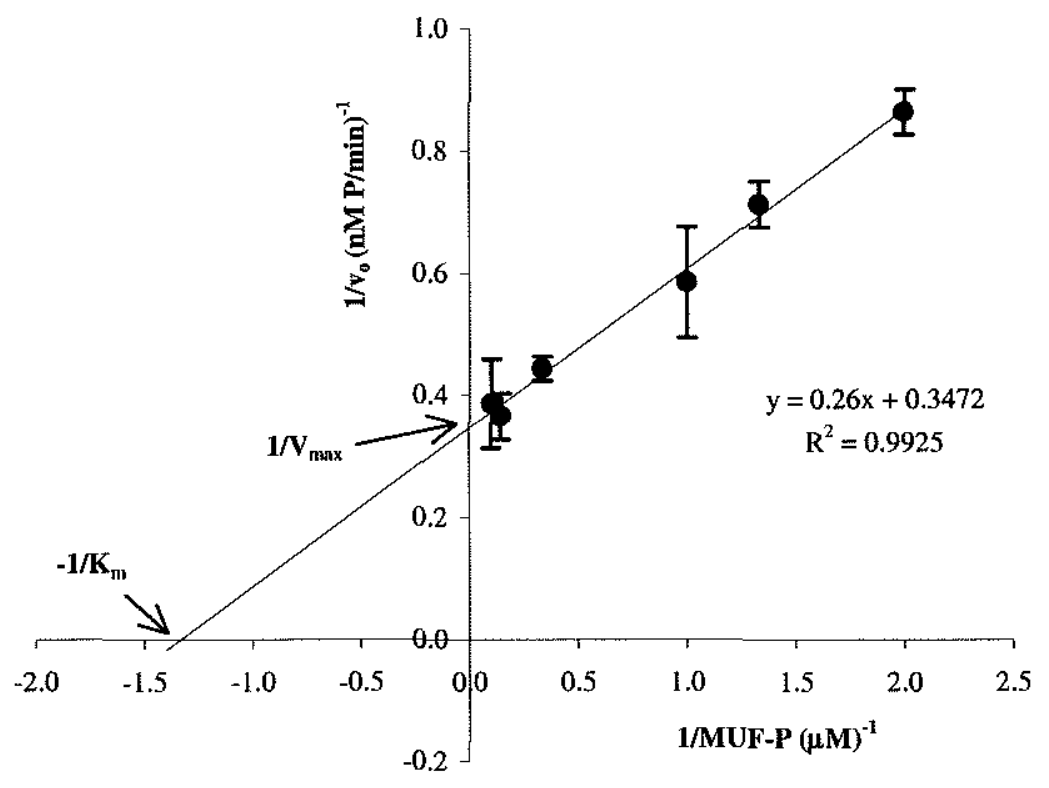


Figure 3.3: Typical saturation curve generated from GraphPad Prism. Alkaline phosphatase activity (APA) increases with increasing substrate concentration (MUF-P) until the enzyme becomes saturated with substrate and the activity levels off. This sample was taken from Fisherman's Cove 2 m on April 29, 1999. Error bars represent standard deviation over triplicates.

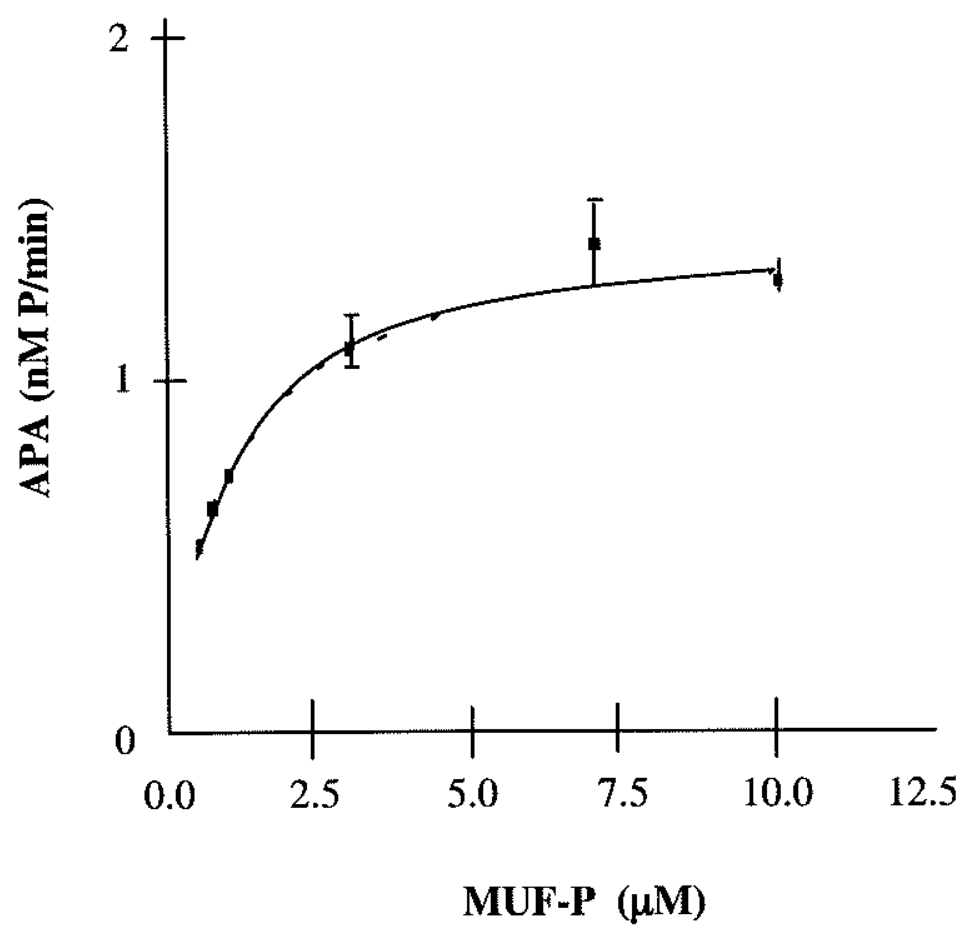


Figure 3.4: Structure of 4-methylumbelliferyl phosphate (MUF-P), a fluorogenic phosphomonoester (PME), and the fluorescent analog, 4-methylumbelliferone (MUF), the product of phosphate cleavage via hydrolysis.

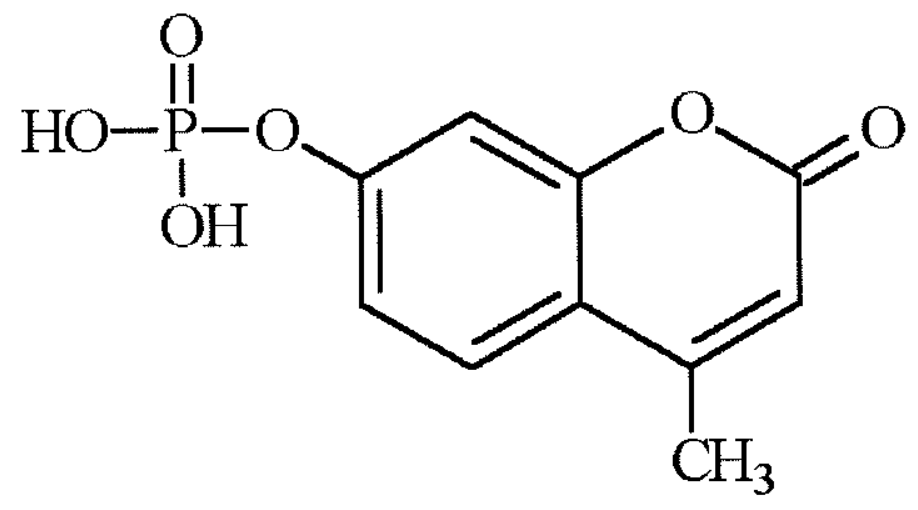

MUF-P (PME)

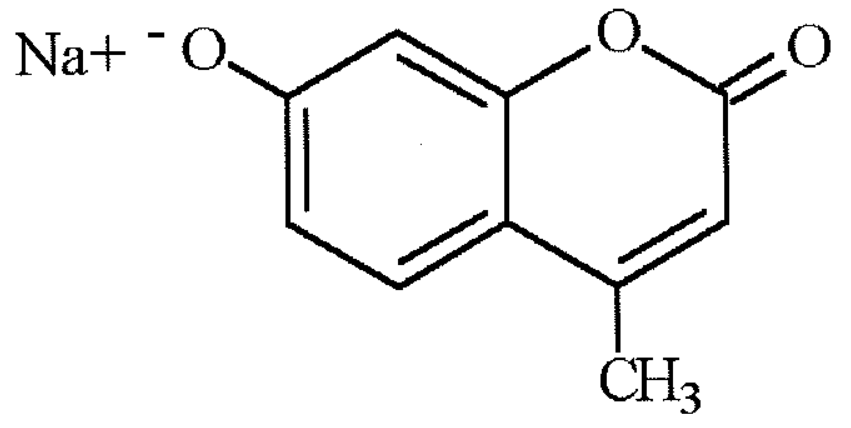

MUF (salt) 
Figure 3.5: Schematic of the electronic orbital transition by an electron during fluorescence (gs denotes ground state energy level, * denotes an excited energy level). Step 1: an electron absorbs light at a certain wavelength. Step 2: the electron is excited into a higher energy state by the absorbing light without undergoing a change in spin. Step 3: light is emitted as the electron relaxes back into the ground state configuration.

Step 1

$$
\begin{aligned}
& \hat{i} \\
& \vdots \\
& \vdots \\
& \vdots \\
& \vdots \\
& \vdots
\end{aligned}
$$

Step 2

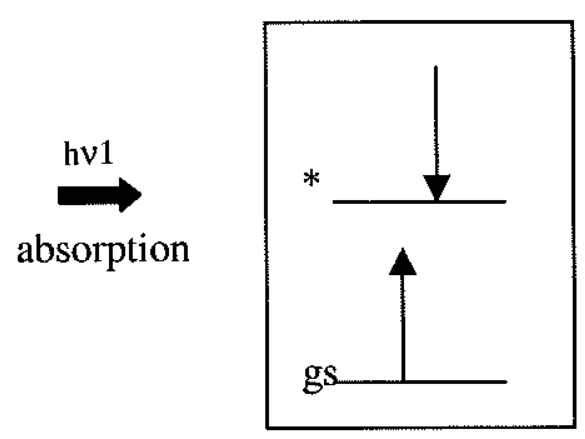

Step 3

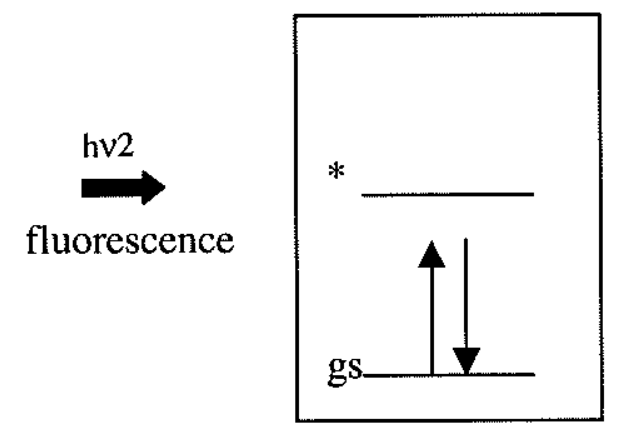

Energy 
Figure 3.6: Schematic of the Turner Designs 10-AU Field and Laboratory Fluorometer (taken from the Turner Designs handbook). The tungsten (W) lamp emits light at all wavelengths. The light is filtered by the excitation filter for wavelengths specific to the sample (in the case of MUF-P, $360 \mathrm{~nm}$ ). The sample is exposed to the filtered light. The electrons of the fluorescent species (MUF) are excited by the light and fluoresce. The fluorescent light travels through an emission filter that filters out all stray light. The emitted light then travels to the detector, a photomultiplier tube, generating the signal which is displayed.

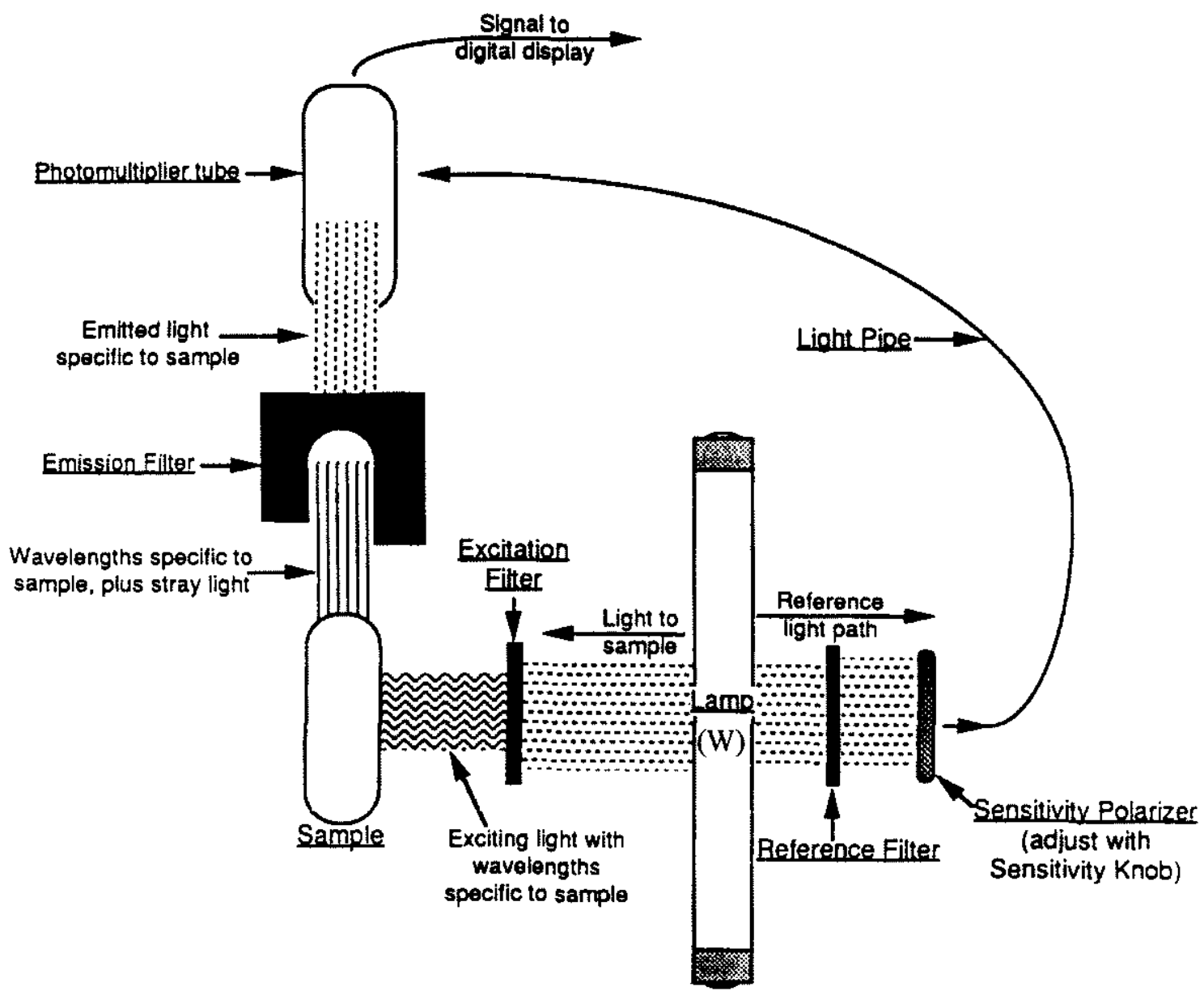


Figure 3.7-a: Standard curve generated for 5 Ashumet Pond samples using MUF concentrations between 0-400 $\mathrm{nM}$ using Turner Designs 10-AU fluorometer. RFI denotes raw fluorescence intensity.

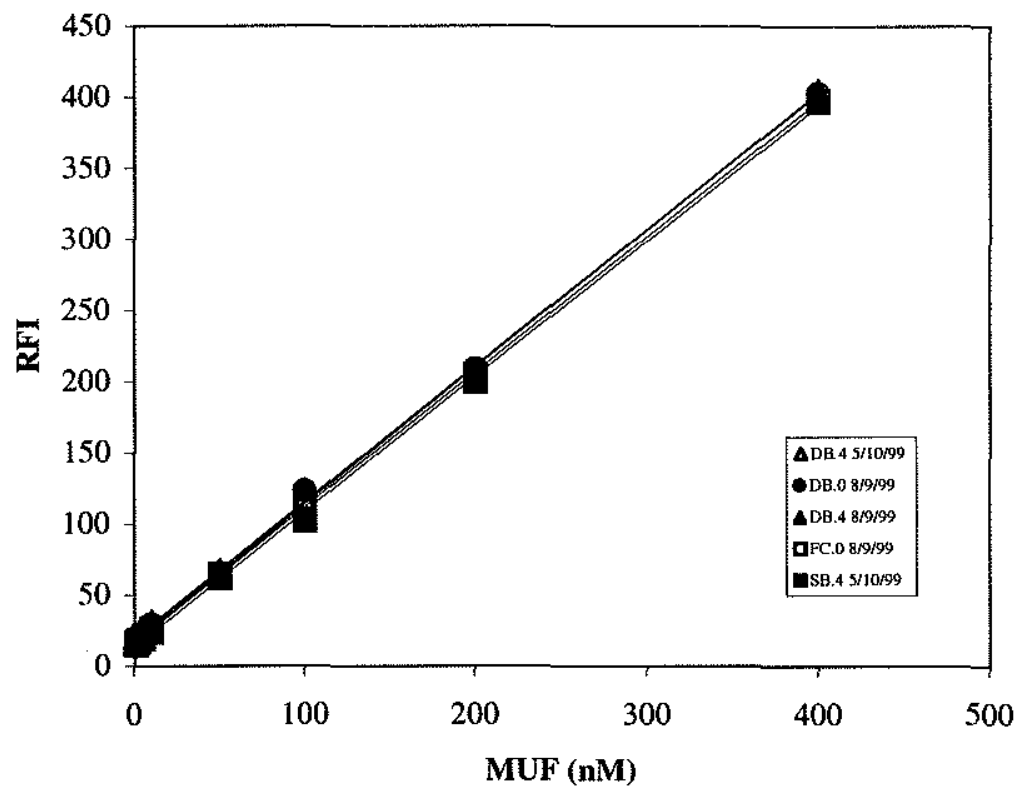

Figure 3.7-b: A closer look at the standard curve generated for the same 5 Ashumet Pond samples, ranging from 0-5 nM MUF. The slope of each sample is relatively consistent. However, there is a distribution of $y$-intercepts resulting from differences in sample matrix. These are natural water samples and have varying amounts of particulate and cellular matter. Therefore, the background fluorescence, or blank, will be different for each sample.

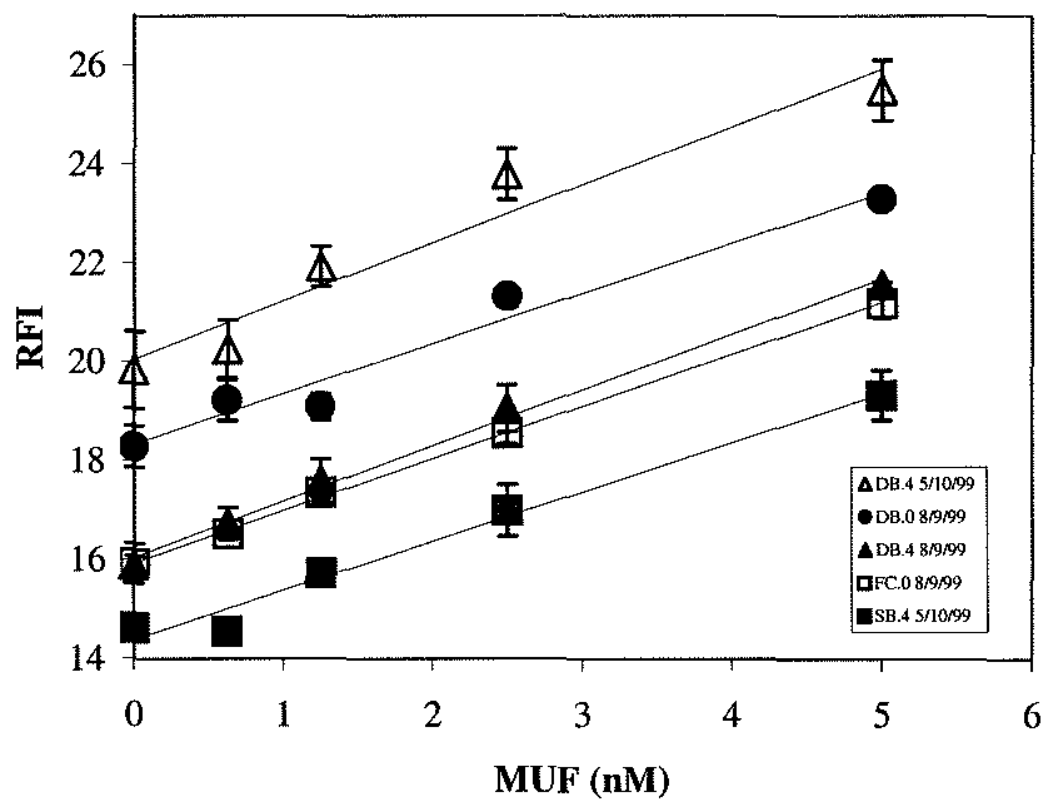


Figure 3.8-a: Standard curve of MUF concentrations ranging between 0-400 $\mathrm{nM}$ for two Ashumet Pond Deep Basin samples generated using a cytofluor. RFI denotes raw fluorescence intensity. Error bars represent the standard deviation between triplicates.

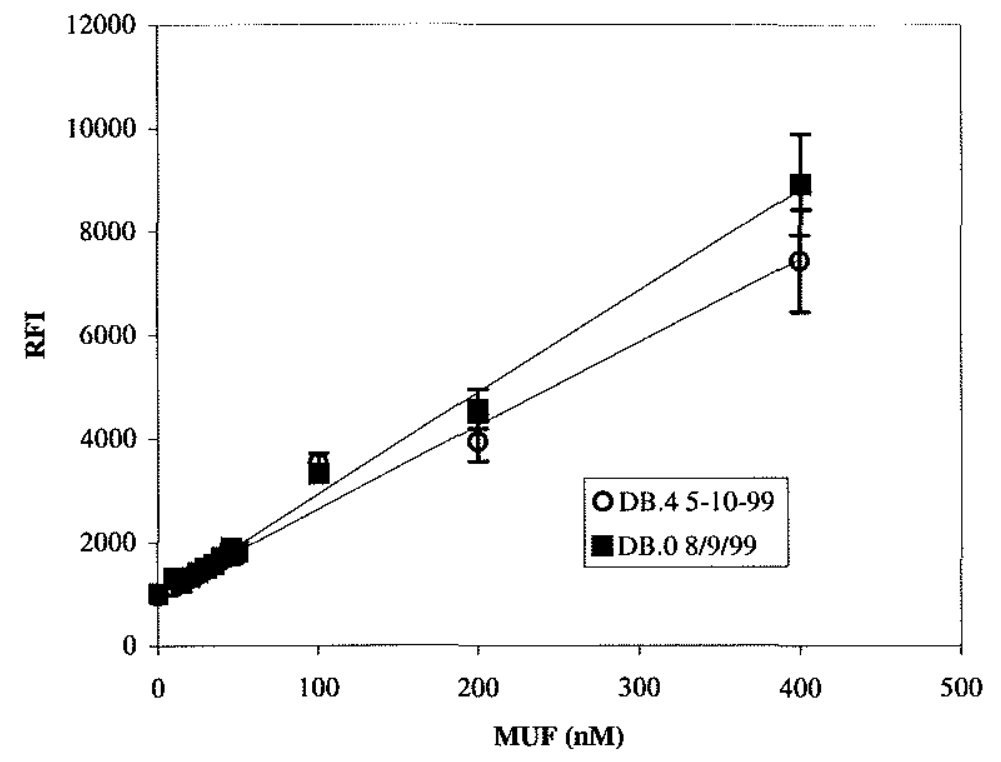

Figure 3.8-b: A closer look at the standard curve generated using a cytofluor, $x$-axis has been decreased to 0-60 nM MUF. The offset between y-intercept is due to differences in the sample matrix and therefore, different blank readings. The error bars represent the standard deviation between triplicates

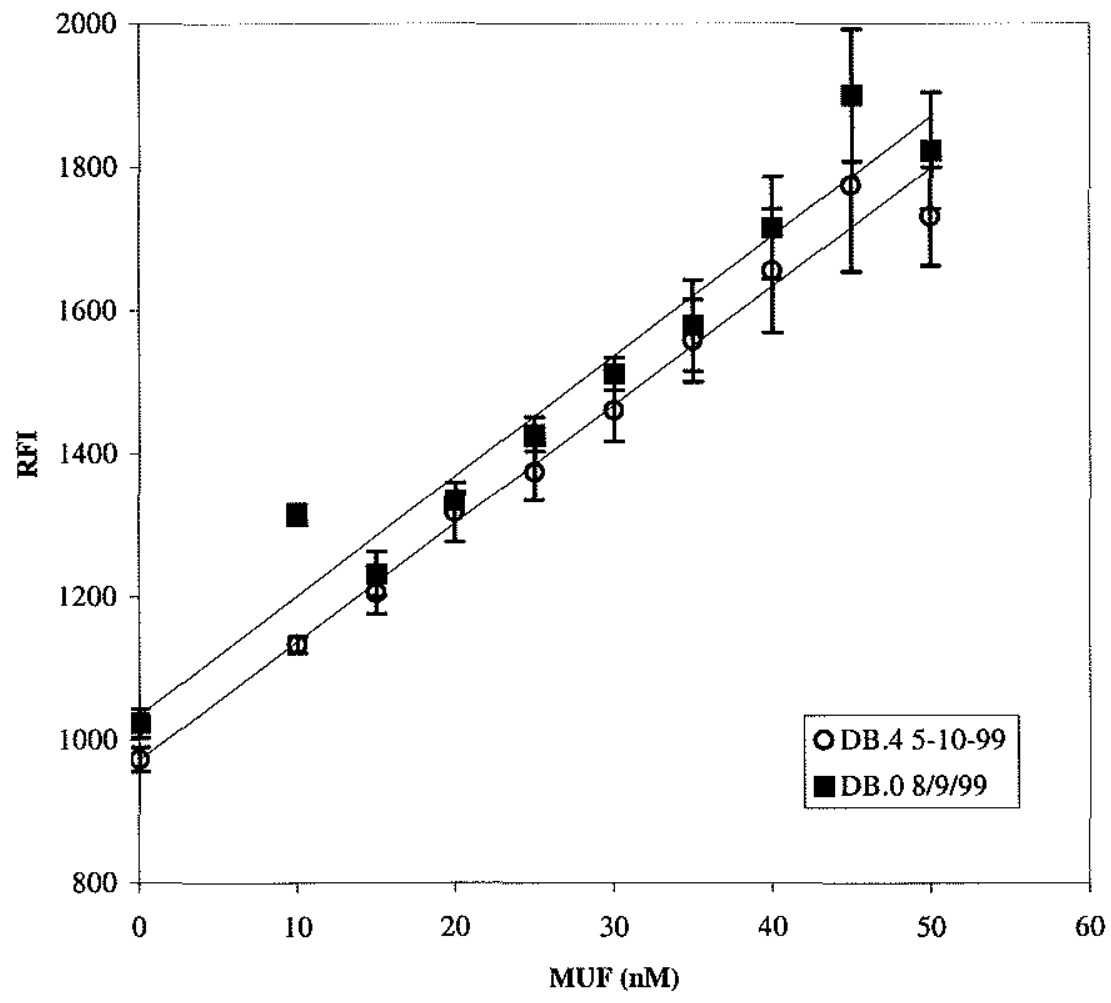


Figure 3.9: Correlation between alkaline phosphatase activity (APA) measurements conducted at 5 and 10 minute intervals on the cytofluor as compared to a 1:1 line. APA is reported in nM P/min. Error bars represent standard deviation over triplicates.

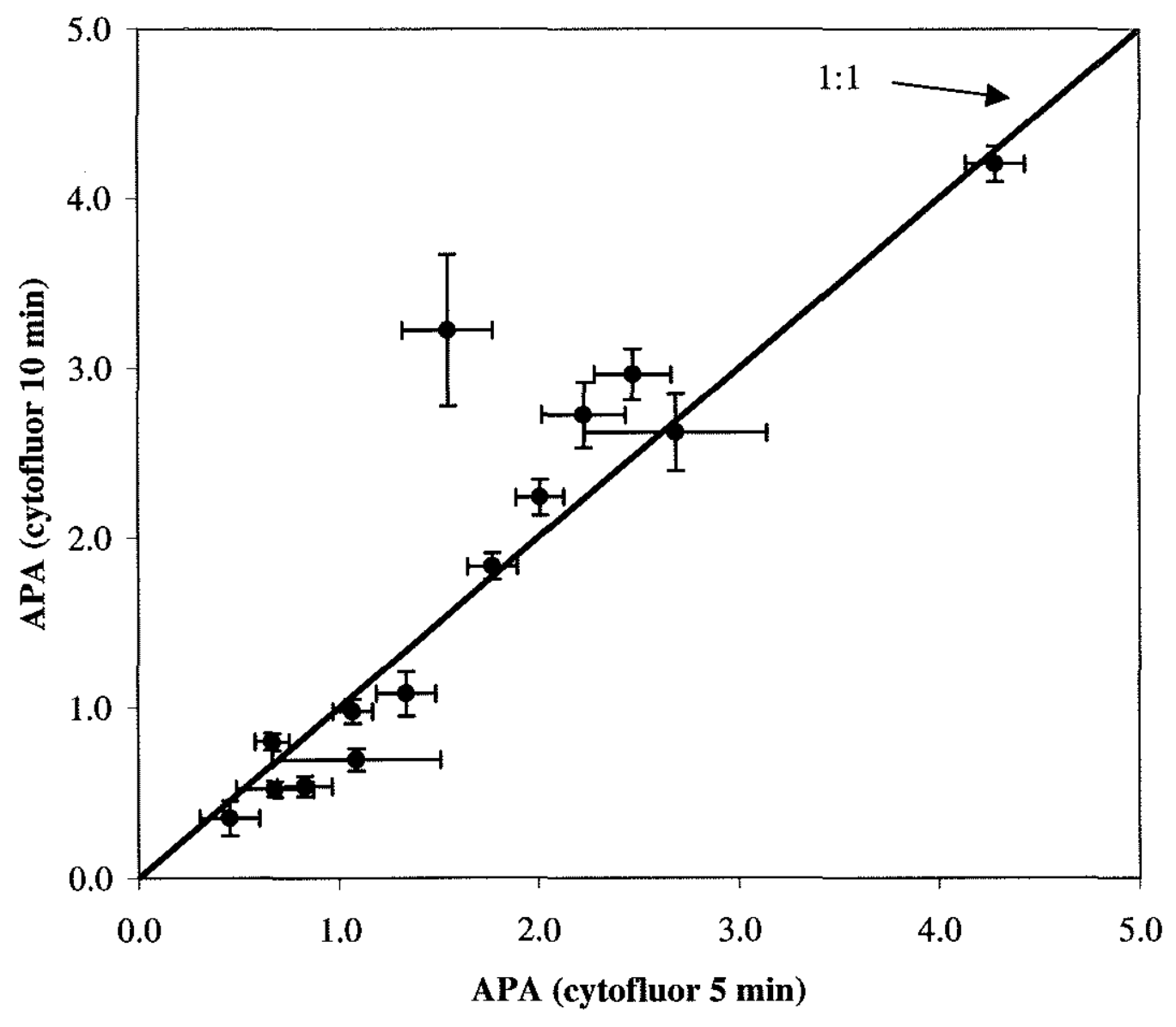


Figure 3.10: Effects of freezing on alkaline phosphatase activity (APA). The APA of samples frozen for 4 months (original APA) were compared to APA of the same samples re-frozen 2-4 months later (Re-run APA). Error bars reflect standard deviation of triplicates. The solid line represents a 1:1 correlation.

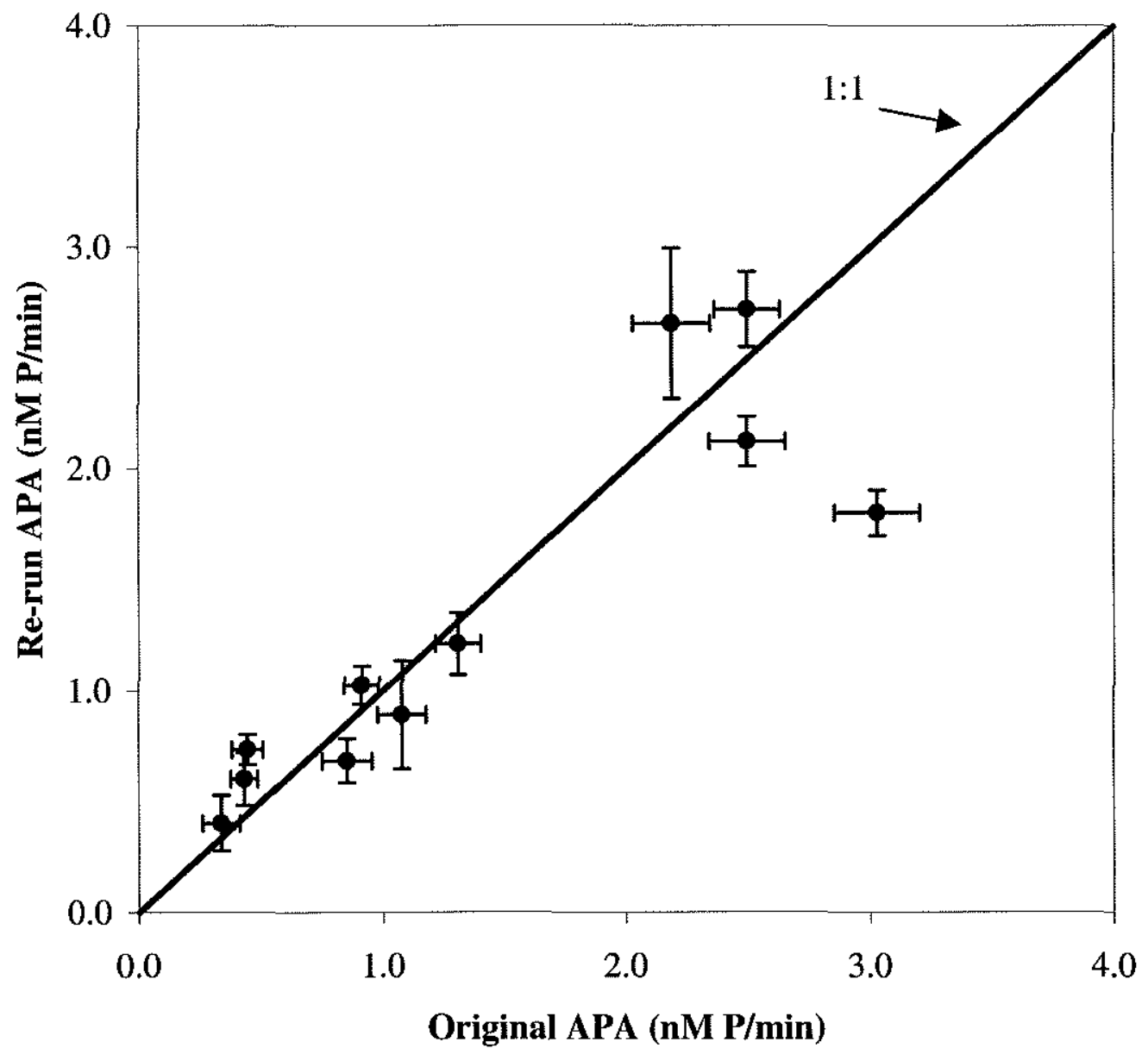


Figure 3.11: Cytofluor-fluorometer direct comparison. Alkaline phosphatase activity (APA) determined using a cytofluor are compared to APA derived from the same samples using a fluorometer. APA is reported as $\mathrm{nM} \mathrm{P/min.} \mathrm{The} \mathrm{solid} \mathrm{line} \mathrm{represents} \mathrm{a} \mathrm{1:1} \mathrm{correlation} \mathrm{and} \mathrm{the}$ dotted line represents the same 1:1 correlation translated over the data points.

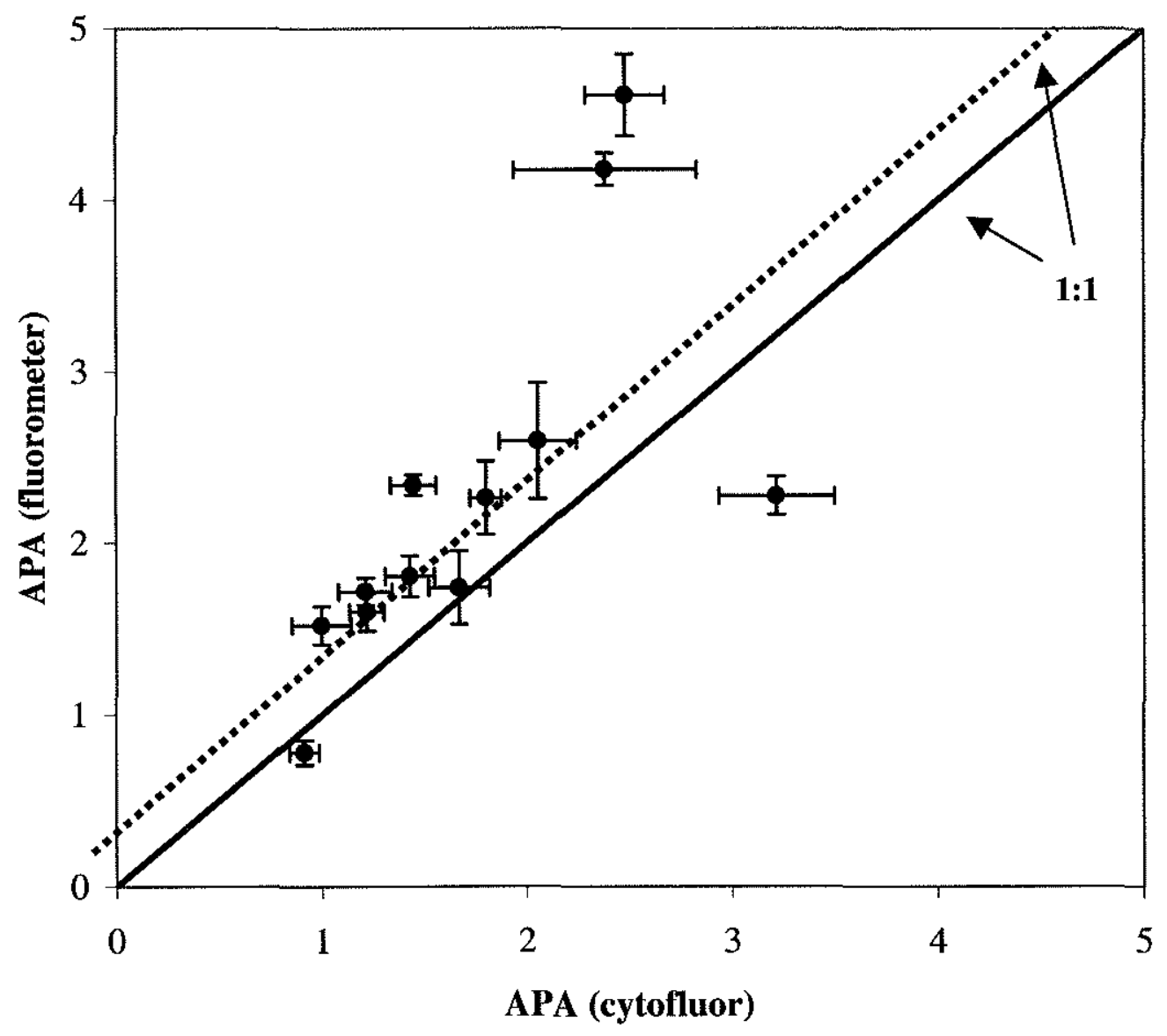


Figure 3.12-a: Cytofluor performance at sea using a 96-well cytoplate at $23{ }^{\circ} \mathrm{C}$ and $31{ }^{\circ} \mathrm{C}$. The raw fluorescence intensity (RFI) at a $3 \mathrm{~m}$ sea-state (SS-3) is compared to that at a $4 \mathrm{~m}$ sea-state (SS-4).

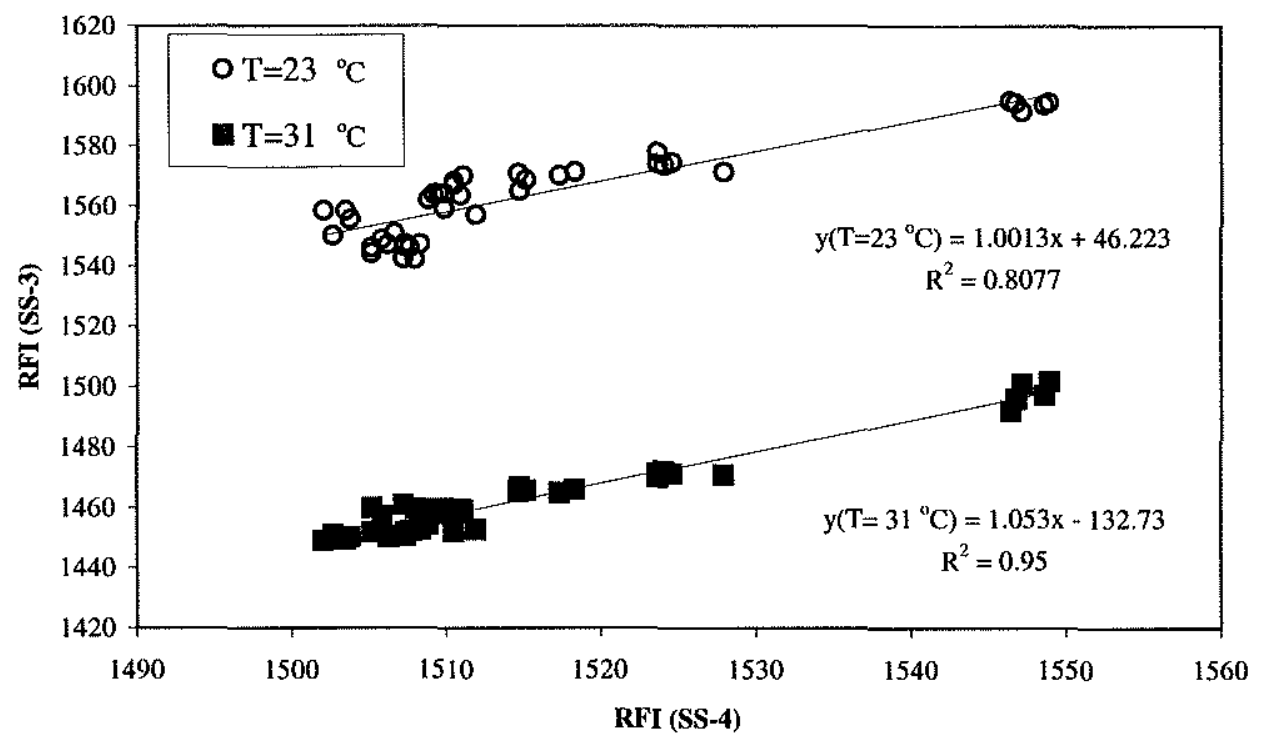

Figure 3.12-b: Cytofluor performance at sea using a 48-well polystyrene plate at $24.5^{\circ} \mathrm{C}$ and $31{ }^{\circ} \mathrm{C}$. The raw fluorescence intensity (RFI) at a $3 \mathrm{~m}$ sea-state (SS-3) is compared to that at a $4 \mathrm{~m}$ sea-state (SS-4).

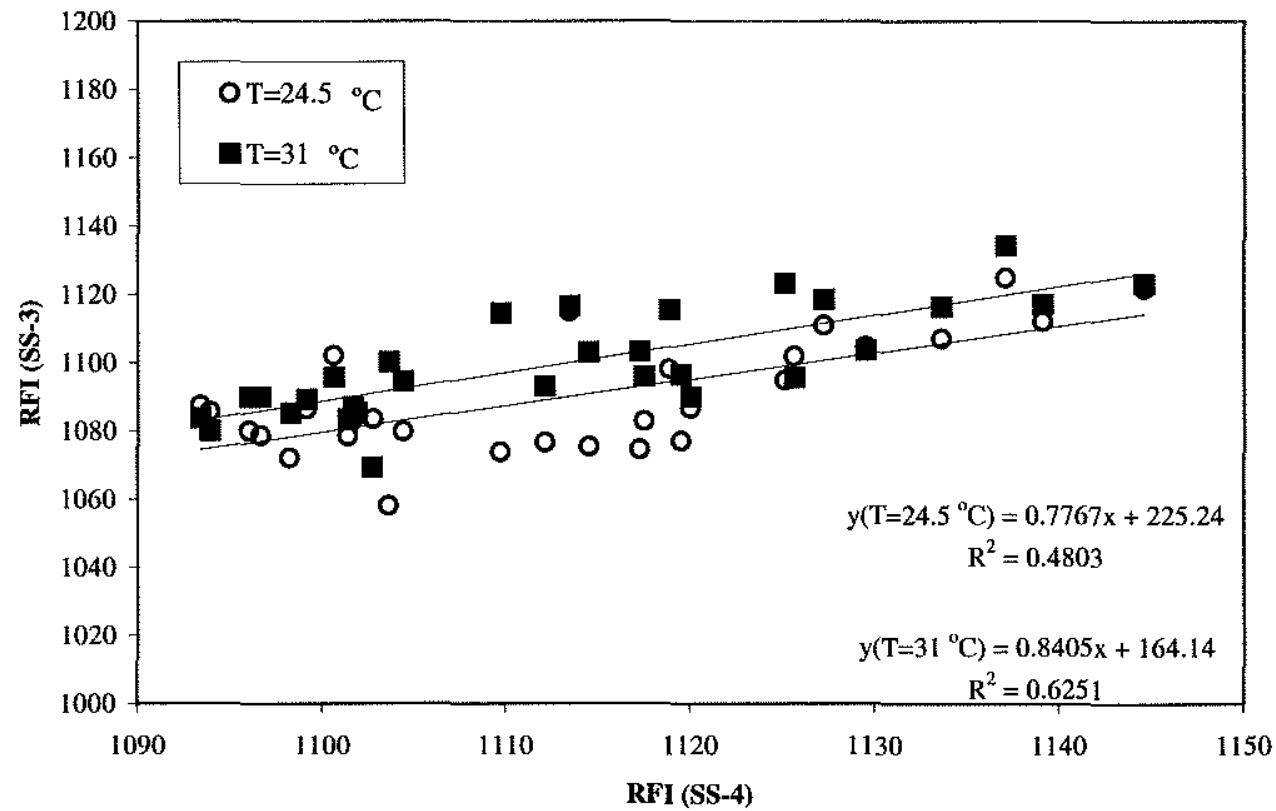




\section{Chapter 4}

\section{NUTRIENT LIMITATION DYNAMICS OF ASHUMET POND: RELIABILITY OF NUTRIENT DEFICIENCY INDICATORS}

\subsection{Introduction}

Ashumet Pond, a freshwater kettle pond on Cape Cod, is being impacted by a nutrient enriched, sewage contaminated groundwater plume. The plume contains elevated levels of phosphorus and nitrogen. The input of this nutrient laden groundwater may influence the nutrient limitation status of the pond. As discussed in Chapter 2, algal and bacterial cells require three macronutrients: (i) carbon, (ii) nitrogen, and (iii) phosphorus, in relatively uniform proportions (i.e., Redfield ratio Redfield, 1958). The "law of the minimum" states that the least abundant substance needed for the growth of a microbial community will limit the overall yield (Wetzel, 1975). Commonly, this limiting substance is a macronutrient. Carbon and nitrogen undergo exchange with the atmosphere allowing biological mechanisms to compensate for carbon and nitrogen deficiencies in the water, whereas phosphorus sources are strictly land derived. Therefore, in freshwater habitats, dissolved inorganic phosphorus (DIP) availability is often regarded as the nutrient that limits the rate of phytoplankton growth (Schindler, 1977). At the initiation of this study, the nutrient limitation status of Ashumet Pond was unknown, but the pond was assumed to be phosphorus-limited. Therefore, an increased load of phosphorus to the pond would result in an increase in biological productivity. Ashumet Pond has been characterized as a mesotrophic system, with moderate nutrient 
loading and seasonal hypolimnetic anoxia (AFCEE, 2000). Therefore, to understand how increased nutrient loads from a groundwater sewage plume will impact the trophic status of Ashumet Pond, the limiting nutrient must first be determined.

An effort to determine the present limiting nutrient and trophic status of the pond was undertaken by the Air Force Center for Environmental Excellence (AFCEE), who enlisted the efforts of the Woods Hole Oceanographic Institution (WHOI), University of Massachusetts School for Marine Science and Technology (SMAST); United States Geological Survey (USGS); and an environmental consulting firm, Jacobs Engineering Group Inc. In order to determine the nutrient limitation status of Ashumet Pond a hydrological and ecological study was undertaken. As part of their effort a comprehensive bi-weekly seasonal study was implemented from April to November 1999. Temperature and dissolved oxygen, dissolved and particulate nutrients, species composition and alkaline phosphatase activity (APA) were used to determine the nutrient limitation status of Ashumet Pond and to indicate if the nutrient load supplied by the groundwater sewage plume is setting the stage for cultural eutrophication, unwarranted algal blooms and potential fish kills.

\subsection{Background \& Context of Study}

\subsubsection{Description of Study Site}

Ashumet Pond $\left(41^{\circ} 38.00 \mathrm{~N}\right.$ and $\left.70^{\circ} 32.50 \mathrm{~W}\right)$ is located within the towns of Falmouth and Mashpee, approximately $0.5 \mathrm{~km}$ southeast of the Massachusetts Military 
Reservation, on Cape Cod, Massachusetts (Figure 4.1). It is a kettle pond, formed from stagnant blocks of ice left behind from a retreating glacier (Plummer and Mcgeary, 1979). The pond encompasses an area of $0.9 \mathrm{~km}^{2}$ and has a mean depth of $7 \mathrm{~m}$ and a maximum depth of $19.2 \mathrm{~m}$. There are two basins, the major basin (Deep Basin) in the northeastern part of the pond, maximum depth $19.2 \mathrm{~m}$, and a smaller basin (South Basin) located along the southern edge, maximum depth approximately $6 \mathrm{~m}$ (Figure 4.2). Ashumet Pond is normally monomictic, having only one overturn, or mixing event each autumn. However, in years when ice forms on the pond, winter stratification and subsequent spring overturn will occur (section 4.4). It is a mesotrophic pond, that is located in a residential area, used for recreational activities, including fishing, and stocked each year with trout and bass,. The pond is positioned in a single groundwater flow system (AFCEE, 1999) within an aquifer made mostly of mixed grained sands and gravel interbedded with silt and clay layers (AFCEE 1999). Ashumet Pond has no surface water outlets, and is mainly supplied by groundwater with smaller contributions coming from precipitation and surface run-off.

\subsubsection{MMR, Sewage Treatment Plant, and Sewage Groundwater Plume}

The Massachusetts Military Reservation (MMR), formerly known as Otis Air Force Base, was established in 1911 to oversee operations such as: troop training and development, fire-fighting training, ordnance development and training, aircraft and vehicle operation and maintenance, and fuel transport and storage (AFCEE, 1999). Operations intensified in the 1940 's during WWII, with over 50,000 troops stationed on base. After the Vietnam War ended, maneuvers decreased substantially. Currently, the 
reservation houses minimal operations conducted by the US Coast Guard, US Marine Corps, US Army National Guard, US Air Force, and US Air National Guard.

The former sewage treatment plant, located on the southeast corner of the MMR (Figure 4.3), consisted of primary and secondary treatment units, sand infiltration beds (outlined on Figure 4.3) and sludge drying beds. Primary treatment occurs in large settling tanks, in which solids found in the wastewater settle out of suspension. The primary treated water then undergoes secondary treatment, or biological treatment. Secondary treatment consists of adding aerobic bacteria, or "activated sludge" to the water, keeping the water under constant aeration. The microbes degrade the organic matter contained within the sewage. The water is then placed onto infiltration beds. Sludge formed from the primary and secondary processes is deposited onto sludge drying beds. Disposal of treated sewage onto the sand infiltration beds began in 1936 and continued irregularly until cessation occurred in 1995 (AFCEE, 1994). In the late 1970's, nutrient laden effluent from the sewage infiltration beds was discovered to be seeping into the groundwater supplying Ashumet Pond (LeBlanc, 1984).

Concentrations of phosphorus (P) contained within the aquifer (Figure 4.3) range from $3 \mu \mathrm{mol} / \mathrm{L}$ along the southern edge of the plume, to $160 \mu \mathrm{mol} / \mathrm{L}$, localized within a small anoxic zone. The USGS has been monitoring the physical and chemical characteristics of the plume through the use of monitoring wells (Figure 4.3), and has determined that the plume is discharging into Fisherman's Cove (Figure 4.2) (Bussey and Walter, 1996). There is concern that this anthropogenic nutrient source will hasten the natural aging process of the pond through cultural eutrophication. Therefore, 
understanding the nutrient limitation status of the pond, determined by this study through the use of alkaline phosphatase activity and other nutrient deficiency indicators, will elucidate the impact that the nutrient laden groundwater discharging into Ashumet Pond will have on the ecology of the pond.

\subsection{Sample Collection \& Analysis}

\subsubsection{SMAST Water Sampling Plan/Collection and Nutrient Analyses}

Ashumet Pond water column profiles and samples were taken by the School for Marine Science and Technology (SMAST) at the University of Massachusetts, Dartmouth once every two weeks between the months of April and November, 1999. Fourteen samples were collected on each sampling date, using a $0.75 \mathrm{~m}$ long Go-Flo bottle, at four sites: Fisherman's Cove (FC: $0 \mathrm{~m}, 2 \mathrm{~m}, 0-1.7 \mathrm{~m}$ depth integrated (int)); Wheeler Road (WR: int); Deep Basin (DB: 0 m, 2 m, 4 m, 6 m, 8 m, 10 m, 12 m, 14 m, $16 \mathrm{~m}, 18 \mathrm{~m}$, int); and South Basin (SB: $0 \mathrm{~m}, 2 \mathrm{~m}, 4 \mathrm{~m}, 6 \mathrm{~m}$, int) (Figure .4.2). Water samples were passed through a $100 \mu \mathrm{m}$ net to remove zooplankton. Physical parameters measured included: temperature, $\mathrm{pH}$, specific conductivity, secchi disk and dissolved oxygen. Nutrient analyses were preformed by SMAST using standard analytical methods (Standard Methods, 1992) for the following parameters (Table 4.1): total phosphorus (TP), dissolved inorganic phosphorus (DIP), total dissolved phosphorus (TDP), nitrate

and nitrite $\left(\mathrm{NO}_{3}{ }^{-}+\mathrm{NO}_{2}{ }^{-}\right)$, total dissolved nitrogen (TDN), ammonium $\left(\mathrm{NH}_{4}{ }^{+}\right)$, total nitrogen (TN), particulate organic carbon (POC), and chlorophyll-a. 
Table 4.1: Analytical methods used by SMAST (All methods are according to Standard Methods $18^{\text {th }}$ edition, 1992).

\begin{tabular}{|c|c|}
\hline Parameter & Analytical Method Used \\
\hline Total phosphorus $(\mu \mathrm{M})$ & $\begin{array}{l}\text { Sulfuric-nitric acid digestion } \\
\text { Molybdate blue reaction-spectrophotometry } \\
\qquad \text { (p. } 4: 112-114)\end{array}$ \\
\hline Total dissolved phosphorus $(\mu \mathrm{M})$ & $\begin{array}{l}\text { Sulfuric acid hydrolysis } \\
\text { Molybdate blue reaction- spectrophotometry } \\
\qquad \text { (p. } 4: 112-114)\end{array}$ \\
\hline Dissolved inorganic phosphorus $(\mu \mathrm{M})$ & $\begin{array}{l}\text { Molybdate blue reaction-spectrophotometry } \\
\text { (p. } 4: 114)\end{array}$ \\
\hline Nitrate and nitrite $(\mu \mathrm{M})$ & $\begin{array}{l}\text { Automated cadmium reduction method- } \\
\text { spectrophotometry } \\
\end{array}$ \\
\hline Ammonia $(\mu \mathrm{M})$ & Phenate method \\
\hline Total dissolved nitrogen $(\mu \mathrm{M})$ & Kjeldahl method \\
\hline Total nitrogen $(\mu \mathrm{g} / \mathrm{L})$ & $\begin{array}{l}\text { CHN analysis (after acidification to remove } \\
\text { inorganic C) }\end{array}$ \\
\hline Particulate organic carbon $(\mu \mathrm{g} / \mathrm{L})$ & $\begin{array}{l}\text { CHN analysis (after acidification to remove } \\
\text { inorganic C) }\end{array}$ \\
\hline Chlorophyll-a $(\mu \mathrm{g} / \mathrm{L})$ & $\begin{array}{l}\text { Acetone extraction } \\
\text { Fluorometric determination after acidification } \\
\text { (p. 10:19) }\end{array}$ \\
\hline
\end{tabular}

\subsubsection{Nutrient Addition Incubations}

Additional samples were collected for three nutrient addition incubations: NA-1, NA-2, and NA-3. Samples for NA-1 were collected on May 26, 1999. Four locations were sampled: FC-int, DB-int, DB-4 m, and SB-int. Splits of each sample were taken for five treatments: no additions (negative control), $+\mathrm{PO}_{4}$ (final concentration $5 \mu \mathrm{M}$ $\mathrm{KH}_{2} \mathrm{PO}_{4}$ ), $+\mathrm{NH}_{4}$ (final concentration $10 \mu \mathrm{M} \mathrm{NH} 4 \mathrm{Cl}$ ), $+\mathrm{NO}_{3}$ (final concentration $10 \mu \mathrm{M}$ 
$\mathrm{NaNO}_{3}$ ), and $+\mathrm{PO}_{4}+\mathrm{DIN}$ (final concentration $5 \mu \mathrm{M} \mathrm{KH}_{2} \mathrm{PO}_{4}+10 \mu \mathrm{M} \mathrm{NH} 4 \mathrm{Cl}+10 \mu \mathrm{M}$

$\mathrm{NaNO}_{3}$ ). Samples were incubated for a total of 30 hours with subsamples taken at 6 and

30 hours. Subsamples were sequentially filtered (see below) and the filters were collected and stored at $-30^{\circ} \mathrm{C}$. Incubating samples were exposed to 24 -hr illumination under a diffuse tungsten-halogen light field of $\sim 150 \mu \mathrm{Em}^{-2} \mathrm{~s}^{-1}$ in a flowing water table maintained at Ashumet Pond's in-situ temperature (AFCEE, 2000). Samples for NA-2, collected on August 9, 1999, were from the same locations and depths as NA-1. Incubating samples were exposed to the same illumination conditions as NA-1. The incubation protocol was modified as follows: 5 day incubation total with subsamples taken on days 2,4 and 5 . Subsamples were filtered immediately after collection and filtrates were collected. The filtrates were stored at $-30^{\circ} \mathrm{C}$. Samples for NA-3 were collected on August 31, 1999. Total incubation time was 5-days, with an 8-hr dark/16-hr light cycle, and subsamples were taken only once on day 5. Only three sites (FC-int, DBint, DB-4 m) and four treatments (no additions, $+\mathrm{PO}_{4},+\mathrm{DIN}$ or $+\mathrm{PO}_{4}+\mathrm{DIN}$ ) were used; each treatment for each sample was incubated in triplicate. The treatments were spiked twice with nutrients, on day 1 and day 3 . Subsamples were filtered, immediately after collection and the filtrates were stored at $-30{ }^{\circ} \mathrm{C}$.

\subsubsection{Size Fractionation}

The sample processing procedure underwent many modifications during the study, resulting in this final size fractionation filtration scheme modified from Hantke et al. (1996). Filters of two pore sizes $(0.8 \mu \mathrm{m}, 47 \mathrm{~mm}$ and $0.2 \mu \mathrm{m}, 47 \mathrm{~mm}$ polycarbonate 
nucleopore filters) were used sequentially to separately collect the algal fraction, the bacterial fraction and the freely dissolved alkaline phosphatases. Prior to filtration, a 100 -mL bulk water sample aliquot was collected. To prevent reduction of effective pore size due to filter clogging, $\leq 200$-mL were passed through two successive $0.8 \mu \mathrm{m}$ filters for a total combined volume of $400-\mathrm{mL}$. A $100-\mathrm{mL}$ aliquot of this combined filtrate was retained; this fraction represents the bacterial plus dissolved fraction. The remainder of the $0.8 \mu \mathrm{m}$ filtrate was then filtered through one $0.2 \mu \mathrm{m}$ filter and a $100-\mathrm{mL}$ aliquot taken, representing the freely dissolved alkaline phosphatase. Subtraction of the $<0.8$

$\mu \mathrm{m}$ fraction from the bulk gives a measure of the algal associated material. All fractions were stored immediately after collection at $-30^{\circ} \mathrm{C}$ until analyzed.

\subsubsection{Alkaline Phosphatase Assay}

Alkaline phosphatase activity (APA) was determined by hydrolyzing a fluorogenic substrate, 4-methlyumbelliferyl phosphate (MUF-P), into the fluorescent species, 4-methylumbelliferone (MUF) (section 3.3). MUF-P is recommended for phosphatase activity measurements in freshwaters, because it offers the most sensitive method and gives low background fluorescence (Pettersson and Jansson, 1978). Six splits of each sample were spiked with a suite of substrate concentrations for final MUF$P$ reaction concentrations of $0.5,0.75,1.0,3.0,7.0$, and $10.0 \mu \mathrm{M}$. These concentrations were used to ensure maximal in-situ APA would be detected. The idea was to stimulate APA that would only be present under natural conditions and therefore low concentrations of substrate were used to mimic natural DOP concentrations (e.g., 0.02 to $1.36 \mu \mathrm{M}$ for Ashumet Pond). Hydrolysis was determined by measuring the temporal 
increase in spiked sample fluorescence using an Applied Biosystems Cytofluor 4000 T/C. APA was measured in triplicate for each standard and for each concentration of substrate. Samples were run at a temperature controlled setting of $30^{\circ} \mathrm{C}\left(5^{\circ} \mathrm{C}\right.$ above room temperature). No correction for $\mathrm{pH}$ was made, again to ensure in-situ APA measurements. Alkaline phosphatase has a maximal operating efficiency at $\mathrm{pH}=8$, however, altering the sample $\mathrm{pH}$ to obtain maximal efficiency of the enzyme would change the natural environment. Modification of the natural environment was an undesirable effect and thus, samples were run at the in-situ $\mathrm{pH}$ of the pond water.

Each sample was run with a set of triplicate MUF standards $(0,10,50,100,200$, and $400 \mathrm{nM}$ MUF) made in the same sample matrix. The kinetic parameters calculated for this study were based on a 30 minute hydrolysis time course. The cytofluor was programmed to take one reading per well for six cycles with a five minute time interval between cycles on triplicate standards and substrate concentrations. Calibration curves were generated from the fluorescence readings of the standards at each time point. The slope and intercept of the calibration curve were then used to determine the concentration of MUF generated in each MUF-P substrate reaction at each time point. The slopes of the standard calibration curves increased at each time point for most samples. Therefore, instead of pooling the entire set of standards for one calibration curve, a calibration curve was generated at each time point and subsequently used to calculate $\mathrm{V}_{\max }$ and $\mathrm{K}_{\mathrm{m}}$. The calculated MUF concentrations (calculated from the time course hydrolysis after addition of MUF-P) were used to calculate hydrolysis rates for each substrate concentration. The subsequent hydrolysis rates, or velocities $\left(\mathrm{v}_{\mathrm{o}}\right)$, were then used to determine the maximal 
enzyme activity, $\mathrm{V}_{\max }$, for the sample employing Michaelis-Menten enzyme kinetics. $\mathrm{V}_{\max }$ and $\mathrm{K}_{\mathrm{m}}$ values were determined using GraphPad Prism ${ }^{\circledR}$ (GraphPad, 2000).

\subsubsection{Species Composition Determination}

Depth integrated samples $(0-1.7 \mathrm{~m})$ were collected from each sample location (Fisherman's Cove, Wheeler Rd., Deep Basin, South Basin), preserved in Lugol's solution and stored in glass amber bottles. A $10-\mathrm{mL}$ split of the samples were settled in settling chambers and cell counts were performed at 10x and 40x magnification using an inverted light microscope (Rengefors, 2000). The number of cells of each taxon were counted. Linear measurements of cells within each taxon were made in order to calculate biovolume/biomass. The number of measured cells depended on the rarity of that taxa, (i) with rare cells $(<10$ counted in sample) measured once, (ii) common cells (10-50) measured at least 5 times, and (iii) dominant cells $(>50)$ measured at least 10 times. The specific volume of the organisms was calculated using a decided formula that depended on the geometric shape of the cell. Once the specific volume was determined, the biovolume and/or biomass per liter of pond water was calculated using the standard assumption that the density of the organism equals that of water.

\subsection{Summer Stratification: Temperature \& Dissolved Oxygen Profiles}

A typical freshwater system in a temperate climate undergoes some degree of seasonal stratification as distinct layers of uniform temperature develop (Wetzel, 1975). The onset of seasonal stratification is driven by physical conditions such as 
temperature/density gradients. Stratification can occur in the summer and the winter (under ice cover), with summer stratification most prevalent. Stratification is a natural progression regardless of the trophic status of the system (section 4.6). Seasonal thermal stratification drives dissolved oxygen and dissolved nutrient profiles. The degree to which these profiles form and to which nutrient cycling occurs is dependant upon the extent of oxygen draw-down by respiring bacteria in bottom waters and sediments (i.e., oxidation of organic matter), as well as phytoplankton production at the surface (e.g., nutrient depletions) and thus, dependant upon the overall production of organic matter within the system.

In order to understand the extent of stratification in Ashumet Pond, profiles of temperature and dissolved oxygen will be used to describe the seasonal development of summer stratification. The effect this phenomenon has on dissolved nutrient cycles will be discussed in the subsequent section.

\subsubsection{Seasonal Development of Temperature and Dissolved Oxygen}

The temperature of a body of water is reflective of the amount of thermal energy received from the environment. As solar radiation warms the surface waters, the water column begins to thermally stratify. Freshwater is densest at $4{ }^{\circ} \mathrm{C}$, therefore water that is colder or warmer will be segregated above it, setting the stage for stratification to occur. In a temperate climate, bodies of freshwater (i.e., ponds and lakes) will commonly be monomictic (having one significant mixing/stratification event per year) or dimictic (two mixing/stratification events per year). The difference occurs during the winter, where a monomictic model remains well mixed (i.e., the entire water column remains nearly 
isothermal at $4^{\circ} \mathrm{C}$ ), in contrast to a dimictic system, where winter stratification occurs as surface waters are cooled and ice forms. Both systems undergo summer stratification. Summer stratification is the process by which the surface waters warm, become less dense, and settle above the cold dense deep waters. By mid-summer the structure of the water column is sectioned into three temperature density regions: (i) epilimnion, (ii) metalimnion, and (iii) hypolimnion (Figure 4.4).

The epilimnion (Figure 4.4), sometimes referred to as the mixed layer, is the uppermost stratum. It is a uniformly warm, well-mixed layer. The isothermal circulating waters are in constant exchange with the atmosphere and remain fully saturated with oxygen. The epilimnion is usually within the photic zone and is the locus of a significant portion of algal production. As phytoplankton grow, they rapidly assimilate most of the dissolved inorganic nutrients. Nutrient regeneration, via grazing and microbial respiration, is a major contributor to nutrient availability throughout the epilimnion (Eppley and Peterson, 1979). Therefore, the rate of regeneration within the epilimnion, the flux of dissolved nutrients from external sources into the epilimnion, and the nutritive needs of the microbial planktonic community are the primary factors controlling the nutrient limitation regime of an aquatic system.

The metalimnion is a region marked by a sharp temperature gradient that separates the warmer epilimnion from the colder hypolimnion. The thermocline, the point at which the maximum rate of decrease in temperature with respect to depth occurs, is located within the metalimnion (Figure 4.4). Pulses of nutrient rich water can be mixed upwards from the hypolimnion during wind events and other de-stabilizing 
conditions, supplying the epilimnion with nutrients. Phytoplankton that can position themselves near or migrate into the metalimnion can take advantage of these nutrient rich fluxes more readily than communities that are restricted to the surface.

The hypolimnion contains cold water that is completely isolated from the surface (Figure 4.4). Under stratified conditions, oxygen levels within this region quickly become depleted via bacterial respiration, a process whereby bacteria utilize oxygen to oxidize organic matter. The extent of oxygen draw-down is dependant on the amount of organic matter produced in the epilimnion and the morphology of the pond. The organic matter from the epilimnion sinks into the hypolimnion and is subsequently degraded via bacterial respiration. The degradation of organic matter quickly depletes oxygen in the hypolimnion because there are no mechanisms that operate to replenish oxygen. Once oxygen levels are depleted, they remain so for the duration of the stratified period. Oxygen is depleted from the sediment-water interface initially, as that is where bacterial activity is greatest. Once depleted from surface sediments, oxygen diffuses from the bottom-water into the sediments to fuel continued microbial respiration. The continued diffusion of oxygen from bottom-waters into sediments results in an erosion of bottomwater oxygen such that the anoxic region expands to fill the hypolimnion, ceasing only when the oxycline reaches the metalimnion (Figure 4.5). Although, organic matter degradation also occurs in the epilimnion, oxygen production by photosynthetic algae compensates for oxygen consumption via bacterial respiration such that it never becomes depleted. 
Ashumet Pond is a typical monomictic freshwater system (AFCEE, 2000). The temperature and dissolved oxygen profiles of Ashumet Pond describe the seasonal development of temperature that results in summer stratification and hypolimnetic oxygen depletion (Figures 4.5 and 4.6). The water column was well mixed and fully oxygenated in late spring (April 29) and began to thermally stratify during the summer months as surface waters warmed and became less dense (June 8-July 7) (Figure 4.6). By mid-summer (August 9) the water column was completely stratified with a fully developed epilimnion, metalimnion and hypolimnion. The epilimnion spanned the top 7 $\mathrm{m}$ of the water column. The thermocline set in at $8 \mathrm{~m}$, as the metalimnion, ranging between $7 \mathrm{~m}$ and $10 \mathrm{~m}$, separated the warmer surface water from the hypolimnion. Depletion of oxygen in the bottom waters proceeded in tandem with the onset of thermal stratification (Figure 4.5). The profiles for temperature and dissolved oxygen illustrate the progression of anoxia to increasingly shallower depths throughout the season until reaching the metalimnion. During the fall season, surface waters cooled, thermal stratification broke down, and the water column completely mixed (October 26), fully oxygenating it, once again. The anoxic zone will increase or decrease depending on the supply of organic matter to the sediments (i.e., extent of oxidation of organic matter by respiring bacteria). Consequently, the occurrence of seasonal anoxia in pond bottom waters changes the redox chemistry of nitrogen $(\mathrm{N})$ and iron $(\mathrm{Fe})$, thus causing a change in phosphorus (P) solubility, and drives $\mathrm{N}$ - and $\mathrm{P}$-cycling, as discussed in the next section. 


\subsection{Nutrient Cycles \& Nutrient Deficiency Indicators}

Nitrogen $(\mathrm{N})$ and phosphorus $(\mathrm{P})$ cycles describe the different pathways through which each nutrient enters and exits a pond or lake, and also any chemical transformations that occur along the way. The characteristics associated with summer stratification influence the distribution of nitrogen and phosphorus and the extent to which they cycle. Thermal stratification restricts the cycling of nutrients within the three distinct pond layers, and the speciation of each nutrient can be different under oxic versus anoxic conditions.

\subsubsection{The Phosphorus Cycle}

The total phosphorus content of Ashumet Pond is affected by influents (i.e., groundwater, aeolian inputs, and terrestrial matter), recycling within the photic zone, and remineralization within sediments. The primary flux of $\mathrm{P}$ into Ashumet Pond comes directly from groundwater inflow and release from anoxic pond-bottom sediments. Phosphorus occurs as dissolved organic and inorganic, and particulate organic and inorganic phases. Orthophosphate is the only significant form of dissolved-P in Ashumet Pond (AFCEE, 2000). However, over $90 \%$ of total-P in freshwater is organic (Wetzel, 1975), most of which is in biogenic particulate matter, as is the case for Ashumet Pond (AFCEE, 2000).

Removal of $\mathrm{P}$ from the epilimnion occurs via orthophosphate assimilation by phytoplankton and bacterioplankton and via sinking particles carrying either organic- or inorganic-P phases into the hypolimnion. In the epilimnion, the biogenic particulate-P 
any dead biota is either quickly remineralized by bacterial activity and released as orthophosphate or DOP, or sediments into the hypolimnion and is deposited as organic matter in sediments. During the growing season the newly released orthophosphate is quickly assimilated by phytoplankton (Cembella et al., 1984), drawing the levels of dissolved inorganic-P (DIP) to virtually zero. This process can be seen in the surface waters of Ashumet Pond during the 1999 growing season (Figure 4.7). Another source of removal of orthophosphate from the epilimnion is through submergence after sorption onto particulate ferric iron phases. Orthophosphate is a very particle reactive element and sorbs onto sinking particles, especially iron-oxyhydroxides ( $\mathrm{FeO}(\mathrm{OH})$ ) (Mortimer, 1941). P-laden particles sink into the deep water and get deposited as sediment.

Once the organic and inorganic particulate-P reach the sediments, redox chemistry becomes an important factor in controlling the amount of bioavailable-P that is returned o the overlying waters (Mortimer, 1941; Mortimer, 1942). The presence/absence of hypolimnetic oxygen influences the abundance of orthophosphate in the pond bottom waters (summarized in Wetzel, 1975). When the water column and sediment-water interface are oxic, inorganic-P is bound onto the ferric iron-oxide, preventing it from re-entering into solution. Under the same oxic conditions, microbial respiration is taking place in sediments, oxidizing organic matter and releasing inorganic$\mathrm{P}$ into pore waters. The inorganic-P becomes bound with iron-oxyhydroxides and is kept out of solution as well. However, as thermal stratification sets in and bacterial respiration consumes/depletes the available oxygen creating anoxic conditions, the ferric oxyhydroxides are reduced and orthophosphate is released (DIP) from the sediments into 
the bottom waters (Mortimer, 1941, Mortimer, 1942). Therefore, the concentration of DIP in the anoxic hypolimnion greatly exceeds that of the oxic epilimnion. This process is clearly operating in Ashumet Pond (Figure 4.7). As the anoxic zone builds up into the hypolimnion from the bottom of the pond, the concentration of orthophosphate increases in tandem. The levels continue to increase while the pond is completely thermally stratified. The build-up of orthophosphate is dependent on the amount of organic matter deposited as sediment and the aerial extent of the iron-oxyhydroxide zone in sediments. During fall overturn (October 26) the orthophosphate built-up in the hypolimnion is released into the epilimnion and the entire water column becomes mixed with respect to orthophosphate (Figure 4.7).

\subsubsection{The Nitrogen Cycle}

The nitrogen cycle (N-cycle) is driven by three major biochemical processes: (i) nitrogen fixation, (ii) nitrification and (iii) denitrification. Nitrogen fixation is a metabolic process that allows photosynthetic cyanobacteria to convert nitrogen gas $\left(\mathrm{N}_{2}\right)$ into ammonium $\left(\mathrm{NH}_{4}{ }^{+}\right)$. Important sources of nitrogen for nitrogen fixation derive from the atmosphere, as well as from denitrifying bacteria inhabiting sediments. Ammonium can undergo bacterial oxidation into nitrate and nitrite via nitrification. The cycle is completed as denitrifying bacteria reduce nitrate and nitrite into nitrogen gas via a pathway known as denitrification. The $\mathrm{N}$-cycle of freshwater systems is primarily microbially driven, as bacteria oxidize and reduce nitrogen compounds making them readily available for assimilation by algae and higher aquatic plants (Wetzel, 1975). 
Most of the nitrogen within the epilimnion is organic and cycled within the photosynthetic and microbial communities.

Similar to DIP of the P-cycle, the nitrogenous species in a freshwater system are influenced by seasonal thermal stratification and oxygen depletion of bottom waters. Under aerobic conditions, such as occur in the epilimnion, ammonium is largely oxidized by heterotrophic bacteria to nitrate, the form of nitrogen most readily available to phytoplankton (Wetzel, 1975). During the growing season, concentrations of nitrate become depleted from the epilimnion, as algal uptake exceeds the rate of external supply and thermal stratification restricts internal recycling (summarized in Reynolds, 1984).

In the anoxic hypolimnion of lakes and ponds, nitrate is reduced to ammonium as nitrification can no longer be supported due to the depletion of oxygen. The principle source of ammonium ions are derived from bacterially-mediated degradation of organic matter (McCarthy, 1980). The hierarchy of oxidants based on the amount of free energy given off during oxidation, stipulates that oxygen is used by bacteria first and then nitrate (Canfield, 1993). Therefore, under anoxic conditions, denitrifying bacteria will dominate the system, as the greatest amount of free energy is available to these organisms during organic matter degradation using $\mathrm{NO}_{3}{ }^{-}$as the electron acceptor. As denitrifying bacteria degrade organic matter in sediments ammonium is released into the hypolimnion. As anoxic conditions develop, ammonium derived from denitrifying bacteria, as well as from the absence of nitrification builds up in the hypolimnion. The progressive increase of ammonium in anoxic bottom waters is manifested in Ashumet Pond (Figure 4.8). The expansion of ammonium continues until fall overturn, at which time the water column 
returns to an oxygenated state and oxygen becomes the primary oxidant of organic matter once again.

\subsection{Trophic Status}

Is algal/phytoplankton growth slow and production of organic matter minimal? Are algae/phytoplankton dividing rapidly, causing the study system to amass large quantities of organic matter? The answers to these questions are crucial when trying to understand the current state of a system with respect to growth. Consequently, a classification scheme was derived, termed trophic status, in order to indicate to what degree an aquatic system is growing (i.e., level of productivity). The three levels of trophic status productivity are: (i) oligotrophic, (ii) mesotrophic, and (iii) eutrophic. Trophic status has been assessed by a number of government agencies. For example, the New York State Department of Environmental Conservation (NYDEC) has issued certain criteria, such as (i) total phosphorus (TP) content, (ii) chlorophyll-a concentrations, and (iii) depth of the photic zone, or region in which light penetrates as measured with a

Table 4.2: Description of the levels of trophic status. Criteria based on NYDEC (AFCEE, 2000).

\begin{tabular}{|c|c|c|c|c|c|}
\hline $\begin{array}{c}\text { Trophic } \\
\text { State }\end{array}$ & $\begin{array}{c}\text { Nutrient } \\
\text { Load }\end{array}$ & $\begin{array}{c}\text { Total P } \\
(\mu \mathrm{g} / \mathrm{L})\end{array}$ & $\begin{array}{c}\text { Chlorophyll-a } \\
(\mu \mathrm{g} / \mathrm{L})\end{array}$ & $\begin{array}{c}\text { Dissolved } \\
\text { Oxygen }\end{array}$ & $\begin{array}{c}\text { Photic } \\
\text { Zone (m) }\end{array}$ \\
\hline Oligotrophic & Low & $<7.0$ & $<3.5$ & Oxygenated & $>5.5$ \\
\hline Mesotrophic & Moderate & $7.0-15.0$ & $3.5-7.0$ & $\begin{array}{c}\text { Seasonal } \\
\text { anoxia }\end{array}$ & $3.0-5.5$ \\
\hline Eutrophic & High & $>15.0$ & $>7.0$ & $\begin{array}{c}\text { Seasonal to } \\
\text { year round } \\
\text { anoxia }\end{array}$ & $<3.0$ \\
\hline
\end{tabular}


secchi disk in order to assess the trophic state of a system (Table 4.2). Aquatic systems with low levels of TP $(<7 \mu \mathrm{g} / \mathrm{L})$ and chlorophyll-a $(<3.5 \mu \mathrm{g} / \mathrm{L})$ and photic zones deeper than $5.5 \mathrm{~m}$ are classified as oligotrophic. Oligotrophic systems have a minimal nutrient load and the hypolimnion may stay oxygenated throughout the summer season depending on the morphology of the system. Some deep oligotrophic lakes, such as Lake Tanganyika, may develop an anoxic hypolimnion (Wetzel, 1975). The other extreme of the classification scheme are eutrophic systems, which are described by high levels of TP $(>15 \mu \mathrm{g} / \mathrm{L})$ and chlorophyll-a $(>7 \mu \mathrm{g} / \mathrm{L})$ and which have shallow photic zones $(<3.0 \mathrm{~m})$. Eutrophic systems have characteristics of high nutrient loads and periods of severe hypolimnetic anoxia.

The interaction between inorganic and organic nutrients and the joint impact these nutrients have on the production of organic matter are the key mechanisms which define each trophic status level of a body of water. As discussed in sections 4.4 and 4.5, important aspects of $\mathrm{N}$ - and $\mathrm{P}$-cycling are in part driven by redox forces that ultimately result from oxidation of organic matter, the onset of seasonal thermal stratification, and the occurrence of hypolimnetic anoxia. The mechanisms associated with $\mathrm{N}$ - and Pcycling within an oligotrophic system, which has low nutrient sources, create a steadystate feedback loop (Figure 4.9) (Wetzel, 1975). An oligotrophic system contains low productivity, which results in low organic matter production, consequently leading to high hypolimnetic oxygen concentrations and minimal release of dissolved nutrients from the sediments. The low nutrient release results in low concentrations of bioavailable nutrients and subsequently low algal/phytoplankton production and low productivity. In 
the absence of high external nutrient sources, the system will continue to cycle with stable levels of productivity. Within a eutrophic system, typically with high nutrient loads, a positive feedback loop occurs (Figure 4.10) (Wetzel, 1975). Eutrophic systems have high productivity and thus substantial organic matter production. The high level of organic matter drives the hypolimnion to anaerobic conditions, stimulating the release of nutrients from sediments. The degree to which the hypolimnion is anoxic greatly influences the degree to which nutrients are released from sediments. The high release of nutrients in turn produces elevated levels of bioavailable nutrients to which stimulated algal/phytoplankton growth results. In the presence of external nutrient sources, such as the groundwater sewage plume, increased phytoplankton production will occur. The increased growth consequently produces more organic matter which increases the anaerobic region within the hypolimnion and further drives increased nutrient release from sediments. In some instances, the spiraling nature of this positive feedback mechanism leads to deterioration of the system, ultimately creating detrimental effects to the ecological state.

\subsection{Nutrient Deficiency Indicators: Alkaline Phosphatase \& Nutrient Ratios}

To assess the nutrient limitation regime of Ashumet Pond, indicators that demonstrate the extent to which the availability of a nutrient is limiting the growth of the microbial community must be investigated. Commonly used nutrient deficiency indicators include: (i) production of enzymes known to alleviate nutrient deficiency, i.e., alkaline phosphatase, (ii) the dissolved nutrient inventories and nutrient ratios 
characteristic of the aquatic system, i.e., DIN:DIP ratios, and (iii) the elemental composition of biogenic particulate material within an aquatic system, i.e., POC:PP (particulate organic carbon:particulate phosphorus).

Alkaline phosphatase is a phosphomonoesterase (i.e., it hydrolyzes phosphomonoesters (PMEs)) produced by the microbial community under conditions of phosphate-deficiency. Therefore, when phosphate concentrations are replete within an aquatic system, phytoplankton and bacteria readily assimilate orthophosphate (DIP), to maintain cellular phosphorus requirements (Cembella et al., 1984). Under these conditions they do not synthesize alkaline phosphatase. However, under depleted DIP conditions, the dissolved organic phosphorus (DOP) pool can be utilized (Berman, 1988; Bjorkman and Karl, 1994). Utilization of DOP by algal and bacterial cells occurs via DOP hydrolysis of the PME pool using alkaline phosphatase, a non-constitutive cellsurface enzyme (Healey and Hendzel, 1980). The presence/absence of alkaline phosphatase, therefore, indicates whether the microbial community is experiencing phosphate-deficiency.

Dissolved and particulate nutrient ratios can determine the limiting nutrient of an aquatic system through the use of deviations from $\mathrm{C}: \mathrm{N}: \mathrm{P}$ levels that are optimal for phytoplankton growth. Most living cells perform the same basic functions and, therefore, require the same biochemical building blocks $(\mathrm{C}, \mathrm{N}, \mathrm{P})$ in roughly the same proportions. It has been shown that the absolute minimum cellular requirements of $\mathrm{C}: \mathrm{N}: \mathrm{P}$ occur in relatively fixed proportions among freshwater algae (Reynolds, 1984). Within marine systems it has been determined that the $\mathrm{C}: \mathrm{N}: \mathrm{P}$ ratio of oceanic phytoplankton 
communities is on average, consistent with the dissolved inorganic C:N:P ratio. This ratio is known as the Redfield Ratio (Redfield, 1958). The similarity of C, N, P ratios within different phytoplankton assemblages form the basis for the use of $\mathrm{C}: \mathrm{N}: \mathrm{P}$ ratios as nutrient deficiency indicators. Therefore, deviations from the Redfield Ratio in C, N, or $\mathrm{P}$, can be indicative of which nutrient is limiting the growth of the microbial community. The elemental C:N:P ratios of both the dissolved and particulate pools in aquatic systems are commonly used to indicate the limiting nutrient. These indicators provide a means for determining whether nutrient deficiency is important in the resident microbial populations, and possibly to what extent the deficiency exists (Healey and Hendzel, 1980).

\subsection{Results}

\subsubsection{Nutrient Addition Experiments}

Three nutrient addition incubation experiments were preformed in order to assess (i) the effectiveness of alkaline phosphatase activity (APA) as a phosphate-deficiency indicator in Ashumet Pond and (ii) to determine the lag time characteristic of a mixed phyto-and bacterio-plankton community under phosphate-deficient conditions before stimulation of alkaline phosphatase production ensued. Due to procedural inadequacies in the first incubation experiment (NA-1) only data from the second (NA-2) and third (NA-3) incubations will be presented. The second and third incubations spanned 5 days. For NA-2, single splits for nutrients and chlorophyll-a were collected on day 2 , and single 
splits for alkaline phosphatase were collected on days 2, 4, and 5. For NA-3, nutrient, chlorophyll-a and alkaline phosphatase water samples were all taken in triplicate on day 5.

The phytoplankton cells in the pond water samples used in NA-2 and NA-3 were not P-limited upon initiation of the incubations, as indicated by the absence of APA (Table 4.3). By day 5, all samples from both experiments exhibited a substantial increase in APA in the nitrogen only treatment $\left(+\mathrm{NO}_{3}\right.$ and $+\mathrm{NH}_{4}$ for $\mathrm{NA}-2$, and $+\mathrm{DIN}$ $\left(+\mathrm{NH}_{4}+\mathrm{NO}_{3}\right)$ for NA-3), with final APA values spanning 5-25 nM P min ${ }^{-1}$ (Figures 4.11 and 4.12-a). Both experiments exhibited minor increases in APA in the control samples, and little to no increases in APA in the phosphorus only treatments $\left(+\mathrm{PO}_{4}\right)$. The amount of APA in the treatments spiked with nitrogen and phosphorus $\left(+\mathrm{DIN}+\mathrm{PO}_{4}\right)$ were variable depending on the day, but on average had little to no increase.

In order to determine the maximal response time for alkaline phosphatase production, NA-2 was run under constant illumination. Restricting the phytoplankton from a rest (dark) period, and sampling the incubation bottles on days 2, 4 and 5 allowed the maximal rate of response to phosphate-deficiency to be determined (Figure 4.11). The response time for alkaline phosphatase production under these conditions was on the order of 2-4 days. By day 2, there were low levels of APA in all treatments, with slightly greater levels in the control, $+\mathrm{NO}_{3}$ and $+\mathrm{NH}_{4}$ treatments. By day 4 , there was a substantial increase in the nitrogen only treatments and the control. An increase occurred again on day 5 , but was not as dramatic as the span between days 2 and 4 . Therefore, phytoplankton experiencing phosphate-deficiency will rapidly respond by producing 
Table 4.3: Initial and final nutrient concentrations of phosphate $\left(\mathrm{PO}_{4}{ }^{3+}\right)$, ammonia $\left(\mathrm{NH}_{4}{ }^{+}\right)$and nitrate $\left(\mathrm{NO}_{3}{ }^{\circ}\right.$ ), chlorophyll-a (Chl-a) and alkaline phosphatase activity (APA) for NA-3. Initial (insitu) concentrations are listed, followed by replicate (rep) values from Day 5. "denotes fluorometer APA samples corrected for 1:1.13 offset.

\begin{tabular}{|c|c|c|c|c|c|c|c|}
\hline Site & Addition & Rep & $\begin{array}{l}\mathbf{P O}_{4}{ }^{3-} \\
(\mu \mathrm{M})\end{array}$ & $\begin{array}{l}\mathrm{NH}_{4}^{+} \\
(\mu \mathrm{M})\end{array}$ & $\begin{array}{l}\mathrm{NO}_{3}{ }^{-1} \\
(\mu \mathrm{M})\end{array}$ & $\begin{array}{c}\text { Chl a } \\
(\mu \mathrm{g} / \mathrm{L})\end{array}$ & $\begin{array}{c}\text { APA } \\
\left(n M P_{\text {min }^{-1}}\right)\end{array}$ \\
\hline \multirow{13}{*}{$\begin{array}{c}\text { Deep Basin } \\
4 \mathrm{~m}\end{array}$} & initial & & 0.08 & 0.99 & 0.20 & 5.74 & 0.00 \\
\hline & control & 1 & 0.00 & 0.31 & 0.32 & 5.60 & 0.44 \\
\hline & & 2 & 0.00 & 0.27 & 0.29 & & 0.27 \\
\hline & & 3 & 0.00 & 0.27 & 0.41 & & 0.05 \\
\hline & $\mathrm{DIN}^{*}$ & 1 & 0.00 & 6.52 & 10.00 & 9.35 & 4.17 \\
\hline & & 2 & 0.00 & 7.59 & 10.11 & & 6.17 \\
\hline & & 3 & 0.00 & 6.57 & 9.72 & & 4.73 \\
\hline & $\mathrm{DIN}+\mathrm{PO}_{4}{ }^{*}$ & 1 & 4.13 & 3.57 & 9.96 & 8.34 & 1.33 \\
\hline & & 2 & 4.24 & 6.07 & 10.16 & & 0.00 \\
\hline & & 3 & 4.29 & 6.25 & 10.18 & & 0.47 \\
\hline & $\mathrm{PO}_{4}$ & 1 & 4.53 & 0.27 & 0.32 & 6.21 & 0.98 \\
\hline & & 2 & 4.48 & 0.09 & 0.33 & & 0.40 \\
\hline & & 3 & 4.56 & 0.18 & 0.21 & & 0.11 \\
\hline
\end{tabular}

\begin{tabular}{|c|c|c|c|c|c|c|c|}
\hline Deep Basin & initial & & 0.07 & 1.77 & 0.35 & 5.51 & 0.00 \\
\cline { 2 - 8 } integrated & control & 1 & 0.00 & 0.27 & 0.94 & 3.19 & 1.87 \\
\cline { 2 - 8 } & & 2 & 0.00 & 0.53 & 0.35 & & 1.53 \\
\cline { 2 - 8 } & & 3 & 0.00 & 0.62 & 0.34 & & 1.74 \\
\cline { 2 - 8 } & & 1 & 0.00 & 5.00 & 10.16 & 8.66 & 0.47 \\
\cline { 2 - 8 } & & 2 & 0.00 & 5.81 & 10.21 & & 1.15 \\
\cline { 2 - 8 } & & 3 & 0.00 & 6.07 & 10.43 & & 1.65 \\
\cline { 2 - 8 } & $\mathrm{DIN}+\mathrm{PO}_{4}{ }^{*}$ & 1 & 4.50 & 3.39 & 10.17 & 6.87 & 0.68 \\
\cline { 2 - 8 } & & 2 & 4.26 & 4.38 & 20.05 & & 0.00 \\
\cline { 2 - 8 } & & 3 & 4.21 & 3.48 & 10.15 & & 0.00 \\
\cline { 2 - 8 } & & 1 & 4.56 & 0.13 & 0.38 & 3.88 & 0.14 \\
\cline { 2 - 7 } & & 2 & 4.43 & 0.09 & 0.23 & & 0.58 \\
\hline
\end{tabular}

\begin{tabular}{|c|c|c|c|c|c|c|c|}
\hline Fisherman's $\begin{array}{c}\text { Cove } \\
\text { integrated }\end{array}$ & initial & & 0.03 & 0.26 & 0.09 & 5.18 & 0.00 \\
\cline { 2 - 8 } & control & 1 & 0.00 & 0.27 & 0.23 & 3.36 & 1.30 \\
\cline { 2 - 8 } & & 2 & 0.00 & 0.22 & 0.29 & & 2.04 \\
\cline { 2 - 8 } & & 3 & 0.00 & 0.13 & 0.28 & & 2.08 \\
\cline { 2 - 8 } & $\mathrm{DIN}^{*}$ & 1 & 0.00 & 6.34 & 9.97 & 7.62 & 3.26 \\
\cline { 2 - 8 } & & 2 & 0.00 & 5.99 & 9.93 & & 4.50 \\
\cline { 2 - 8 } & & 3 & 0.00 & 6.07 & 9.92 & & 2.72 \\
\cline { 2 - 8 } & $\mathrm{DIN}^{*} \mathrm{PO}_{4}{ }^{*}$ & 1 & 4.13 & 4.06 & 9.79 & 7.22 & 0.35 \\
\cline { 2 - 8 } & & 2 & 4.26 & 4.02 & 10.03 & & 0.00 \\
\cline { 2 - 8 } & & 3 & 4.29 & 3.75 & 9.72 & & 0.00 \\
\cline { 2 - 8 } & & 1 & 4.45 & 0.18 & 0.24 & 4.06 & 0.73 \\
\cline { 2 - 8 } & & 2 & 4.45 & 0.04 & 0.13 & & 0.65 \\
\hline
\end{tabular}


alkaline phosphatase with in 4 days at which time the enzymes will steadily hydrolyze phosphomonoesters until the cells meet their cellular-P needs.

The third incubation experiment (NA-3) was illuminated with an 8-hr dark/16-hr light cycle. The light/dark cycle used during this experiment mimicked natural conditions and allowed for a measure of the natural response to phosphate-deficiency. Based upon results from NA-1 and NA-2, the experimental design for NA-3 was changed to provide triplicate subsamples for better elucidation of the APA response. This latter experiment was used to determine the effectiveness of alkaline phosphatase as a phosphate-deficiency indicator (Table 4.3). The triplicate samples were run through the normal 30 minute time-course hydrolysis experiment on the cytofluor. A curious interference problem was detected in the standards for all samples treated with nitrogen $\left(+\mathrm{DIN}\right.$ and $\left.+\mathrm{DIN}+\mathrm{PO}_{4}\right)$. The initial slope of the standard calibration curve was drastically elevated above normal and the slope decreased at each time interval resulting in a final slope $0.5 *$ initial slope. The nitrogen treated samples differed from the control and $+\mathrm{PO}_{4}$ subsamples by having significant levels of green algae, as confirmed by microscopical analyses (during filtration, the filters turned green as opposed to the normal brown color of the control and $\left.+\mathrm{PO}_{4}\right)$. To rule out interference derived from the presence of chlorophyll-a, chlorophyll-a standards were run on the cytofluor and the fluorescence measured through time. A decreasing signal was not detected. In order to determine if the interference problem was cytofluor derived, the fluorometer was used to determine APA of the nitrogen treated samples. No interference occurred. Therefore, the APA values reported for $+\mathrm{DIN}$ and $+\mathrm{DIN}+\mathrm{PO}_{4}$ in Table 4.3 were derived from 
measurements made on the fluorometer. The samples run on the fluorometer have been corrected for the 1:1.13 offset determined in Chapter 3. The reason for the abundant cytofluor measurements for these samples remains unexplained.

At the end of NA-3, an increase in chlorophyll-a occurred in the nitrogen enriched treatments $\left(+\mathrm{DIN}\right.$ and $\left.+\mathrm{DIN}+\mathrm{PO}_{4}\right)$, indicating that phytoplankton growth was stimulated in these treatments (Figure 4.12-b). In the control and $+\mathrm{PO}_{4}$ treatments there was equal or lower chlorophyll-a, as compared to the initial level (Figure 4.12-b). The increased biomass was due to nitrogen addition. The APA indicated that the nitrogen addition forced phytoplankton cells to become P-limited. Therefore, APA is a robust phosphatedeficiency indicator in Ashumet Pond.

\subsubsection{Pond-Wide Lateral Homogeneity \& Vertical Patchiness}

A pond-wide comparison of bulk water APA, chlorophyll-a, and dissolved inorganic $\mathrm{N}$ and $\mathrm{P}$ (DIN and DIP) was performed to evaluate the variability of each parameter laterally and vertically throughout the pond on each sampling date (Table 4.4). In order to determine variability on a lateral scale, the seasonal distribution of each parameter was averaged pond-wide at 0,2 , and $4 \mathrm{~m}$ for Deep Basin, Fisherman's Cove and South Basin (Figure 4.2) respectively, and compared to the seasonal distributions measured for Deep Basin. Deep Basin made a good candidate for comparison between locations because the locale was the primary basin in the pond, it encompassed a significant portion of the total area of Ashumet Pond , and summer stratification (i.e., thermal stratification followed by hypolimnetic anoxia and dissolved nutrient build-up during summer months, sections 4.4 and 4.5 ) occurred here during the span of the study. 
Table 4.4: Pond-wide values of bulk water alkaline phosphatase activity (APA), chlorophyll-a, and dissolved inorganic $\mathrm{N}$ and $\mathrm{P}$ (DIN and DIP) for Deep Basin 0, 2, $4 \mathrm{~m}$ (DB0, DB2, DB4), South Basin 0, 2, $4 \mathrm{~m}$ (SB0, SB2, SB4) and Fisherman's Cove 0, $2 \mathrm{~m}$ (FC0, FC2). Avg, Stdev denote pond average and standard deviation.

\begin{tabular}{|c|c|c|c|c|c|c|c|c|c|c|}
\hline \multicolumn{11}{|c|}{ Chlorophyll-a $(\mu \mathrm{g} / \mathrm{l})$} \\
\hline & DBO & DB2 & DB4 & SBO & SB2 & SB4 & FCO & FC2 & Avg & Stdev \\
\hline Apr-29 & 10.70 & 10.43 & 9.93 & 9.44 & 9.23 & 9.65 & 10.15 & 9.70 & 9.90 & 0.50 \\
\hline May-10 & 1.17 & 1.64 & 2.08 & 1.41 & 1.72 & 2.84 & 1.45 & 1.27 & 1.70 & 0.54 \\
\hline May-26 & 1.42 & 1.46 & 1.63 & 1.06 & 1.54 & 1.37 & 1.02 & 1.22 & 1.34 & 0.22 \\
\hline Jun-8 & 2.82 & 3.03 & 3.01 & 3.23 & 2.70 & 3.68 & 4.47 & 4.36 & 3.41 & 0.69 \\
\hline Jun-22 & 0.97 & 1.28 & 1.20 & 1.43 & 1.26 & 1.24 & 2.09 & 3.62 & 1.64 & 0.87 \\
\hline Jul-7 & 7.88 & 9.02 & 11.83 & 11.18 & 9.30 & 14.91 & 7.45 & 9.85 & 10.18 & 1.80 \\
\hline Jul-20 & 5.89 & 5.24 & 4.99 & 4.53 & 4.66 & 22.64 & 3.30 & 2.27 & 6.69 & 1.60 \\
\hline Aug-9 & 7.22 & 6.76 & 6.73 & 3.78 & 3.78 & 2.98 & 6.89 & 7.04 & 5.65 & 1.79 \\
\hline Aug-17 & 5.32 & 5.91 & 5.74 & 4.46 & 4.04 & 3.50 & 3.18 & 3.84 & 4.50 & 1.04 \\
\hline Aug-30 & 5.30 & 5.81 & 5.87 & 4.74 & 4.95 & 4.01 & 5.55 & 5.64 & 5.23 & 0.64 \\
\hline Sep-14 & 7.35 & 6.48 & 5.79 & 3.21 & 3.35 & 3.32 & 3.93 & 3.45 & 4.61 & 1.67 \\
\hline Sep-27 & 4.30 & 3.86 & 4.28 & 1.87 & 5.37 & 9.65 & 7.02 & 7.13 & 5.44 & 1.42 \\
\hline Oct-12 & 4.01 & 2.13 & 1.99 & 1.31 & 1.88 & 2.15 & 1.15 & 1.33 & 1.99 & 0.91 \\
\hline Oct-26 & 8.73 & 7.54 & 7.39 & 6.79 & 6.79 & 6.31 & 7.40 & 7.17 & 7.27 & 0.72 \\
\hline \multicolumn{11}{|c|}{ DIP $(\mu \mathrm{mol})$} \\
\hline Apr-29 & 0.05 & 0.05 & 0.05 & 0.08 & 0.05 & 0.10 & 0.15 & 0.30 & 0.10 & 0.09 \\
\hline May-10 & 0.02 & $0 . \overline{02}$ & 0.02 & 0.08 & 0.05 & 0.05 & 0.10 & 0.05 & 0.05 & 0.03 \\
\hline May-26 & 0.13 & 0.20 & 0.16 & 0.20 & 0.16 & 0.17 & 0.17 & 0.17 & 0.17 & 0.02 \\
\hline Jun-8 & 0.08 & 0.06 & 0.06 & 0.10 & 0.09 & 0.20 & 0.10 & 0.10 & 0.10 & 0.04 \\
\hline Jun-22 & 0.12 & 0.12 & 0.12 & 0.14 & 0.07 & 0.10 & 0.10 & 0.12 & 0.11 & 0.02 \\
\hline Jul-7 & 0.07 & 0.06 & 0.08 & 0.07 & 0.06 & 0.18 & 0.12 & 0.18 & 0.10 & 0.05 \\
\hline Jul-20 & 0.08 & 0.10 & 0.11 & 0.09 & 0.09 & 0.10 & 0.10 & 0.10 & 0.10 & 0.01 \\
\hline Aug-9 & 0.03 & 0.03 & 0.07 & 0.12 & 0.13 & 0.12 & 0.10 & 0.16 & 0.10 & 0.05 \\
\hline Aug-17 & 0.09 & 0.08 & 0.10 & 0.30 & 0.20 & 0.24 & 0.16 & 0.14 & 0.17 & 0.08 \\
\hline Aug-30 & 0.08 & 0.06 & 0.08 & 0.09 & 0.11 & 0.08 & 0.03 & 0.08 & 0.08 & 0.02 \\
\hline Sep-14 & 0.02 & 0.03 & 0.02 & 0.02 & 0.04 & 0.04 & 0.04 & 0.04 & 0.03 & 0.01 \\
\hline Sep-27 & 0.01 & 0.02 & 0.08 & 0.03 & 0.03 & 0.03 & 0.07 & 0.16 & 0.05 & 0.05 \\
\hline Oct-12 & 0.32 & 0.44 & 0.41 & 0.38 & 0.41 & 0.38 & 0.93 & 0.50 & 0.47 & 0.19 \\
\hline Oct-26 & 0.93 & 0.96 & 0.93 & 0.93 & $\begin{array}{l}0.87 \\
\end{array}$ & 0.87 & 0.93 & 0.98 & 0.92 & 0.04 \\
\hline \multicolumn{11}{|c|}{ DIN $(\mu \mathrm{mol})$} \\
\hline Apr-29 & 0.75 & 0.88 & 0.68 & 1.95 & 1.33 & 0.71 & 5.75 & 4.59 & 2.08 & 1.98 \\
\hline May-10 & 3.69 & 3.94 & 3.82 & 3.06 & 2.80 & 3.26 & 4.50 & 3.90 & 3.62 & 0.55 \\
\hline May-26 & 5.83 & 6.18 & 5.90 & 5.71 & 5.84 & 5.72 & 6.30 & 5.80 & 5.91 & 0.22 \\
\hline Jun-8 & 4.65 & 5.33 & 4.78 & 5.37 & 4.74 & 7.85 & 5.36 & 5.49 & 5.45 & 1.03 \\
\hline Jun-22 & 1.18 & 1.02 & 1.62 & 0.64 & 0.49 & 2.54 & 1.66 & 0.78 & 1.24 & 0.68 \\
\hline Jul-7 & 0.43 & 0.24 & 0.40 & 1.05 & 0.27 & 0.38 & 1.45 & 0.49 & 0.59 & 0.43 \\
\hline Jul-20 & 0.51 & 0.50 & 0.62 & 1.27 & 1.03 & 1.46 & 1.65 & 1.66 & 1.09 & 0.50 \\
\hline Aug-9 & 1.05 & $4 . \overline{35}$ & 2.54 & 1.18 & 1.49 & 1.38 & 1.42 & 2.09 & 1.94 & 1.09 \\
\hline Aug-17 & 0.49 & 0.62 & 0.74 & 2.58 & 1.47 & 2.44 & 1.85 & 1.75 & 1.49 & 0.81 \\
\hline Aug-30 & 2.29 & 0.69 & 1.19 & 0.32 & 0.40 & 0.24 & 0.24 & 0.35 & 0.72 & 0.71 \\
\hline Sep-14 & 0.24 & 0.11 & 0.24 & 0.09 & 0.14 & 0.45 & 0.36 & 0.35 & 0.25 & 0.13 \\
\hline Sep-27 & 0.14 & 0.09 & 0.33 & 0.36 & 0.28 & 0.27 & 0.23 & 0.87 & 0.32 & 0.24 \\
\hline Oct-12 & 9.52 & 9.56 & 9.49 & 8.82 & 8.74 & 8.59 & 12.20 & 9.78 & 9.59 & 1.15 \\
\hline Oct-26 & 15.84 & 16.20 & 15.40 & 14.34 & 14.42 & 14.34 & 15.54 & 15.52 & 15.20 & 0.73 \\
\hline
\end{tabular}


Table 4.4 continued:

\begin{tabular}{|l|l|l|l|l|l|l|l|l|l|l|}
\hline \multicolumn{1}{|c|}{ APA (nmol P $\mathbf{~ I}^{-1} \min ^{-1}$ ) } \\
\hline & DB0 & DB2 & DB4 & SB0 & SB2 & SB4 & FC0 & FC2 & Avg & Stdev \\
\hline Apr-29 & 2.88 & 2.00 & 4.16 & 2.41 & 3.20 & 7.32 & 5.02 & 1.43 & 3.55 & 1.91 \\
\hline May-10 & 0.00 & 0.00 & 0.00 & 0.00 & 0.00 & 1.36 & 0.00 & & 0.19 & 0.51 \\
\hline May-26 & 0.39 & 0.30 & 0.00 & 0.41 & 0.00 & 0.00 & 0.00 & 1.06 & 0.27 & 0.37 \\
\hline Jun-8 & & 0.24 & 0.00 & 0.00 & 0.00 & 0.00 & & 0.00 & 0.04 & 0.10 \\
\hline Jun-22 & 1.89 & 2.59 & 2.32 & 1.58 & 3.04 & 1.66 & 2.42 & 2.33 & 2.23 & 0.49 \\
\hline Jul-7 & 2.43 & 2.35 & 2.03 & 2.37 & 2.85 & 0.00 & 2.12 & 2.96 & 2.14 & 0.92 \\
\hline Jul-20 & 0.00 & 0.86 & 0.50 & 0.73 & 0.55 & 0.60 & 0.00 & 0.89 & 0.51 & 0.35 \\
\hline Aug-9 & 1.18 & 0.00 & 0.41 & 0.39 & 0.00 & & 0.88 & 0.00 & 0.41 & 0.47 \\
\hline Aug-17 & 0.00 & 0.00 & 0.00 & 0.00 & 0.00 & 0.00 & 0.00 & 0.00 & 0.00 & 0.00 \\
\hline Aug-30 & 0.00 & 0.00 & 0.00 & 0.00 & 0.00 & 0.00 & 0.00 & 0.00 & 0.00 & 0.00 \\
\hline Sep-14 & 0.00 & 2.49 & 1.59 & 1.35 & 1.99 & 1.24 & 0.00 & 1.84 & 1.31 & 0.90 \\
\hline Oct-12 & 0.00 & 0.00 & 0.00 & 0.00 & 0.00 & 0.00 & 0.00 & & 0.00 & 0.00 \\
\hline Oct-26 & 0.54 & 0.00 & 0.00 & 0.00 & 0.00 & 0.00 & 0.00 & 0.00 & 0.07 & 0.19 \\
\hline
\end{tabular}

Fisherman's Cove and South Basin were shallow and located along the perimeter of the pond. These characteristics render Fisherman's Cove and South Basin less ideal for a detailed interpretation of typical seasonal processes than Deep Basin. The primary focus within Deep Basin was placed on 0, 2, and $4 \mathrm{~m}$. These depths at this site had the most complete data set available for comparison. On average, within the standard deviation of the three sample locations, the APA, DIN and DIP content of the pond were indistinguishable from that of Deep Basin at each depth interval (Table 4.4 and Figures $4.13,4.14$, and 4.15 ), implying that the pond is laterally homogeneous with respect to these parameters. Instances of patchiness occurred in the chlorophyll-a comparison in which the average pond APA deviated from Deep Basin samples. However, the overall trend between sites remained similar to that of Deep Basin (Figures 4.13-b, 4.14-b, 4.15b). On a lateral scale, the average pond behaved similarly to Deep Basin, and therefore the focus of the study was directed to Deep Basin. The patterns that developed in Deep 
Basin during the time course of the study were extrapolated to the entire pond for the purposes of comparison to other typical freshwater systems.

With the focus of the study directed to Deep Basin, differences in DIN, DIP and chlorophyll-a concentrations and APA at different depths were examined for 0,2 , and 4 $m$ in order to determine the amount of vertical patchiness in Ashumet Pond. After the initial strong depletion at the end of April (April 29), the seasonal trends for DIN and DIP had elevated levels of each nutrient during the late spring (May 26) that in general declined through out the season (Figures 4.16-a and -b). Vertical patchiness existed between depths, but was not present throughout the span of the study. The seasonal dissolved inorganic $\mathrm{N}$ (DIN) profile for each depth was displayed little vertical patchiness during the spring and early summer, in contrast to mid- to late-summer where vertical patchiness was more prevalent (Figure 4.16-a). Four peaks of varying DIN proportions were present at each depth. The largest peak occurred during fall overturn around midOctober. The second-largest peak occurred on May 26, coincident with the DIP peak. The initial peak, present at the onset of the season, had DIN concentrations of equal proportions of $6 \mu \mathrm{M}$ at each depth. DIN concentrations of the second peak were variable in magnitude with the greatest quantity, $4 \mu \mathrm{M}$, located at $2 \mathrm{~m}$. Minima occurred at the beginning of July as well as in September for all depths. The absolute minimum DIN level occurred on September 14 and 27 for all depths.

The seasonal DIP concentration profiles at the three depths displayed minimal variability as a function of depth within the epilimnion. DIP concentrations appeared to oscillate on a bi-weekly time scale (Figure 4.16-b): the levels of DIP at each depth 
increased on one sampling date and then were drawn-down a fortnight later. This up and down trend occurred throughout the time-span of the study. The total inventory of DIP at each sampling date was split evenly between the three depths. A noticeable deviation in DIP distribution occurred during the first peak, on May 26, in which DIP levels at $2 \mathrm{~m}$ were elevated above the other depths. The concentration of DIP never reach zero, with the absolute minimum DIP concentration of $0.02 \mu \mathrm{M}$ occurring on September 14 at all depths. A substantial increase in DIP concentrations occurred during fall overturn between October $12-26$.

APA observed at 0, 2, and $4 \mathrm{~m}$ water depth at the Deep Basin site had similar patterns of peaks and valleys throughout the growing season (Figure 4.17-a). The presence of APA oscillated throughout the duration of the study with APA more prevalent during late spring to mid-summer (APA present on 6 dates) than during late summer into fall (APA present on 3 dates). The values of APA ranged between 0.5 to 4.5 $\mathrm{nMP} \min ^{-1}$ and the variance in APA values was calculated as the standard deviation between triplicates (shown as error bars on figure 4.17-a). APA was present at all depths on April 29, June 22, and July 7. A period of continued APA occurred throughout May 26-August 9, in which the onset and disappearance of APA was depth dependent. APA at 0 and $2 \mathrm{~m}$ occurred on May 26, whereas APA at $4 \mathrm{~m}$ was not present until June 22. All three depths had equivalent APA on June 22 and July 7 . APA at $0 \mathrm{~m}$ disappeared on July 20, while APA was still present at 2 and $4 \mathrm{~m}$. On August 9, APA at $2 \mathrm{~m}$ disappeared, whereas APA continued to be present at $4 \mathrm{~m}$. A spike in APA at $0 \mathrm{~m}$ also occurred on 
August 9. A late summer depth dependent peak occurred on September 14, with APA present at 2 and $4 \mathrm{~m}$ respectively.

The water column of Ashumet Pond at 0, 2, and $4 \mathrm{~m}$ was homogeneous with respect to chlorophyll-a concentrations; this indicated that the levels of phytoplankton

were evenly distributed on a vertical scale (figure 4.17-b). Low chlorophyll-a levels were present until the beginning of summer at which time the only exception to the even vertical distribution of chlorophyll-a concentrations occurred. On July 7, a chlorophyll-a maximum was observed at $4 \mathrm{~m}$ depth. Immediately following the July 7 peak, a decline in chlorophyll-a levels ensued and remained constant throughout the remaining summer. Chlorophyll-a diminished briefly throughout late September into early October until fall overturn released nutrients into the water stimulating a fall bloom.

\subsubsection{Size Fractionation Studies}

The contribution of algal, bacterial and freely dissolved APA to total APA in Ashumet Pond was determined by sequential filtration. Bulk water samples for Deep Basin 0,2 , and $4 \mathrm{~m}$ were filtered through $0.8 \mu \mathrm{m}$ and $0.2 \mu \mathrm{m}$ pore-sized filters, which split the microbial community into discrete artificial pools: the $<0.8 \mu \mathrm{m}$ pore size filtrate represented the bacterial plus dissolved pool, and the $<0.2 \mu \mathrm{m}$ pore size filtrate represented the dissolved pool. Any biomass $>0.8 \mu \mathrm{m}$ was operationally defined as algal (zooplankton $<100 \mu \mathrm{m}$, such as ciliates and small rotifers would fall within this size fraction, as well), and the bacterial phase was defined as the fraction $<0.8 \mu \mathrm{m}$ and $>0.2$ $\mu \mathrm{m}$. 
The APA pool in Ashumet Pond was predominantly governed by algal production of alkaline phosphatase (Table 4.5). The $<0.8 \mu \mathrm{m}$ samples, representing the bacterial

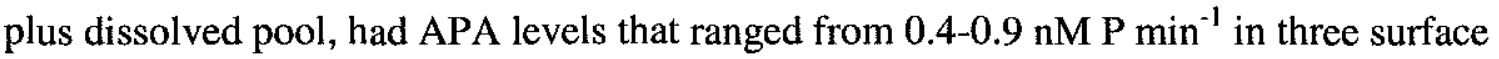
samples (April 29, June 22 and August 17) and two samples at $4 \mathrm{~m}$ (April 29 and May 26). No APA was detected in size fractionated samples for $2 \mathrm{~m}$. The $<0.2 \mu \mathrm{m}$ samples had no detectable APA for the entire seasonal study, indicating that the algal population was not excreting freely dissolved alkaline phosphatase. Therefore, the APA detected in the $<0.8 \mu \mathrm{m}$ filtrate represented APA of bacterial origin (Table 4.5). There were two dates, August 17 for $0 \mathrm{~m}$ and May 26 for $4 \mathrm{~m}$ in which APA was detected in the $<0.8 \mu \mathrm{m}$ fraction but not in the bulk water sample.

Table 4.5: Algal and bacterial contributions to total alkaline phosphatase activity (APA) for Deep Basin 0, 2, $4 \mathrm{~m}$ during time course of study.

\begin{tabular}{|l|c|c|c|}
\multicolumn{1}{c}{} & \multicolumn{3}{c|}{ Algal Fraction $(>\mathbf{0 . 8} \boldsymbol{\mu m}$ ) } \\
\cline { 2 - 4 } \multicolumn{1}{c|}{} & \multicolumn{2}{c|}{ APA (nM P min } \\
\hline Deep Basin & $\mathbf{0 ~ m}$ & $\mathbf{2 ~ m}$ & $\mathbf{4} \mathbf{~ m}$ \\
\hline Apr-29 & 2.35 & 2.10 & 3.87 \\
\hline May-10 & 0.00 & 0.00 & 0.00 \\
\hline May-26 & 0.05 & 0.38 & 0.00 \\
\hline Jun-8 & 0.00 & 0.27 & 0.00 \\
\hline Jun-22 & 1.15 & & 2.20 \\
\hline Jul-7 & 2.48 & 2.50 & 2.19 \\
\hline Jul-20 & 0.00 & 0.91 & 0.44 \\
\hline Aug-9 & 1.14 & 0.00 & 0.43 \\
\hline Aug-17 & 0.00 & 0.00 & 0.00 \\
\hline Aug-30 & 0.00 & 0.00 & 0.00 \\
\hline Sep-14 & 0.00 & 2.90 & 1.86 \\
\hline Oct-12 & 0.00 & 0.00 & 0.00 \\
\hline Oct-26 & 0.55 & 0.00 & 0.00 \\
\hline
\end{tabular}

Bacterial Fraction $(<0.8 \mu \mathrm{m})$

\begin{tabular}{|c|c|c|}
\hline \multicolumn{3}{|c|}{ APA (nM P min $\left.^{-1}\right)$} \\
\hline $\mathbf{0 ~} \mathbf{~ m ~}$ & $\mathbf{2 ~ m}$ & $\mathbf{4 ~ m}$ \\
\hline 0.57 & 0.00 & 0.44 \\
\hline 0.00 & 0.00 & 0.00 \\
\hline 0.20 & 0.00 & 0.38 \\
\hline 0.00 & 0.00 & 0.00 \\
\hline 0.91 & & 0.00 \\
\hline 0.00 & 0.00 & 0.00 \\
\hline 0.00 & 0.00 & 0.00 \\
\hline 0.00 & 0.00 & 0.00 \\
\hline 0.45 & 0.00 & 0.00 \\
\hline 0.00 & 0.00 & 0.00 \\
\hline 0.00 & 0.00 & 0.00 \\
\hline 0.00 & 0.00 & 0.00 \\
\hline 0.00 & 0.00 & 0.00 \\
\hline
\end{tabular}




\subsubsection{Substrate Binding Affinity}

Inverse correlations between the Michaelis constant $\left(\mathrm{K}_{\mathrm{m}}\right)$, an indicator of substrate binding affinity, and APA in freshwater samples have been observed (Chróst and Overbeck, 1987 and Yiyong and Xinyu,1997). However, another bi-weekly seasonal study observed no significant correlation (Hantke et al., 1996). The inverse correlation observed by Chróst and Overbeck (1987) and Yiyong and Xinyg (1997) indicated that the alkaline phosphatases produced under severe phosphate-deficient conditions (high APA) had a greater affinity (low $K_{m}$ ) for PMEs (phosphomonoesters) than those produced under moderately deficient conditions. In order to determine if such a condition existed in Ashumet Pond, $\mathrm{K}_{\mathrm{m}}$ values for Deep Basin 0, 2, and $4 \mathrm{~m}$ were determined using the non-linear regression program GraphPad Prism ${ }^{\circledR}$ and compared to corresponding APA (table 4.6). There was no correlation between $K_{m}$ and APA $\left(R^{2}=0.0679\right)$.

Table 4.6: Michaelis constant, $K_{m}$, and corresponding alkaline phosphatase activity values for Deep Basin 0, 2, and $\mathbf{4 m}$.

APA (nmol P L $\left.\mathbf{~}^{-1} \mathbf{m i n}^{-1}\right)$
\begin{tabular}{|l|c|c|c|}
\hline Deep Basin & $\mathbf{0 ~} \mathbf{~ m}$ & $\mathbf{2 ~} \mathbf{~ m}$ & $\mathbf{4} \mathbf{~ m}$ \\
\hline Apr-29 & 2.92 & 2.10 & 4.31 \\
\hline May-10 & 0.00 & 0.00 & 0.00 \\
\hline May-26 & 0.25 & 0.38 & 0.00 \\
\hline Jun-8 & & 0.27 & 0.00 \\
\hline Jun-22 & 2.30 & 2.59 & 2.20 \\
\hline Jul-7 & 2.48 & 2.50 & 2.19 \\
\hline Jul-20 & 0.00 & 0.91 & 0.44 \\
\hline Aug-9 & 1.14 & 0.00 & 0.43 \\
\hline Aug-17 & 0.00 & 0.00 & 0.00 \\
\hline Aug-30 & 0.00 & 0.00 & 0.00 \\
\hline Sep-14 & 0.00 & 2.90 & 1.86 \\
\hline Oct-12 & 0.00 & 0.00 & 0.00 \\
\hline Oct-26 & 0.55 & 0.00 & 0.00 \\
\hline
\end{tabular}

Km $(\mu \mathbf{M})$
\begin{tabular}{|c|c|c|}
\hline $\mathbf{0 ~} \mathbf{m}$ & $\mathbf{2 ~ \mathbf { ~ }}$ & $\mathbf{4} \mathbf{~ m}$ \\
\hline 0.75 & 1.11 & 0.83 \\
\hline 0.00 & 0.00 & 0.00 \\
\hline 1.38 & 0.87 & \\
\hline & 1.06 & 0.00 \\
\hline 0.52 & & 0.37 \\
\hline 0.60 & 0.61 & 0.70 \\
\hline 0.00 & 0.88 & 0.41 \\
\hline 0.59 & & 0.46 \\
\hline 0.00 & 0.00 & 0.00 \\
\hline 0.00 & 0.00 & 0.00 \\
\hline 0.00 & 1.14 & 1.52 \\
\hline 0.00 & 0.00 & 0.00 \\
\hline 0.30 & 0.00 & 0.00 \\
\hline
\end{tabular}




\subsubsection{Comparison of Nutrient Deficiency Indicators}

A comparison was made between APA and two commonly used nutrient deficiency indicators, DIN:DIP and POC:PP (the ratio of particulate organic carbon to particulate phosphorus), in order to determine the effectiveness of each indicator in determining the nutrient limitation regime of Ashumet Pond. Within marine systems it has been determined that the $\mathrm{C}: \mathrm{N}: \mathrm{P}$ ratio of oceanic phytoplankton communities is consistent with the dissolved inorganic $\mathrm{C}: \mathrm{N}: \mathrm{P}$ ratio, and is on average $106 \mathrm{C}: 16 \mathrm{~N}: 1 \mathrm{P}$. This ratio is known as the Redfield Ratio (Redfield, 1958). Deviations from the Redfield Ratio are commonly used to determine if the growth of a system is limited by the availability of $\mathrm{P}$. Two frequently used approaches in determining the limiting nutrient consist of examining deviations in DIN:DIP from $16 \mathrm{~N}$ : $1 \mathrm{P}$ and deviations in POC:PP from $106 \mathrm{C}: 1 \mathrm{P}$. Values greater than the Redfield N:P and C:P ratios indicate a P-limited system where values less than Redfield N:P and C:P ratio indicate no deficiency in the availability of $\mathrm{P}$. The relative amount of bioavailable $\mathrm{N}$ and $\mathrm{P}$ is indicated by DIN:DIP. The ratio represents the amount of $\mathrm{N}$ and $\mathrm{P}$ that can be immediately assimilated by phytoplankton (refer to section 2.3.1). Particulate nutrient ratios represent the extent to which nutrients are located within an algal cell and therefore indicate the immediate nutritional condition of the cell, rather than the extent to which nutrients are available outside the cell (refer to section 2.3.2). Particulate nutrient ratios were investigated for freshwater systems and it was determined that not only can POC:PP be diagnostic of nutrient deficiency, it can also indicate the degree to which the population is deficient (Healey and Hendzel, 1980). A POC:PP ratio greater than 258:1 denotes severe P- 
deficiency, where as a POC:PP less than 129:1 indicates no P-deficiency. Between these regions marks the boundary for moderate P-deficiency (Healey and Hendzel, 1980).

Using the nutrient ratio guidelines set forth by Redfield (1958) and Healey and Hendzel (1980), the nutrient limitation patterns of DIN:DIP, POC:PP and APA were compared for Deep Basin 0, 2, and $4 \mathrm{~m}$ water samples. The DIN:DIP ratio indicated that the nutrient limitation regime of the pond switched from predominately P-limited throughout late spring to predominately $\mathrm{N}$-limited throughout summer and fall. There were three occasions when the DIN:DIP ratio suggested that the pond was P-limited during the summer (Figures 4.18-a, 4.19-a, and 4.20-a). Nutrient limitation as indicated by the POC:PP ratio was often contradictory to that indicated by DIN:DIP. According to the POC:PP guidelines set forth by both Redfield (1958) and Healey and Hendzel (1980), Ashumet Pond was not P-limited during the spring, except for April 29, but was P-limited throughout the remaining growing season (Figures 4.18-b, 4.19-b, and 4.20-b). There was no systematic correlation between the nutrient limitation regime indicated by the presence of APA and that indicated by the nutrient ratios. The trend in APA suggests a dynamic nutrient limitation regime in which $\mathrm{P}$-limitation in the pond often reversed on a timescale of two-week intervals (Figures 4.18,4.19, and 4.20). According to the trend in APA, the pond was P-limited on April 29 and then throughout the early summer months. No indication of P-limitation was apparent late into the growing season, however, bar the peak on September 14 which appears at 2 and $4 \mathrm{~m}$, but not at $0 \mathrm{~m}$. In comparing the pattern of APA to the patterns in DIN:DIP ratio and POC:PP ratio, the nutrient limitation 
regime indicated by the trend in APA more closely matched that of POC:PP than that of DIN:DIP (common points are indicated on figures $4.20,4.21$ and 4.22 as stars).

\subsubsection{Influence of Species Composition}

Numerous studies focused on phytoplankton cultures have discovered that while different classes of phytoplankton require the same nutrients in roughly the same proportion, differences in uptake rates and the ability to utilize alternative nutrient sources exist (e.g., Smith and Kalff, 1982; Riegman et al., 2000). Given these facts, changes in the phytoplankton species composition of Ashumet Pond may be expected to correlate with changes in the availability of nutrients and consequently with presence/absence of APA. In order to determine the role that species composition had on the dynamic trend observed for APA, species counts were performed on $0-1.7 \mathrm{~m}$ integrated water samples from Deep Basin and Wheeler Road (when Deep Basin integrated samples were unavailable, Wheeler Road integrated samples were used as horizontal variation was small).

The composition of phytoplankton in Ashumet Pond changed throughout the growing season. Pond surface waters were dominated by diatoms, cryptophyceae and chrysophyceae early in the growing season, and cyanophyceae was the dominant class of phytoplankton during the latter period of the study, except for August 17 when dinoflagellates dominated the total biomass (table 4.7 and Figure 4.21).

In the surface waters of Ashumet Pond the dominant species within the different classes varied on a bi-weekly timescale, and changes in species composition were tightly correlated to fluctuations in the presence of APA and to fluctuations in DIN, DIP and 
Table 4.7: Dominant classes and genera in Ashumet Pond during course of the study. WR denotes Wheeler Rd 0-1.7 $\mathrm{m}$ depth integrated samples, and DB denotes 0-1.7 $\mathrm{m}$ depth integrated samples. SSGC $=$ spiny solitary green coccoid.

\begin{tabular}{|c|c|c|c|}
\hline Site & Date & Dominant Classes & Dominant Genera \\
\hline WR & Apr-28 & $\begin{array}{l}\text { Bacillariophyceae } \\
\text { Cryptophceae }\end{array}$ & $\begin{array}{l}\text { Asterionella formosa } \\
\text { Aulacoseira sp. }\end{array}$ \\
\hline WR & May-9 & $\begin{array}{l}\text { Bacillariophyceae } \\
\text { Cryptophceae }\end{array}$ & $\begin{array}{l}\text { Cryptomonas sp. } \\
\text { Asterionella formosa }\end{array}$ \\
\hline WR & May-25 & $\begin{array}{l}\text { Cryptophceae } \\
\text { Chrysophyceae }\end{array}$ & $\begin{array}{l}\text { Cryptomonas sp. } \\
\text { Ochromonadaceae spp. }\end{array}$ \\
\hline WR & Jun-7 & $\begin{array}{l}\text { Bacillariophyceae } \\
\text { Chrysophyceae }\end{array}$ & $\begin{array}{l}\text { Asterionella } \mathrm{sp} . \\
\text { Ochromonadaceae } \mathrm{spp} . \\
\text { Cryptomonas } \mathrm{sp} .\end{array}$ \\
\hline
\end{tabular}

\begin{tabular}{|llll|}
\hline DB & Jun-21 & $\begin{array}{l}\text { Bacillariophyceae } \\
\text { Chrysophyceae }\end{array}$ & $\begin{array}{l}\text { Asterionella } \text { sp. } \\
\text { Ochromonadaceae spp. }\end{array}$ \\
\hline
\end{tabular}

\begin{tabular}{|lll|}
\hline WR Jul-6 & $\begin{array}{l}\text { Cyanophyceae } \\
\text { Bacillariophyceae }\end{array}$ & $\begin{array}{l}\text { Oscillatoria } \text { sp. } \\
\text { Anabaena } \mathrm{sp} . \\
\text { Stephanodiscus } \mathrm{sp} .\end{array}$ \\
\hline
\end{tabular}

\begin{tabular}{|llll|}
\hline DB & Jul-19 & Cyanophyceae & $\begin{array}{l}\text { Aphanizomenon } \text { sp. } \\
\text { Oscillatoria } \text { sp. }\end{array}$ \\
\hline DB & Aug-8 & $\begin{array}{l}\text { Cyanophyceae } \\
\text { Bacillariophyceae }\end{array}$ & $\begin{array}{l}\text { Lyngbya } \text { sp. } \\
\text { Oscillatoria } \text { sp. } \\
\text { Stephanodiscus } \text { sp. }\end{array}$ \\
\hline
\end{tabular}

\begin{tabular}{|llll|}
\hline DB & Aug-16 & $\begin{array}{l}\text { Dinophyceae } \\
\text { Bacillariophyceae }\end{array}$ & $\begin{array}{l}\text { Peridinum spp. } \\
\text { Cryptomonas } \mathrm{sp} .\end{array}$ \\
\hline
\end{tabular}

\begin{tabular}{|c|c|c|c|}
\hline$\overline{D B}$ & Aug-30 & $\begin{array}{l}\text { Cyanophyceae } \\
\text { Chrysophyceae }\end{array}$ & $\begin{array}{l}\text { Dinobryon sp. } \\
\text { SSGC sp. } \\
\text { Lyngbya sp. }\end{array}$ \\
\hline
\end{tabular}

\begin{tabular}{|c|c|c|c|}
\hline DB & Sep-27 & $\begin{array}{l}\text { Cyanophyceae } \\
\text { Bacillariophyceae }\end{array}$ & $\begin{array}{l}\text { Oscillatoria sp. } \\
\text { Lyngbya } \text { sp. } \\
\text { Stephanodiscus sp. }\end{array}$ \\
\hline
\end{tabular}

\begin{tabular}{|c|c|c|c|}
\hline DB & Oct-11 & $\begin{array}{l}\text { Cyanophyceae } \\
\text { Bacillariophyceae }\end{array}$ & $\begin{array}{l}\text { Oscillatoria sp. } \\
\text { small sphere (unidentified) } \\
\text { Lynbya sp. }\end{array}$ \\
\hline
\end{tabular}

\begin{tabular}{|llll|}
\hline DB & Oct-25 & Cyanophyceae & Oscillatoria $\mathrm{sp}$. \\
\hline
\end{tabular}


chlorophyll-a concentrations (table 4.7 and Figure 4.22). The surface waters were dominated by Asterionella sp., a diatom species, at the tail end of the spring bloom (April 29). Between June 22 and July 7 , a definite major taxa switch occurred, corresponding to the early summer chlorophyll-a peak. The diatoms (Asterionella $\mathrm{sp}$.) were replaced with two cyanobacterial species, Oscillatoria sp. and Anabaena sp.. There was a large peak in APA on June 22 and July 7. Another species change had occurred by July 20 , as a nitrogen-fixing (able to convert atmospheric di-nitrogen gas into ammonia) cyanobacteria, Aphanizomenon sp., became dominant. There was significant draw-down of nitrogen between June 22 and July 20 preceeding the Aphanizomenon sp. peak. DIP stayed fairly constant throughout July with a slight increase on July 20 . No APA was present on July 20, which indicated that either the Aphanizomenon sp. had a lower threshold for phosphate than Oscillatoria sp. and Anabaena sp. or it did not produce the enzyme. On the next sampling date, August 9 , another species change occurred, as Aphanizomenon sp. was replaced by a non-nitrogen fixing cyanobacteria, Lyngbya sp. Between July 20 and August 9, DIN levels increased, a significant portion of DIP was drawn down and APA was present. Between August 9 and 17, the cyanobacterial species were replaced by Peridinum spp., a dinoflagellate. This was the only time dinoflagellates dominated the surface waters. A pulse of phosphate occurred on August 17, while nitrogen levels were drawn down. Two species switches occurred during the remaining part of the study: (i) another switch to nitrogen-fixer, Dinobryon sp., and a crysophyceae on August 30 and (ii) a switch back to Oscillatoria sp. on September 28 when DIN and DIP levels were at their lowest levels. Oscillatoria sp. dominanted for the remaining 
part of the study. The crysophyceae seemed to only appear when nitrogen levels were above $2 \mu \mathrm{M}$, suggesting that they had higher requirements for nitrogen than other dominant species.

\subsubsection{Dissolved Inorganic-P Threshold for Alkaline Phosphatase Activity}

Since the levels of bioavailable DIP must be depleted before phytoplankton can produce alkaline phosphatase (as shown by nutrient addition 3, Figure 4.12 and Table 4.3), it is likely that a DIP threshold for APA exists. In order to determine if a DIP threshold for APA existed in Ashumet Pond, APA values were compared to DIP concentrations pond wide. The level of APA at all sampling locations was inversely correlated with DIP concentrations indicating two DIP thresholds for APA occurred (Figures 4.23). The two DIP threshold concentrations were defined: (i) $<0.3 \mu \mathrm{M}$, below which $99.9 \%$ of total APA occurred, and $<0.15 \mu \mathrm{M}$, below which $80 \%$ of the samples exhibiting APA fell.

\subsection{Discussion}

\subsubsection{Influence of Species Composition and Nutrient Distribution on APA}

There are many factors that regulate the distribution of nutrients and phytoplankton in the water column. Some of these factors keep the water column well mixed, such as overturn events, and others cause discrete areas or patches to form, such as migrating masses of phytoplankton. Averaging pond parameters by depth and 
comparing the pond averages to Deep Basin indicated that the pond is laterally homogeneous (Figures 4.13, 4.14, and 4.15). However, the pond was not vertically homogeneous (Figures 4.16 and 4.17). The formation of discrete areas characterized by distinct concentrations of nutrients or phytoplankton cause vertical patchiness. The presence of vertical patchiness with respect to nutrients can influence the phytoplankton species distribution with depth, and therefore determine the presence or absence of APA. Vertical patchiness was apparent in DIN, DIP and chlorophyll-a concentrations, and APA, within the $0-4 \mathrm{~m}$ depth range in Ashumet Pond (Figures 4.16 and 4.17). In a thermally stratified water column, vertical patchiness in APA and DIN, DIP and chlorophyll-a concentrations can be caused by (i) minor de-stratification events in the metalimnion and/or (ii) changes in the species composition with depth. De-stabilization of the metalimnion can occur during strong mixing-events, such as wind storms. The overturning epilimnion, caused by the wind, breaks into the metalimnion causing pulses of nutrient rich water from the hypolimnion to be welled-up (Wetzel, 1975). Such an event may have caused the vertical patchiness in DIN and DIP concentrations on August 9. Between July 20 and August 9 , the top of metalimnion was mixed down from $7 \mathrm{~m}$ to 9 $\mathrm{m}$ (Figure 4.6). The erosion of the metalimnion, would have allowed for DIN at $9 \mathrm{~m}$ from the hypolimnion to mix into the epilimnion (Figure 4.8). Pulses of hypolimnetic water may have driven up the levels of each nutrient in the $4 \mathrm{~m}$ water, and possibly the 2 $m$ water (as in the case for DIN), leaving the surface waters to remain depleted. DIP would not have been mixed up, because there was little $9 \mathrm{~m}$ DIP at this depth (Figure 4.7). The DIP profile explains to the lack of DIP at $4 \mathrm{~m}$. 
Another explanation for vertical patchiness may be strategic positioning of phytoplankton populations. It has been shown that vertical patchiness of phytoplankton communities can migrate within a scale of several meters (Wetzel, 1975). For example, dinoflagellate communities stratify at a depth of optimum light (Nauwerck, 1963). Certain taxa disperse evenly throughout the water column in darkness and as daylight appears a migration towards the surface begins until the population reaches its optimum light requirement. The level at which the dinoflagellates stratify will depend on daily weather conditions (e.g., irradiance and turbulence), thusly the community may exist at $0.5 \mathrm{~m}$ one day and $2 \mathrm{~m}$ the next (Nauwerck, 1963). Extrapolating this phenomenon to other phytoplankton communities, it is possible that various taxa strategically position themselves in the water column to maximize their particular cellular requirements, as in the case for cyanobacteria (Reynolds, 1984).

The ability of strategic positioning by phytoplankton may account for the depletion of nutrients at one depth without depletion occurring at depths above or below, which in turn could influence the presence of APA. For example, on July 20, DIN and chlorophyll-a levels were uniform throughout the upper $4 \mathrm{~m}$ of the water column, but DIP and APA levels varied with depth (Figures 4.16 and 4.17). DIP levels decreased with increasing depth and were most concentrated at $4 \mathrm{~m}$. The varying concentrations of DIP may have influenced the phytoplankton distribution within the water column, because APA was present at 0 and $2 \mathrm{~m}$, the depths with lowest DIP, whereas no APA was detected at $4 \mathrm{~m}$. Therefore, it is possible that different phytoplankton populations were present between $0-2 \mathrm{~m}$ and $4 \mathrm{~m}$. A species of phytoplankton able to produce alkaline 
phosphatase may have existed at 0 and $2 \mathrm{~m}$ allowing it to take advantage of higher irradiance and thus promoting more efficient growth, whereas a species unable to produce the enzyme may have been restricted to $4 \mathrm{~m}$. It is possible that levels of chlorophyll-a stayed uniform throughout the water column on July 20 , because the different species within the system produced equivalent amounts of chlorophyll-a.

Not only can depth variations in species composition and nutrient distributions regulate the presence of APA, variations in the nutrient status and species composition through time can impact APA levels as well. The species composition of Ashumet Pond surface waters changed on a bi-weekly time scale. These species shifts often coincided with changes in one or more of the parameters (Figure 4.22). The expression or repression of APA was tightly coupled with changes in the dominant phytoplankton species and dissolved nutrient concentrations. Take for example changes that occurred between July 7 and August 9. On July 7, the presence of APA coincided with a summer maximum in chlorophyll-a and a decrease in both DIP and DIN levels. The dominant species on July 7 was a cyanobacteria, Oscillatoria $s p$., an alkaline phosphatase producing phytoplankton (Feuillade et al., 1990). The dramatic drop in DIP from the previous sampling date may have triggered the production of alkaline phosphatase by Oscillatoria sp. resulting in its dominance.

Proceeding on to the next sampling date, DIP levels increased and DIN levels remained very low, a species change occurred on July 20 to a nitrogen-fixing (able to convert atmospheric di-nitrogen gas into ammonia) cyanobacteria, Aphanizomenon sp. Repression of APA occurred on July 20 as well. It is possible that the continuing 
diminished levels of DIN initiated the species switch. Oscillatoria sp. was out competed by Aphanizomenon sp. because the latter was able to meet it's nitrogen requirements, while Oscillatoria sp. was unable to fix nitrogen. The species switch to the nitrogen-fixer prompted the loss of APA either because Aphanizomenon sp. had a lower threshold for phosphate than Oscillatoria sp. or is not capable of producing alkaline phosphatase. Aphanizomenon sp. has not been studied with the same degree of detail as Oscillatoria sp., however, we can make inferences about Aphanizomenon sp. from the well-studied, and similar, Anabaena sp. Anabaena sp. and Aphanizomenon sp. are very closely related genera, and Anabaena sp. has the ability to store $\mathrm{P}$ as polyphosphates, via luxury consumption (Reynolds, 1984). Anabaena sp. are notoriously hard to phosphate starve and it make take weeks to drive them to P starvation in culture (Rubin et al., 1977; Whitton et al., 1991). By analogy with the closely related Anabaena sp., we infer that Aphanizomenon sp. stockpiles $\mathrm{P}$ as polyphosphates and can therefore maintain its growth rate at low DIP concentrations. Therefore, it is possible that the coupling of APA to DIN, DIP, and species composition on July 20 was due to the specific cellular requirements of the dominant species.

On the next sampling date, August 9 , another species change occurred, as Aphanizomenon sp. was replaced by a non-nitrogen fixing cyanobacteria, Lyngbya sp. Between July 20 and August 9, DIN levels increased at the same time DIP levels dropped. These changes in the nutrient regime coincided with the re-appearance of APA occurred as well. It is possible that the re-appearance of APA was linked to the changing levels of DIN and DIP and the species switch. As DIP levels decreased, Aphanizomenon 
sp., possibly unable to produce APA, would deplete it's cellular-P stocks, become phosphate-deficient and be unable grow efficiently. Therefore, with DIN no longer a limiting nutrient, Lyngbya sp., an alkaline phosphatase producing algae (Whitton et al., 1991) would be able to out compete Aphanizomenon sp. for phosphate. The fact that Lyngbya sp. cannot fix nitrogen is no longer a deterrent due to the higher DIN levels on August 9 relative to the previous sampling date, July 20. As indicated by the second nutrient addition incubation study, production of alkaline phosphatase upon depletion of phosphate occurs on a time scale of days (Figure 4.11). Therefore, it is reasonable to consider that within in a two week period, Lyngbya sp. could out-compete Aphanizomenon sp. for phosphate via stimulated production of the enzyme.

In summary, the preceding discussion illustrates the way in which species composition can to be an important factor in stimulating the expression/repression of alkaline phosphatase production on spatial and temporal time scales in Ashumet Pond. The coupling of APA to changes in species composition is a clear example of the importance of understanding the species composition within the context of understanding the nutrient limitation regime of a system.

\subsubsection{Algal, Bacterial and Dissolved APA}

Bacterial and dissolved APA have been shown to be a significant fraction of the overall APA contribution in some freshwater systems (e.g. Jansson et al., 1988; Chróst and Overbeck, 1987; Hantke et al., 1996). Ashumet Pond, predominantly governed by algal production of APA, showed little contribution of APA from bacterial and dissolved fractions (Table 4.5) indicating that (i) bacteria were either not sufficiently phosphate- 
deficient or were unable to produce alkaline phosphatase, and (ii) the microbial population did not need to excrete dissolved phosphatases into the water to maintain cellular-P needs.

\subsubsection{Methodological Differences in APA and $K_{m}$}

Correlations between the activity of alkaline phosphatase (APA) and the ability of the enzyme to bind PMEs (phosphomonoesters) $\left(\mathrm{K}_{\mathrm{m}}\right)$ have been contradictory within the published literature. Two freshwater investigations have shown inverse correlations between $\mathrm{K}_{\mathrm{m}}$ and APA (Chróst and Overbeck,1987, Yiyong and Xinyu,1997). Chróst and Overbeck (1987) and Yiyong and Xinyu (1997) argued that the alkaline phosphatases produced under severe phosphate-deficient conditions (high APA) had a greater affinity (low $\mathrm{K}_{\mathrm{m}}$ ) for PMEs than those produced under moderately deficient conditions. This makes some intrinsic sense because the more severely a cell is starved of phosphate, the more efficiently it would want to hydrolyze phosphomonoesters. In order to increase the efficiency of hydrolysis, the affinity of the enzyme for the substrate must be increased. However, this study has shown that there was no correlation between $\mathrm{K}_{\mathrm{m}}$ and APA $\left(\mathrm{R}^{2}=0.0679\right)$. The finding of this study is consistent with another bi-weekly seasonal study of three freshwater lakes in which similar ranges in $\mathrm{K}_{\mathrm{m}}$ and APA as observed during this study had no significant correlation (Hantke et al., 1996).

It is possible that the presence or absence of a correlation between $\mathrm{K}_{\mathrm{m}}$ and APA in separate studies arises due to differences in methodology. Chróst and Overbeck (1987) used MUF-P as a substrate, but at levels ranging from 10-200 $\mu \mathrm{M}$ MUF-P, which are much greater than that used by either this study (0.5-10 $\mu \mathrm{M}$ MUF-P) or Hantke et al. 
(1996) (0.05-5 $\mu \mathrm{M}$ MUF-P). Alkaline phosphatase has been shown to be bi-phasic, having more than one operating level (Rivkin and Swift, 1980). Therefore, examining APA of natural water systems using elevated substrate levels may activate otherwise dormant alkaline phosphatase. Chróst and Overbeck (1987) may have stimulated APA that would not have been active in-situ by altering the efficiency at which the enzyme operated by using the high range of MUF-P concentrations. Yiyong and Xinyu (1997) used a completely different substrate altogether, $p$-nitrophenylphosphate ( $p$ NPP). The $p$ NPP method is not as sensitive as the MUF-P assay (Pettersson and Jansson, 1978). It offers a reliable determination when working with high phosphatase concentrations and long incubations (Jansson et al., 1988). However, if low concentrations of alkaline phosphatase are present, it may not be a reliable method.

Therefore, methodology can significantly effect the amount of measurable APA. If concentrations of substrate are higher than in-situ DOP levels (as in the cases of Chróst and Overbeck (1987) and Yiyong and Xinyu (1997)), or if the method used is not sensitive enough to detect all levels of APA (as in the case of the $p$ NPP method), then the end result will not be directly reflective of the natural system. The examples given provide good reason to believe that without a systematic protocol for measuring the kinetic parameters of alkaline phosphatase, $K_{m}$ and APA values between studies can not be compared, and generalizations about parameters cannot be made.

\subsubsection{Discrepancies Between C:N:P and APA as Nutrient Deficiency Indicators}

The nutrient limitation regime indicated by the presence of APA was contradictory to that implied by DIN:DIP and POC:PP ratios (Figures 4.18, 4.19, and 
4.20). The DIN:DIP ratio indicated the nutrient limitation regime of the pond switched from predominately P-limited throughout late spring to predominately $\mathrm{N}$-limited throughout summer and fall, whereas, the POC:PP ratio indicated the reverse regime as DIN:DIP ratios: that Ashumet Pond was not predominately P-limited during the spring, but was P-limited throughout the remaining growing season. According to the presence/absence in APA, the pond was P-limited throughout the early summer months, however, no indication of P-limitation was apparent late into the growing season, with the exception of the peak on September 14.

Discrepancies between the nutrient limitation regimes described by APA, DIN:DIP and POC:PP raise questions as to the effectiveness of each as a nutrient deficiency indicator. This study unequivocally demonstrated that APA is a robust indicator of phosphate-deficiency in Ashumet Pond through the use of the third nutrient addition incubation study (NA-3). At the onset of NA-3 there was no alkaline phosphatase activity in Ashumet Pond. After 5 days of incubating samples in either phosphorus, nitrogen, phosphorus and nitrogen additions, APA and subsequent increased algal growth was stimulated only in samples enriched solely with nitrogen and not in any other addition (Figure 4.12). The presence of APA in the absence of phosphate, and vise versa, indicated that the phyto- and bacterio-plankton community in Ashumet Pond only produced alkaline phosphatase under phosphate-deficient conditions. Therefore, the presence of detectable APA in Ashumet Pond water samples signifies that the level of DIP immediately available to the in-situ phyto- and bacterio-plankton community is not sufficient to maintain cellular-P requirements. 
Dissolved inorganic $\mathrm{N}: \mathrm{P}$ ratios reflect the relative availability of each nutrient to support growth of the phytoplankton community. However, they are not a direct indicator of the cellular nutritional state. DIN:DIP ratio will only hold as a nutrient deficiency indicator assuming the ratio is reflective of the cellular nutritional state. This assumption is not always accurate as some species of phytoplankton have the ability to store excess cellular N (McCarthy, 1980) and P (Reynolds, 1984), via luxury consumption. Some phytoplankton species can maintain cellular stocks high enough to support four mitotic divisions, as in the case of Anabaena sp. (Reynolds, 1984). If such a species is dominating the system, as it is assumed to be on July 20 with Aphanizomenon sp. dominating the biomass, then DIN:DIP ratios will not reflect the nutrient limitation status of the system. Therefore, even though DIN:DIP has been shown to be a reliable nutrient deficiency indicator in some cases (Ruttenberg et al., 1998, Monaghan and Ruttenberg, 1999, Karl, 1999), there are possible pitfalls that must be examined.

Particulate nutrient ratios are indicators of the cellular nutritional state of the microbial community. However, due to methodological limitations, it is often difficult to separate the living biota from dead cells and detrital (non-biogenic) matter. Detrital influences can complicate the use of particulate nutrient ratios as indicators of cellular nutritional status because they have a different C:P signal (Parsons et al., 1984). Detrital matter is often enriched in carbon with respect to phosphorus, due to the labiality of phosphorus moieties. Even though Ashumet Pond has no surface inlets, detrital material can enter the pond through the atmosphere as well as surface run-off. Without a measure for the total detrital influence, POC:PP ratios are inherently uncertain, and therefore must 
be used in conjunction with another nutrient deficiency indicator, as was done in this study.

Due to the weakness of dissolved and particulate nutrient ratios as nutrient deficiency indicators, and the support from NA-3 for the use of APA as a nutrient deficiency indicator, it is concluded that the trend in APA describes the nutrient limitation conditions of Ashumet Pond. Therefore, the nutrient limitation regime of Ashumet Pond is one of oscillating limiting nutrients. Ashumet Pond experienced episodic events of phosphate-deficiency throughout the growing season, with a significant period of phosphate-deficiency occurring during the onset of summer. However, it is difficult to say anything about the other nutrients, because alkaline phosphatase is only an indicator of the status of the system with respect to $P$.

\subsubsection{Phosphate Threshold for Alkaline Phosphatase Activity}

This study has shown that APA is a robust indicator of phosphate-deficiency. The presence of APA indicates that phytoplankton are not able to reach their cellular-P needs solely using ambient DIP. It is therefore possible for phytoplankton to possess a uniform phosphate threshold below which alkaline phosphatase production ensues. Through a comparison of APA and DIP at all station locations within Ashumet Pond, an inverse correlation existed between APA and DIP, indicating two DIP thresholds for APA: (i) < $0.3 \mu \mathrm{M}$, and $<0.15 \mu \mathrm{M}$, (Figures 4.23 ). The thresholds designated by this study can perhaps be used in other aquatic systems to indicate the probability of the presence of APA. 


\subsection{Conclusions}

This study demonstrated that APA was a robust indicator of phosphate-deficiency and is superior to the other nutrient deficiency indicators, such as dissolved and particulate nutrient ratios, for determining the nutrient limitation status of Ashumet Pond. According to the trend in APA, nutrient limitation in Ashumet Pond was episodic with respect to phosphate-deficiency. The APA pool was found to be predominately governed by algal alkaline phosphatase production. The episodic presence/absence of APA was observed to be dependent on phytoplankton species composition and nutrient distributions within Ashumet Pond. De-stabilization events of the metalimnion supplied nutrients to the epilimnion, producing changes in the phytoplankton species. The ability of phytoplankton to produce alkaline phosphatase on the order of days as shown in the second nutrient addition experiment supported this observation. APA fluctuated on a biweekly time scale corresponding to changes in the cellular requirements of the dominant phytoplankton species. Therefore, in order to understand the nutrient limitation in an aquatic system on short time scales, APA measurements must be accompanied by species identification. Due to the inter-dependence between APA and species composition in determining the nutrient limitation status of Ashumet Pond, it is recommended in future studies to sample the entire epilimnion for species composition in order to understand trends caused by vertical patchiness. 
Figure 4.1: Location of the Massachusetts Military Reservation (MMR) in relation to Ashumet Pond.

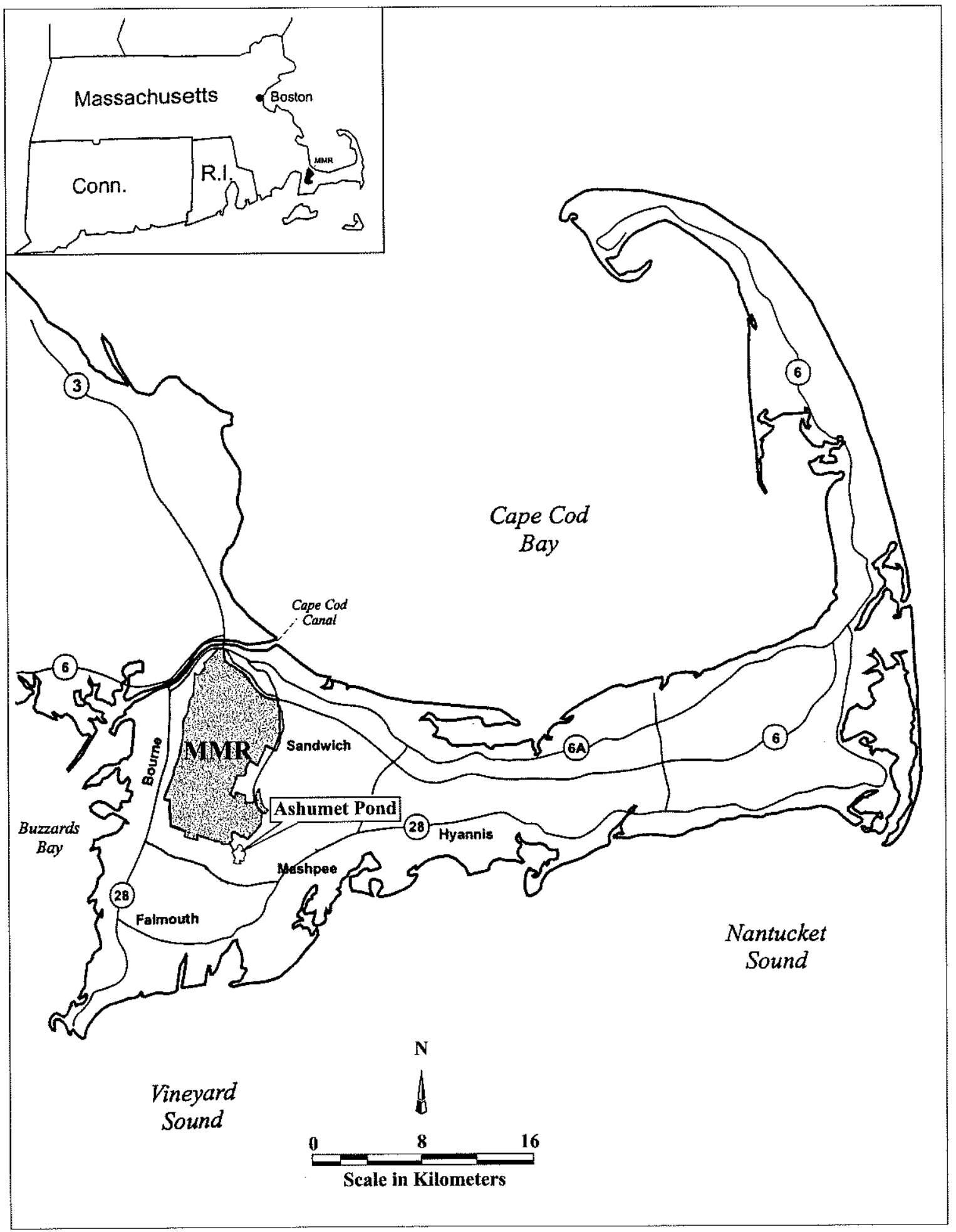


Figure 4.2: Bathymetric map for Ashumet Pond, with sampling locations (figure after AFCEE, 2000).

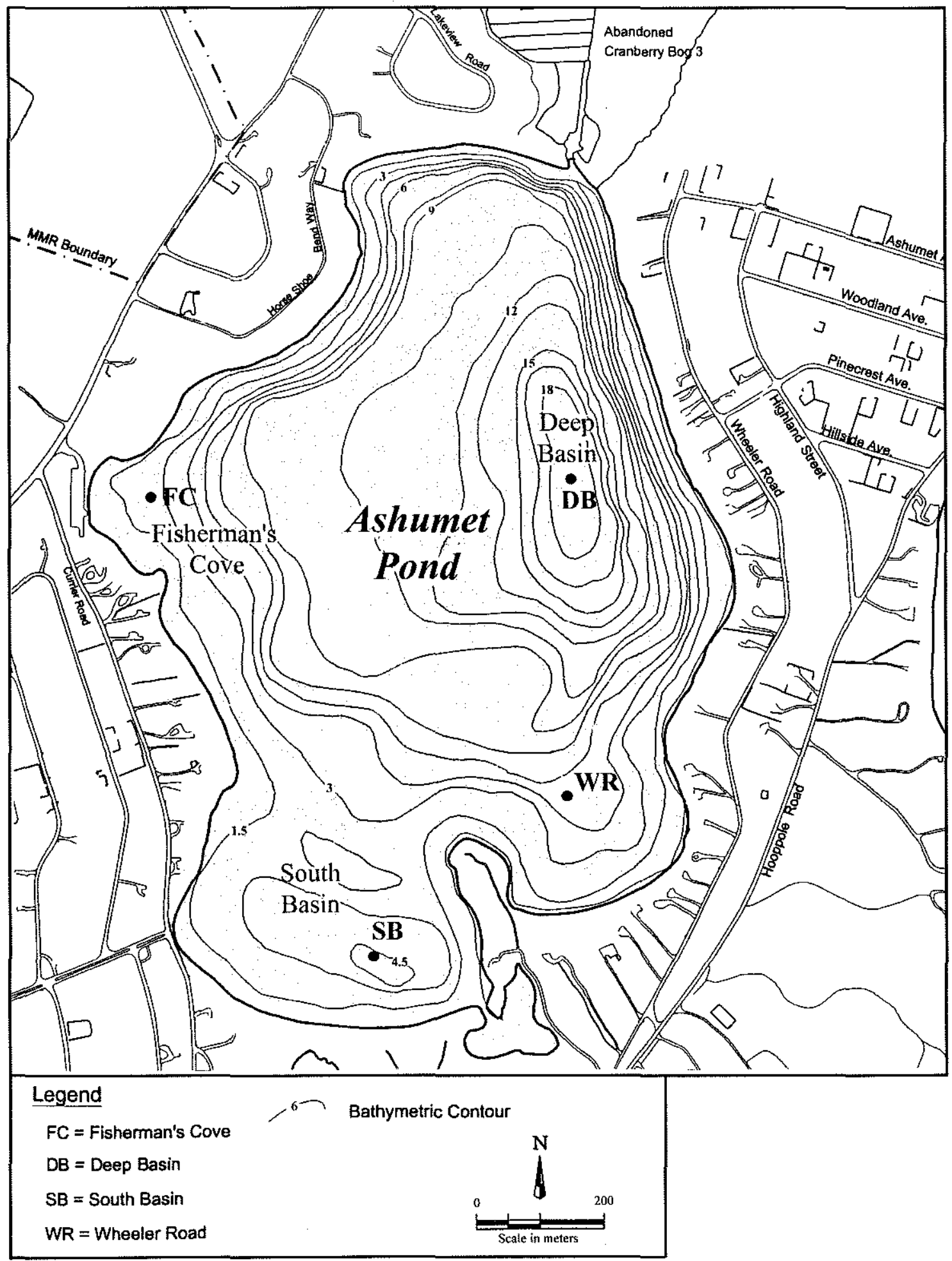


Figure 4.3: Sewage Treatment Plant location and phosphorus plume with respect to Ashumet Pond. The plume enters Ashumet Pond through Fisherman's Cove. The groundwater plume is highlighted in the solid lines, with USGS monitoring wells denoted by the open circles (figure after USGS).

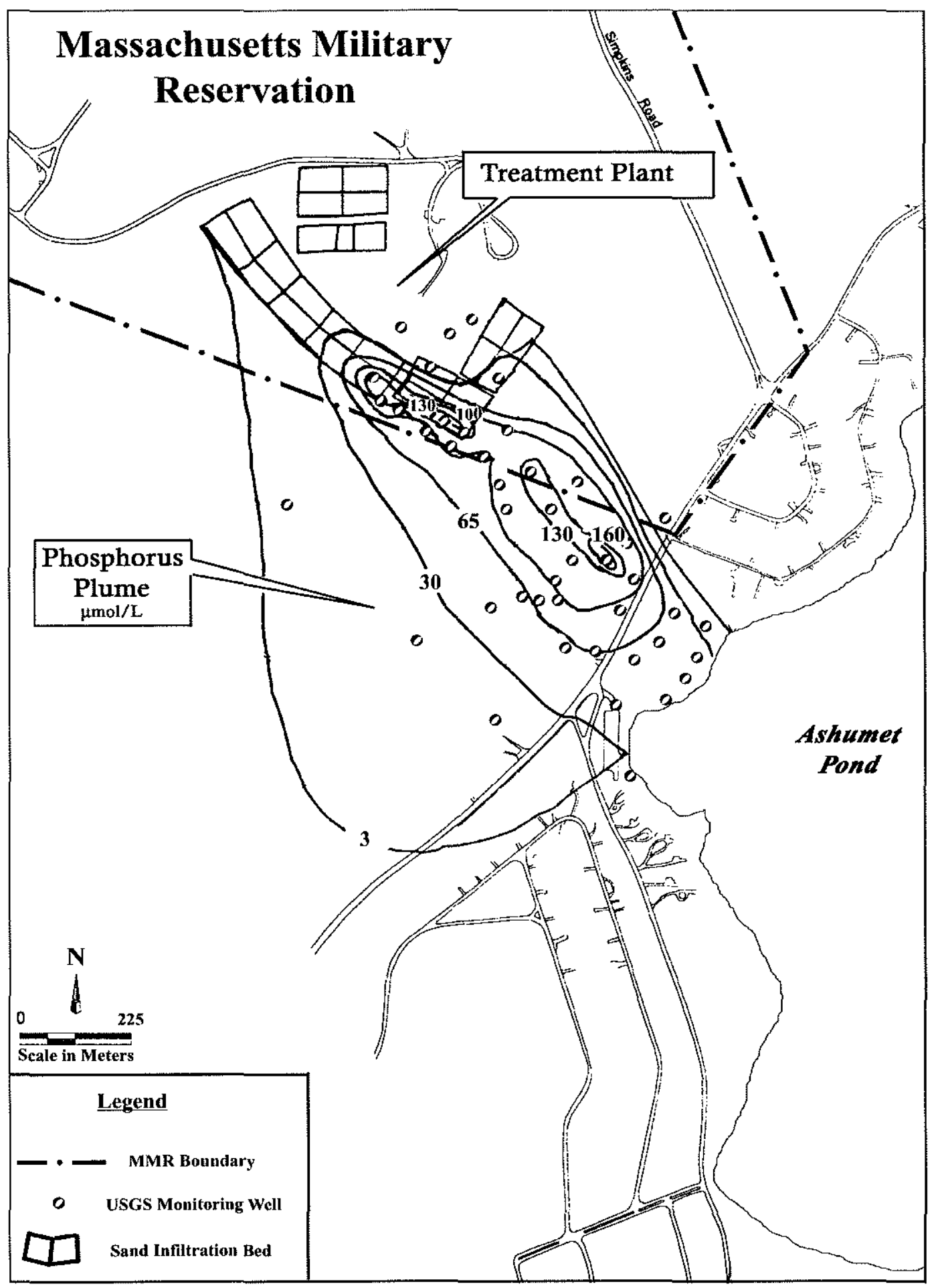


Figure 4.4: Thermal stratification of a typical aquatic system (after Wetzel, 1975).

TEMPERATURE $\left({ }^{\circ} \mathrm{C}\right)$

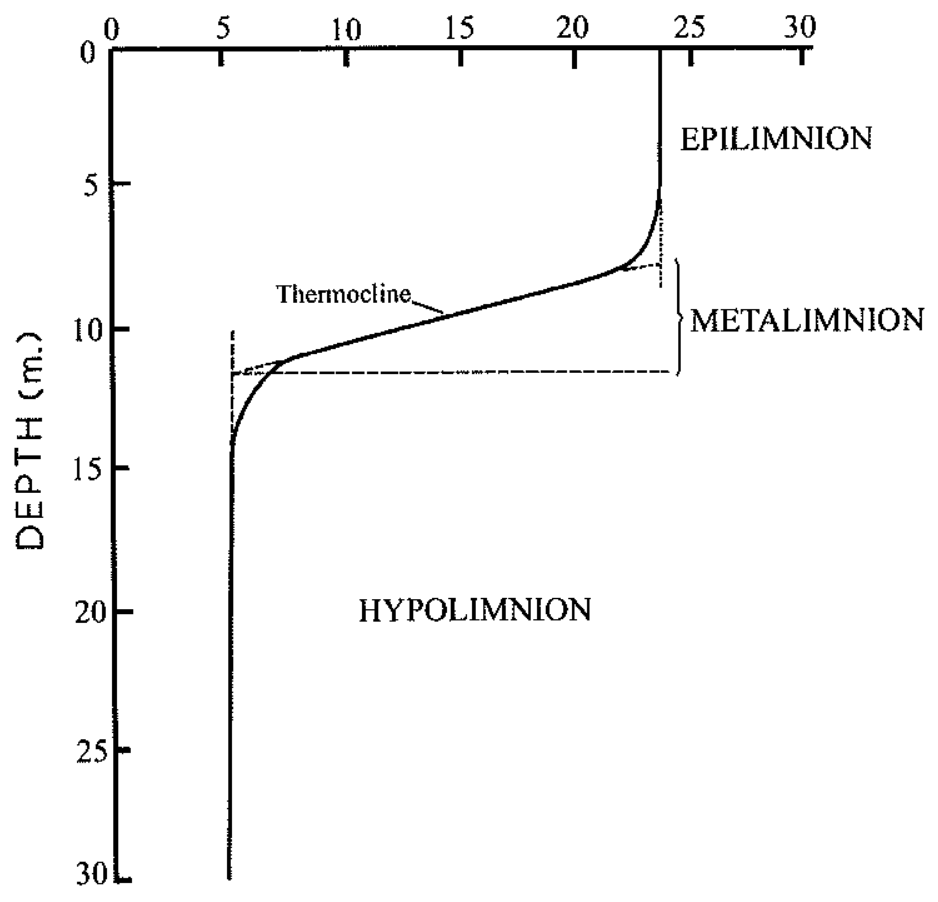


Figure 4.5: Dissolved Oxygen levels at the Deep Basin site in Ashumet Pond for selected sampling dates spanning the period of the study (taken from AFCEE, 2000).

\section{Dissolved Oxygen $(\mathrm{mg} / \mathrm{L})$}

$\vec{\infty}$

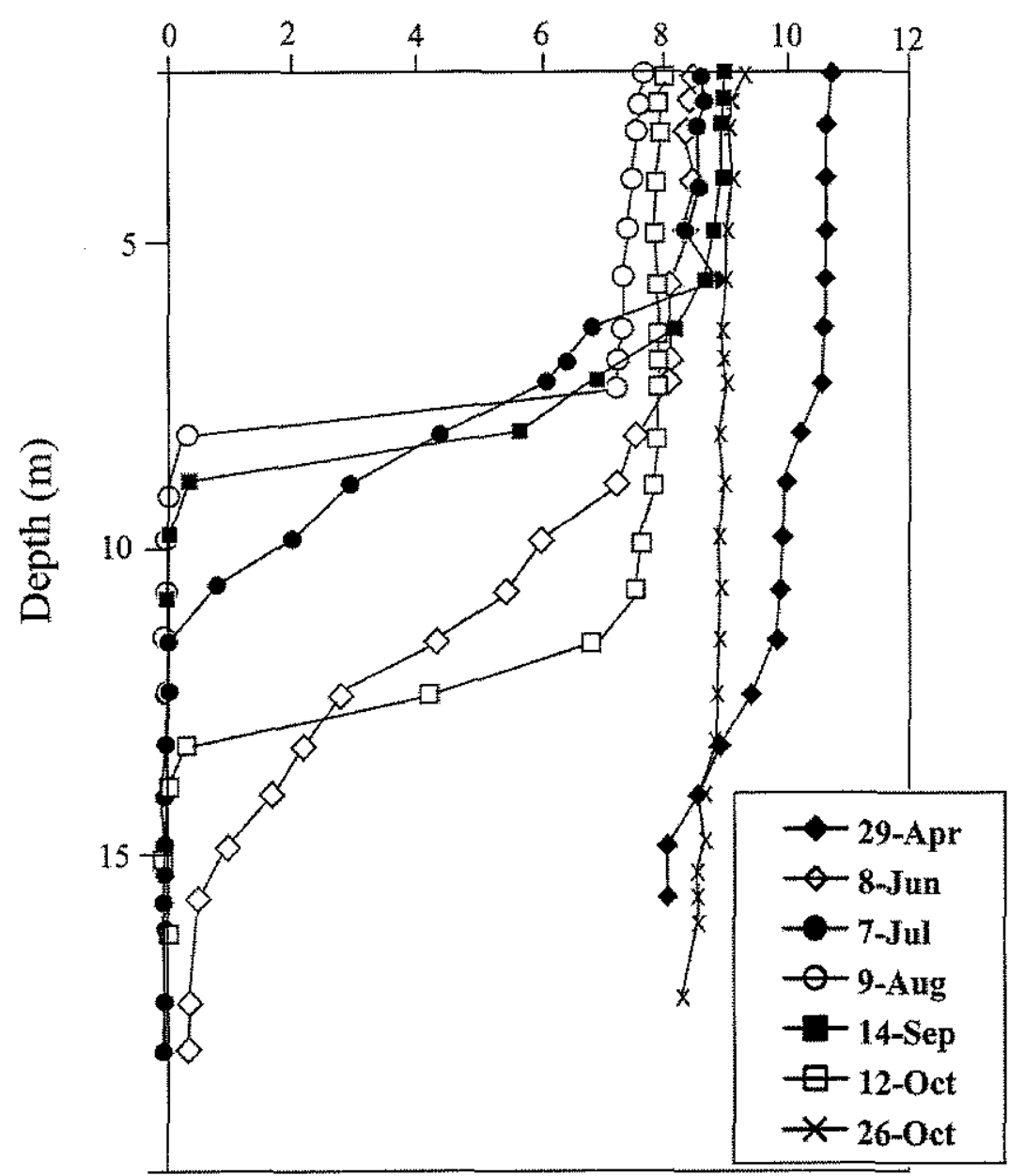

Figure 4.6: Temperature profiles at the Deep Basin site in Ashumet Pond for selected sampling dates spanning the period of the study (taken from AFCEE, 2000).

\section{Temperature $\left({ }^{\circ} \mathrm{C}\right)$}

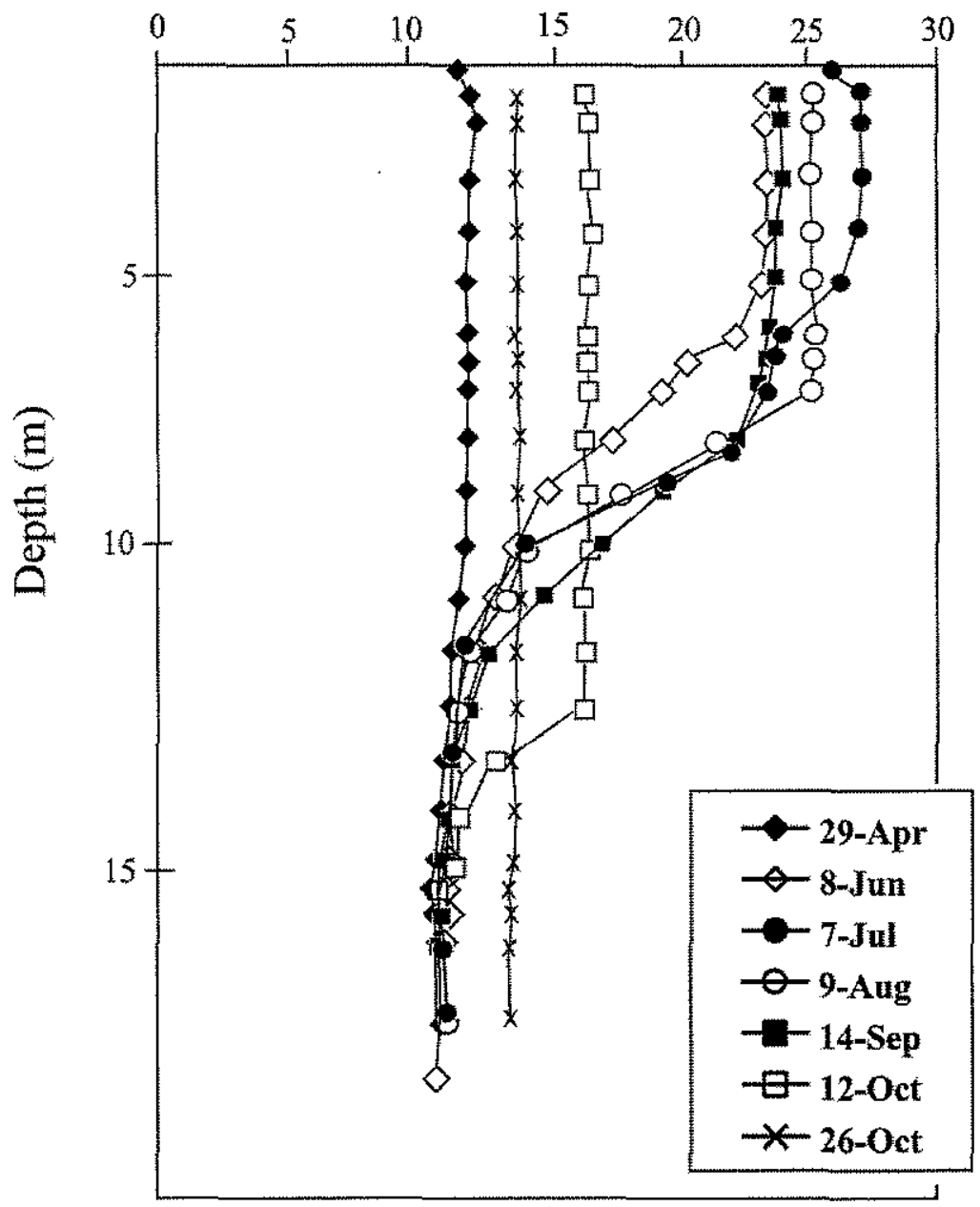


Figure 4.7: DIP profile with depth for selected Ashumet Pond samples. DIP increases in concentration throughout the seasonal study, until fall overturn on Oct 26 (figure after AFCEE, 2000).

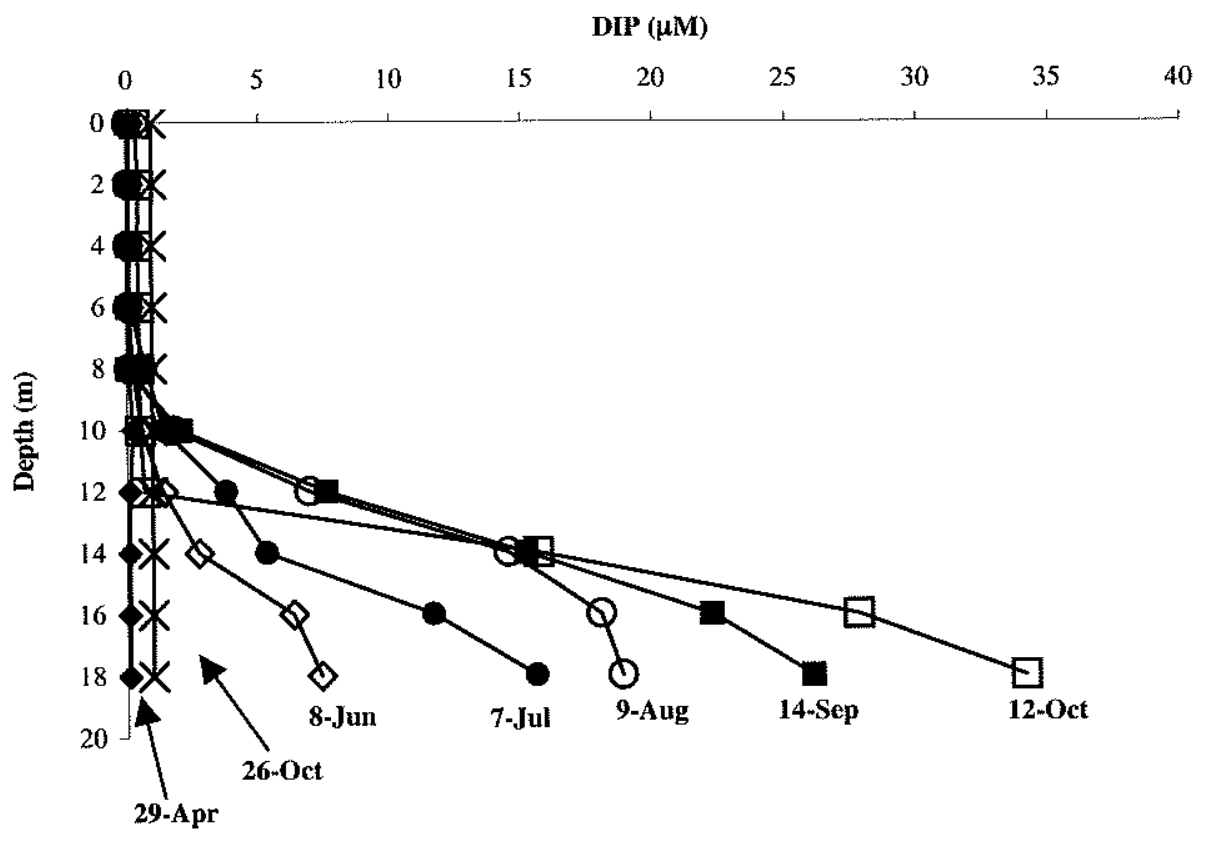

Figure 4.8: Ammonium profile with depth for selected Ashumet Pond samples. Ammonium increases in concentration throughout the seasonal study, until fall overturn on Oct 26 (figure after AFCEE, 2000).

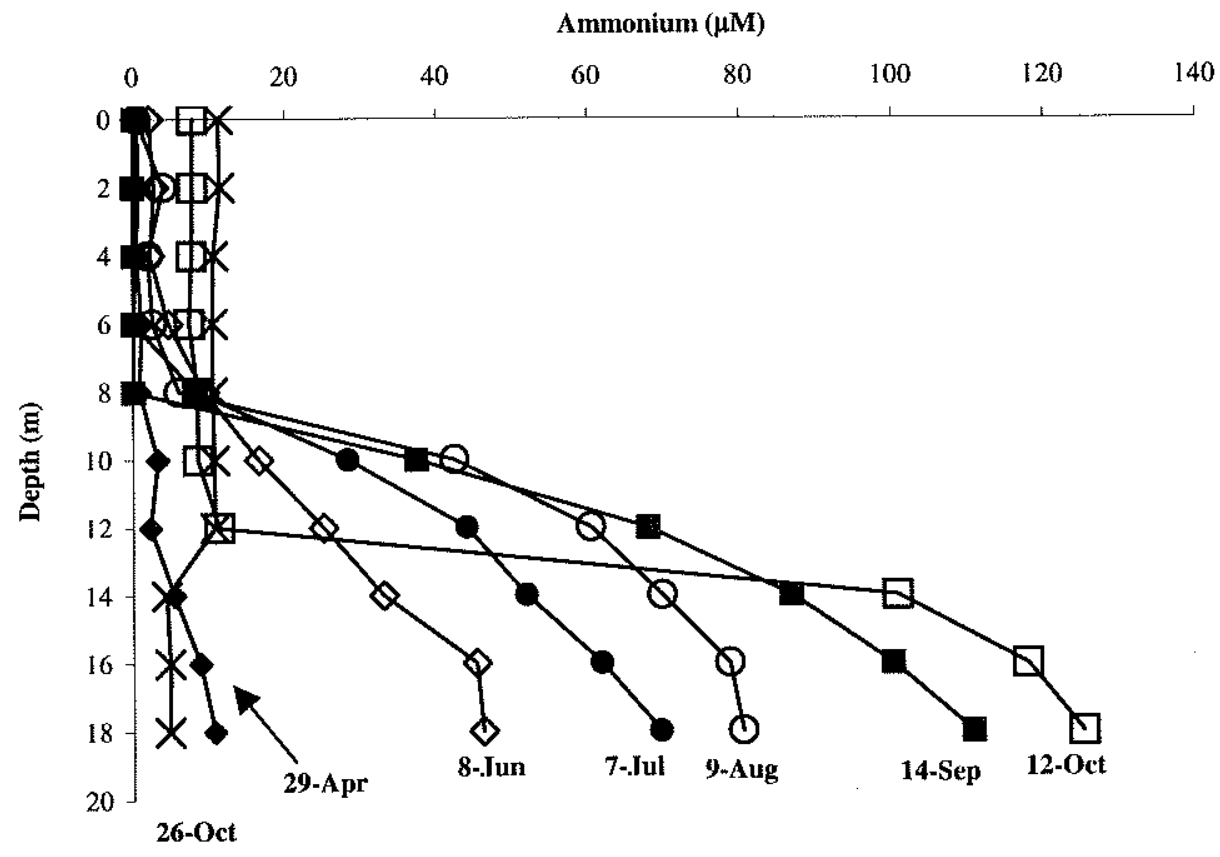


Figure 4.9: Major inorganic and organic interactions influencing the metabolism of phytoplankton of oligotrophic systems (taken from Wetzel, 1975).

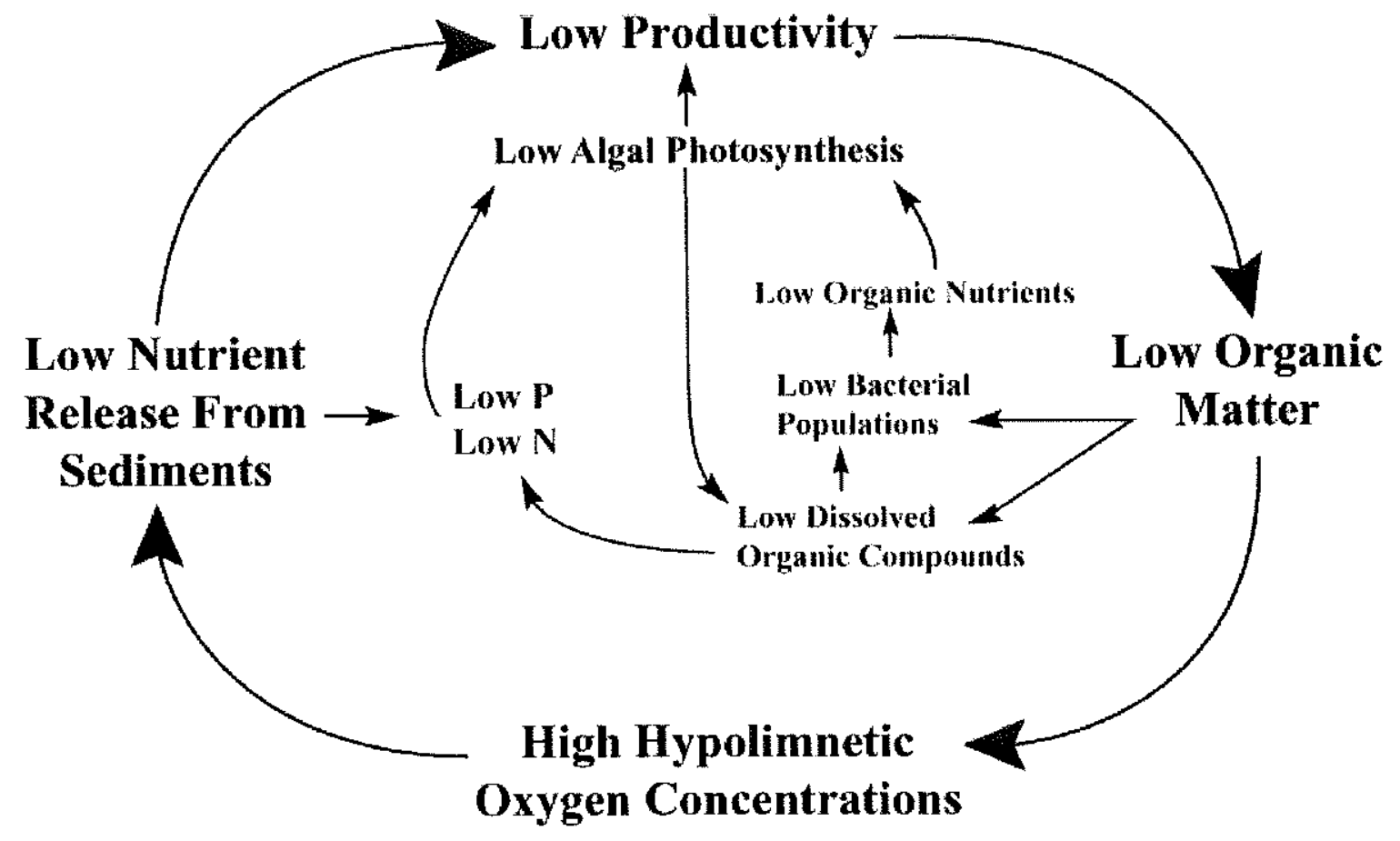

Figure 4.10: Major inorganic and organic interactions influencing the metabolism of phytoplankton of eutrophic systems (taken from Wetzel, 1975).

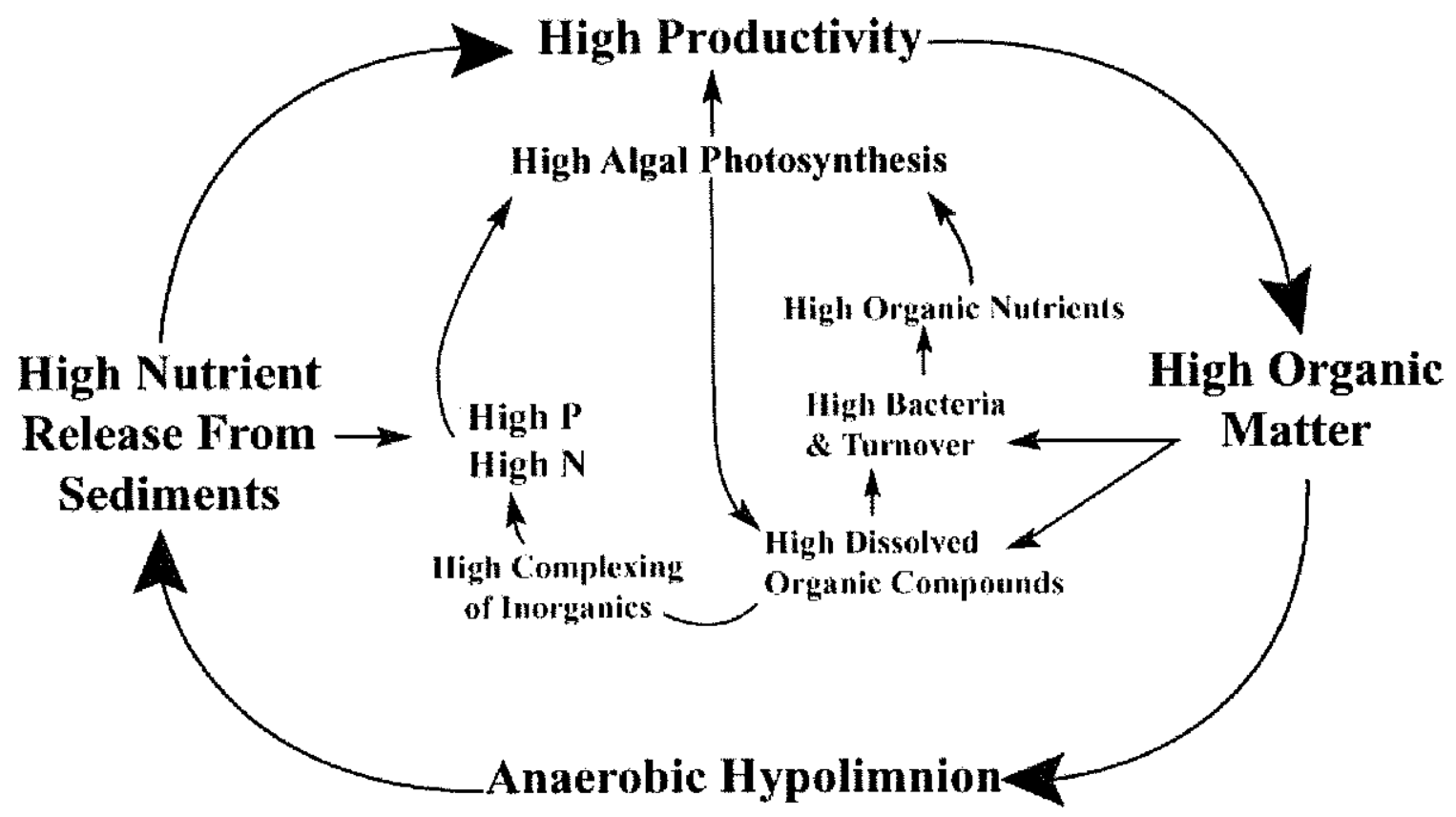


Figure 4.11: Nutrient Addition \#2. FC denotes Fisherman's Cove integrated, SB denotes South Basin integrated, DB denotes Deep Basin integrated, DB.4 denotes Deep Basin 4 m.

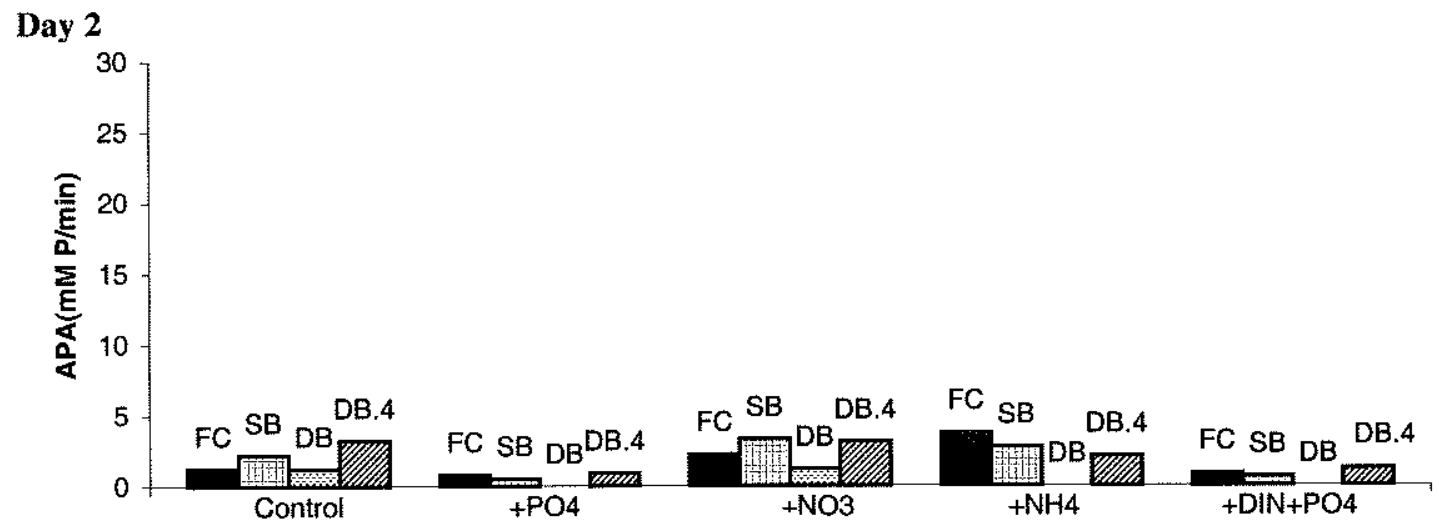

Day 4

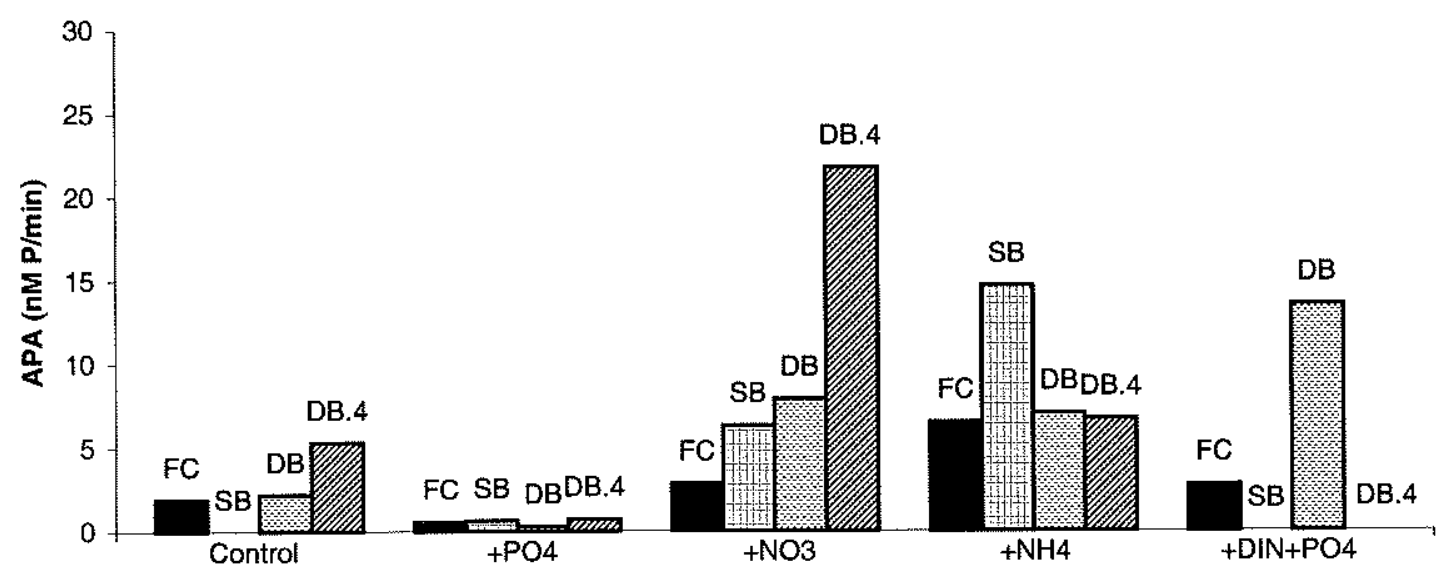

Day 5

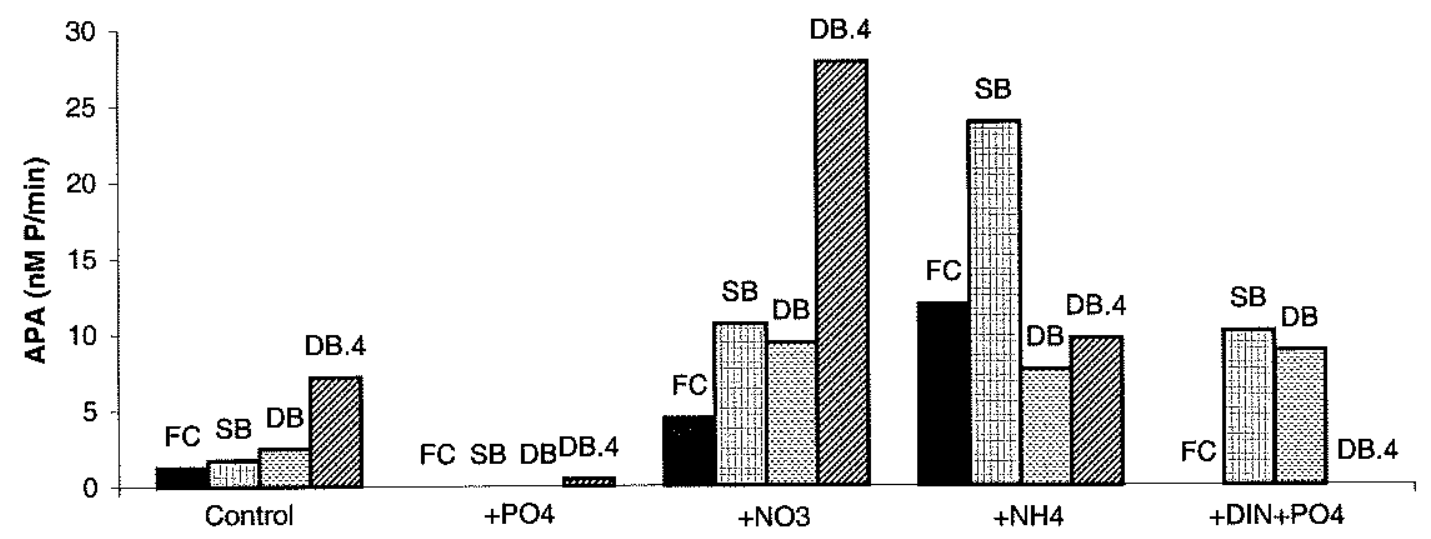


Figure 4.12-a: Alkaline phosphatase activity (APA) response on day 5 of experiment for Deep Basin 0-1.7 m (DB.int) and $4 \mathrm{~m}$ (DB.4) and in Fisherman's Cove 0-1.7 m (FC.int) for Nutrient addition \#3. Treatments were control-no additions, + PO4-phosphate addition, +DIN-nitrate and ammonia addition, $+\mathrm{DIN}+\mathrm{PO} 4$-phosphate, nitrate, and ammonia addition. Error bars represent the standard deviation over triplicates.

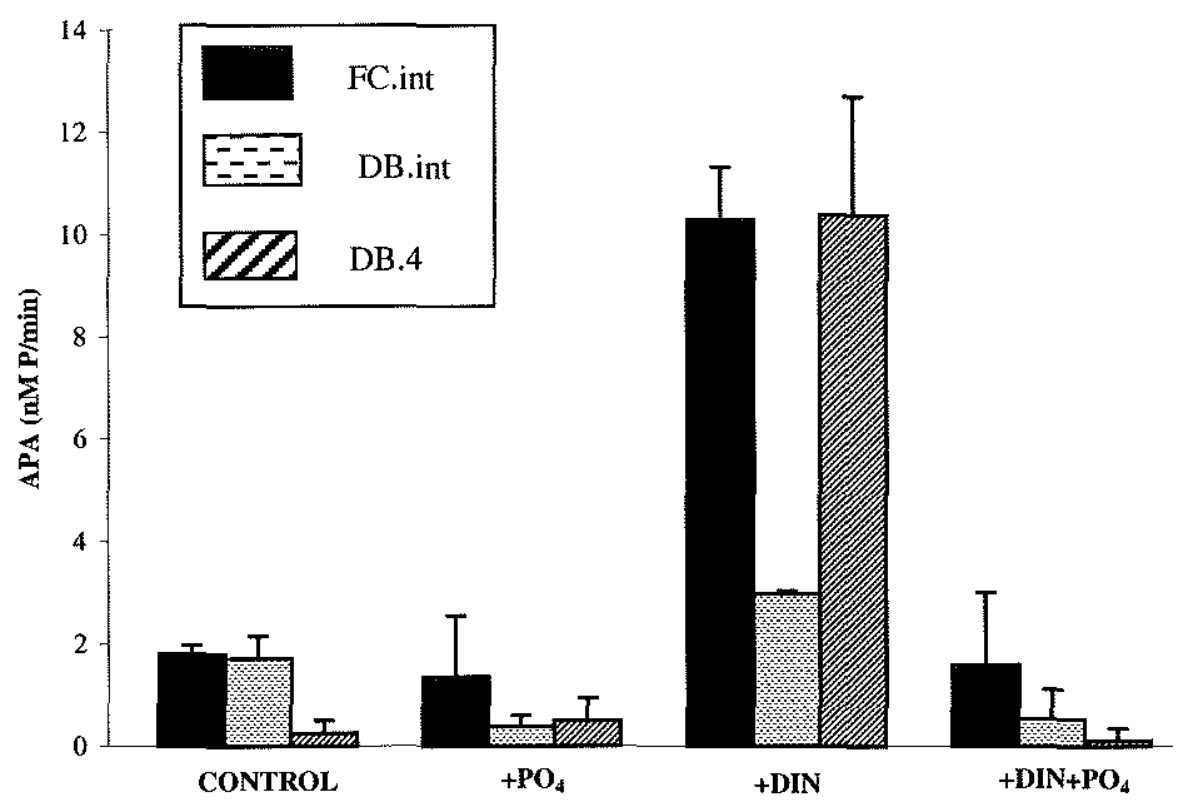

Figure 4.12-b: Chlorophyll-a response for same sample set for Nutrient addition \#3. Lines denote initial chlorophyll-a concentrations (ug/L) and bars represent chlorophyll-a concentrations on day 5.

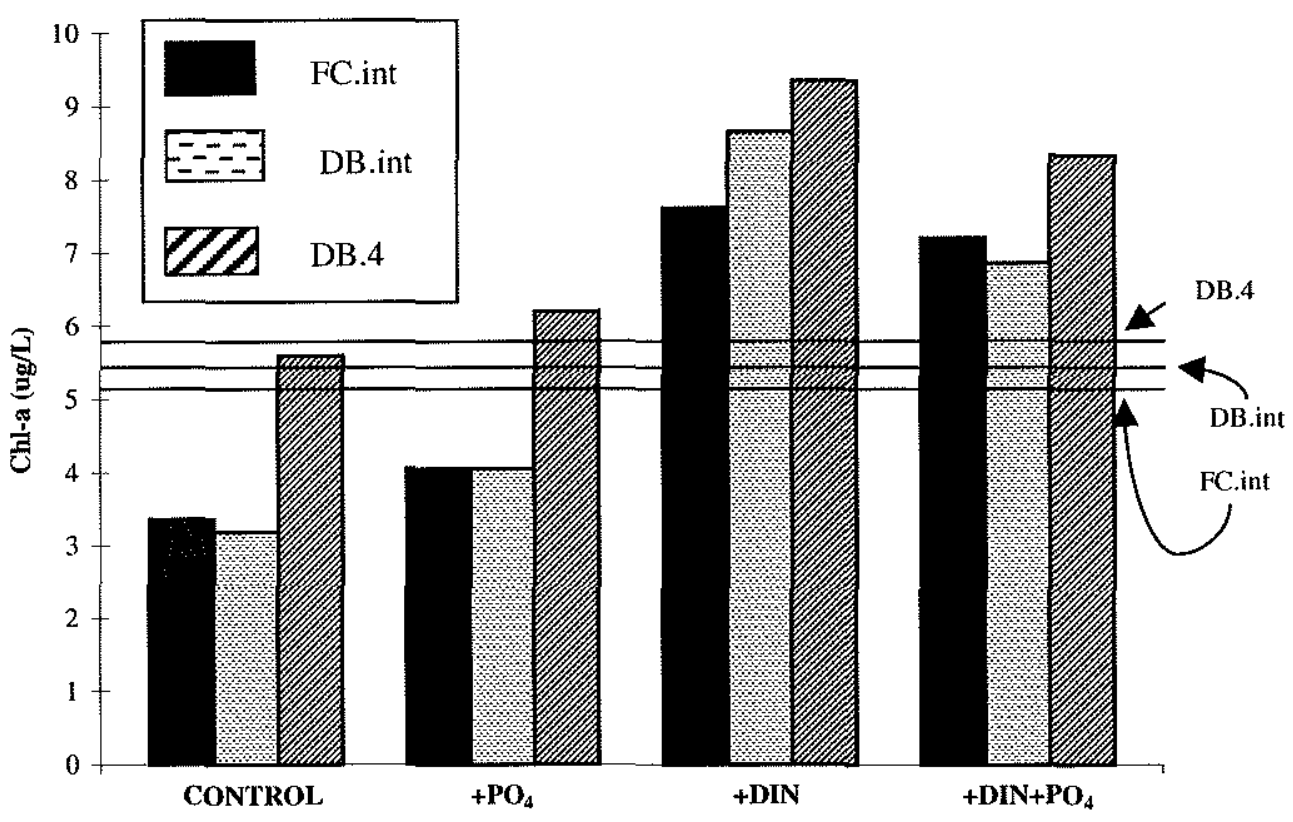


Figure 4.13: Pond-wide homogeneity for Deep Basin $0 \mathrm{~m}$. Solid lines denote Deep Basin $0 \mathrm{~m}$. Dotted lines denote pond wide averages at $0 \mathrm{~m}$ with error bars represented as standard deviation over triplicates.

a) Alkaline Phosphatase Activity (APA)

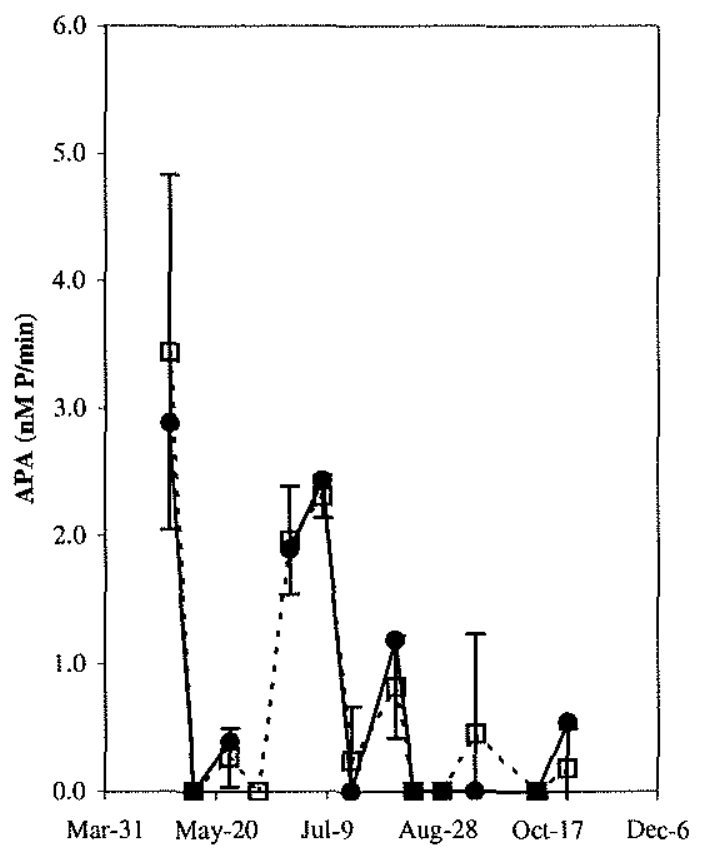

c) Dissolved Inorganic Phosphate (DIP)

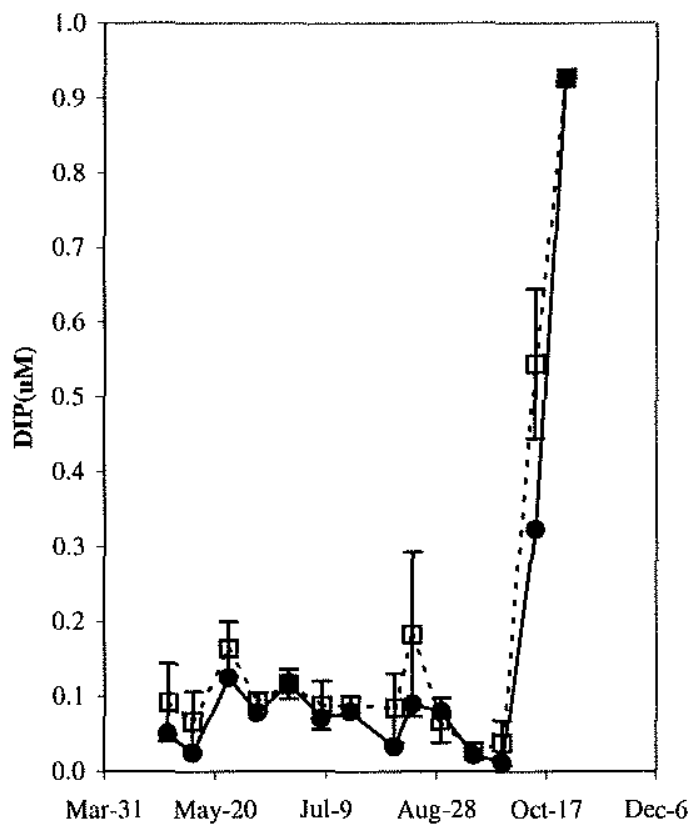

\section{b) Chlorophyll-a}

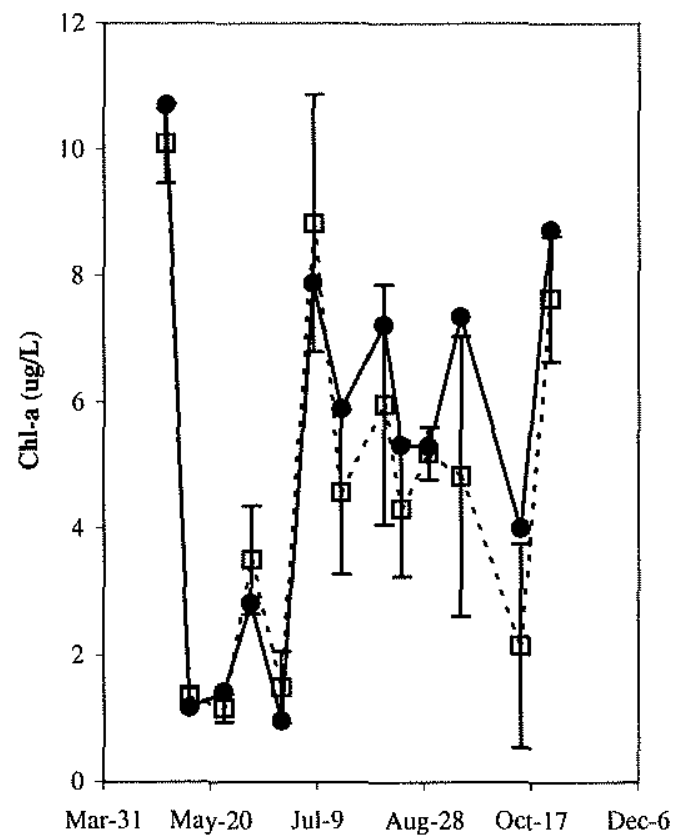

d) Dissolved Inorganic Nitrogen (DIN)

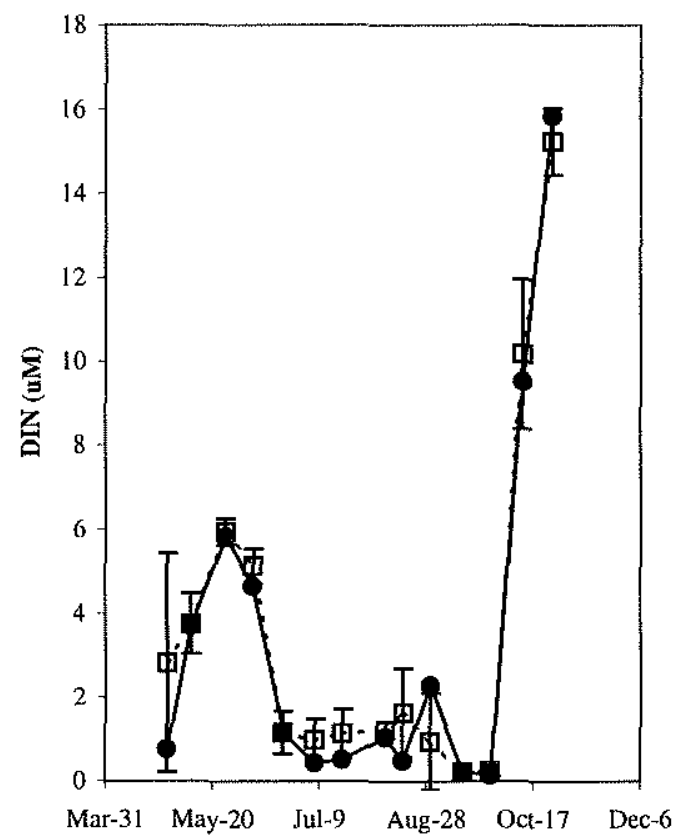


Figure 4.14: Pond-wide homogeneity for Deep Basin $2 \mathrm{~m}$. Solid lines denote Deep Basin $0 \mathrm{~m}$. Dotted lines denote pond wide averages at $0 \mathrm{~m}$ with error bars represented as standard deviation over triplicates.

a) Alkaline Phosphatase Activity (APA)

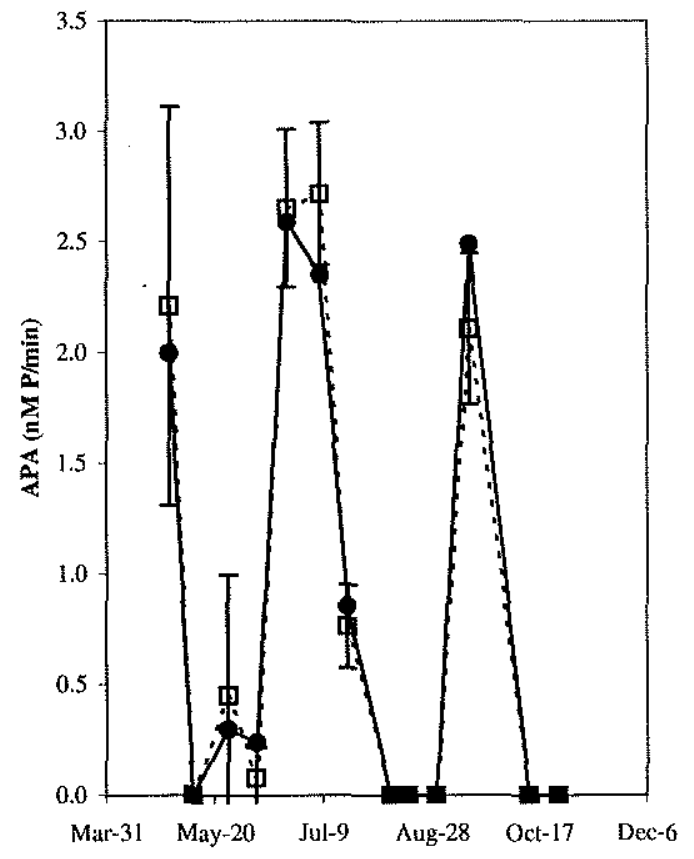

c) Dissolved Inorganic Phosphate (DIP)

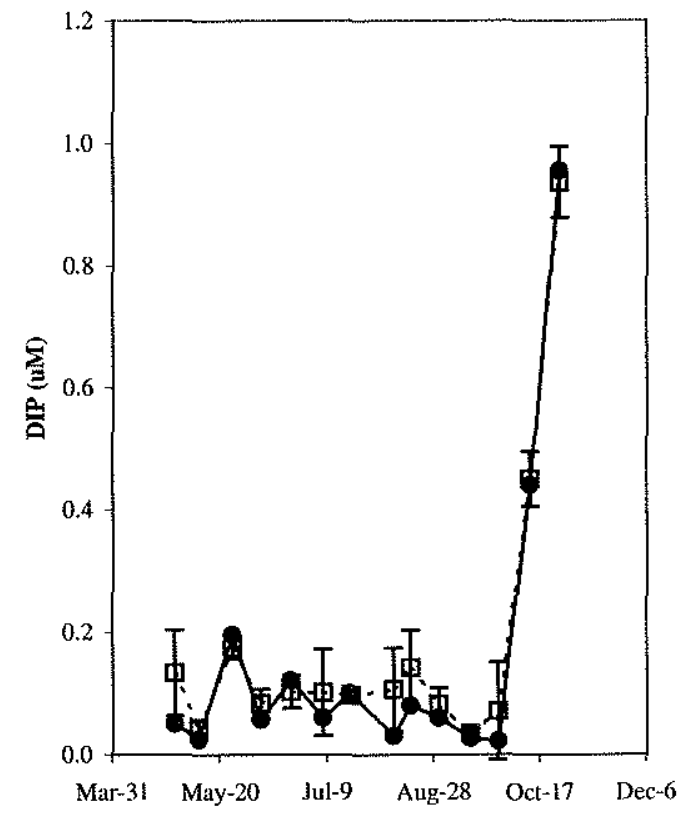

b) Chlorophyll-a

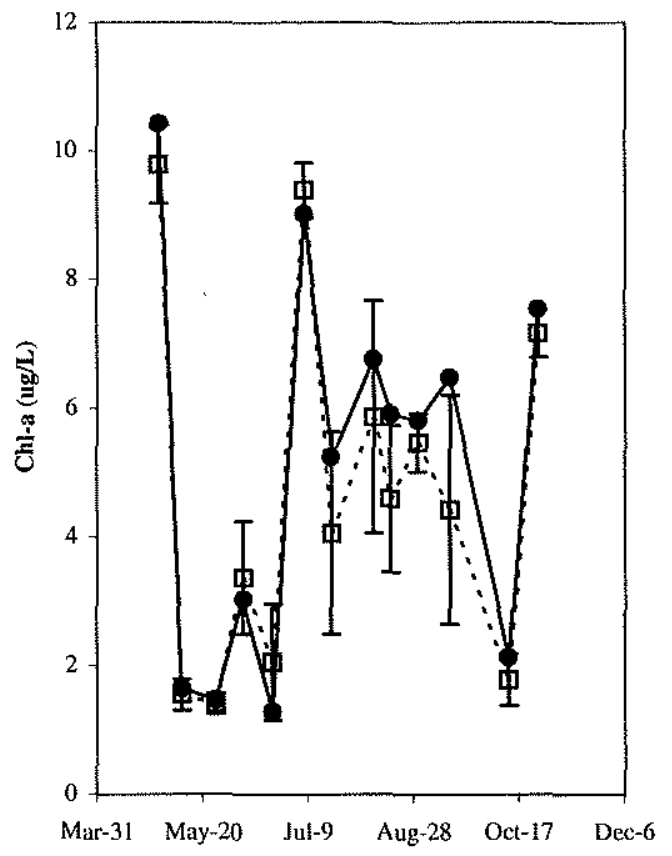

d) Dissolved Inorganic Nitrogen (DIN)

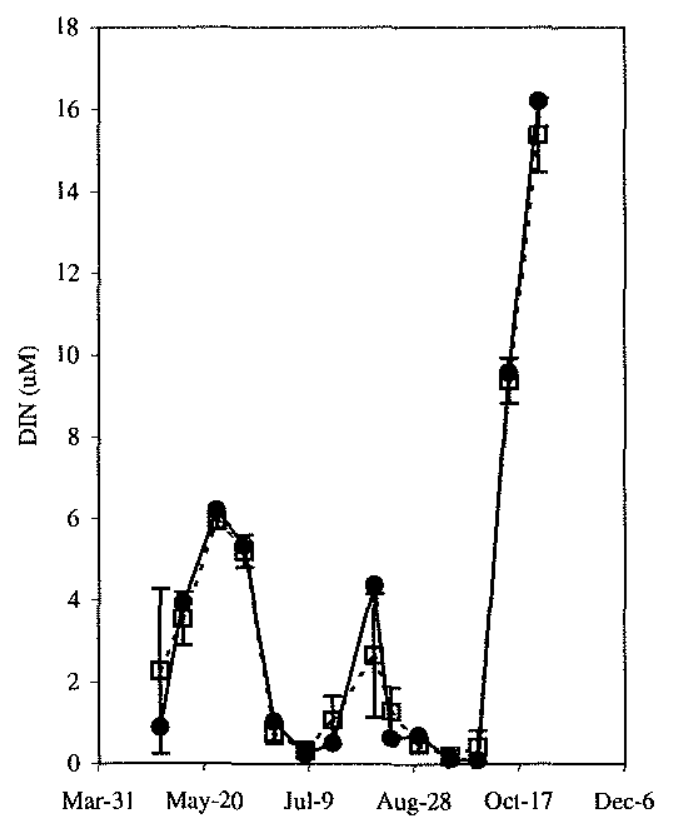


Figure 4.15: Pond-wide homogeneity for Deep Basin $4 \mathrm{~m}$. Solid lines denote Deep Basin $0 \mathrm{~m}$. Dotted lines denote pond wide averages at $0 \mathrm{~m}$ with error bars represented as standard deviation over triplicates.

a) Alkaline Phosphatase Activity (APA)

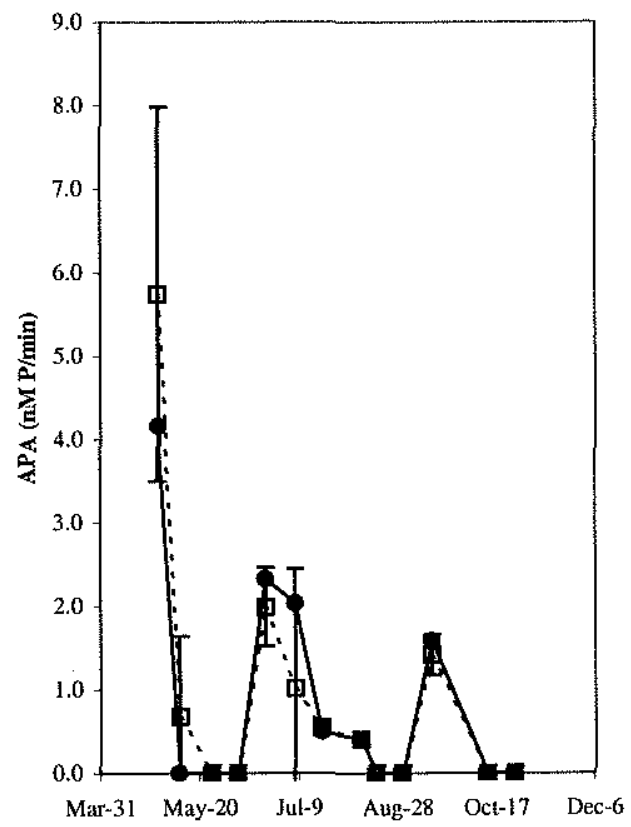

c) Dissolved Inorganic Phosphate (DIP)

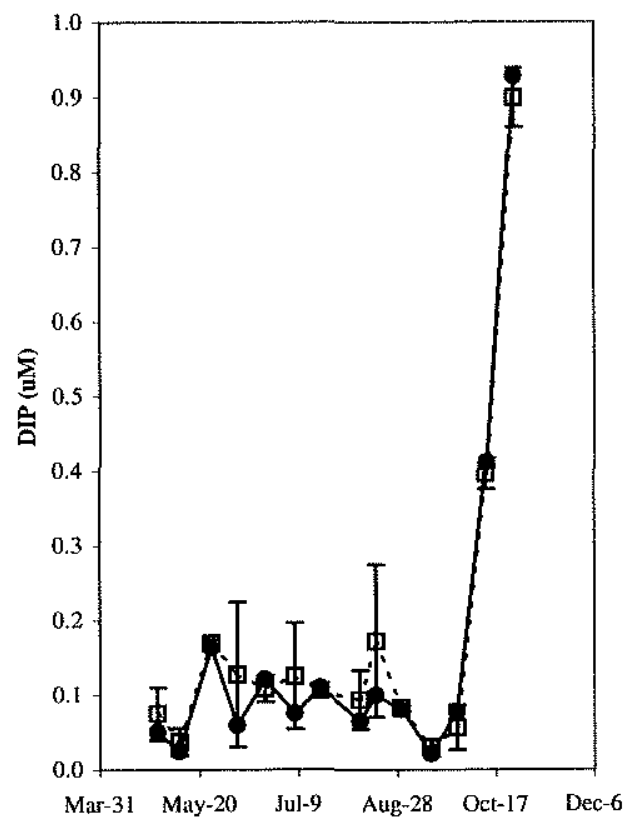

b) Chlorophyll-a

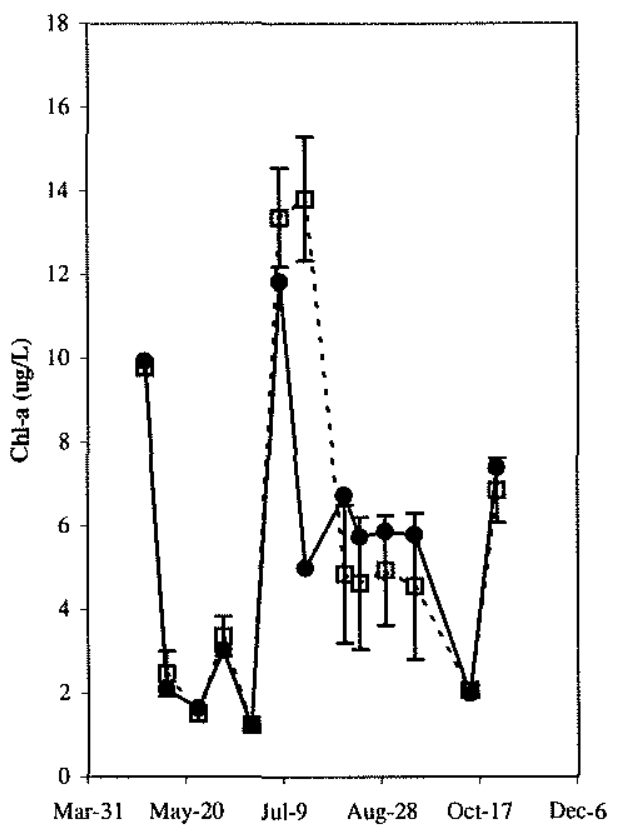

d) Dissolved Inorganic Nitrogen (DIN)

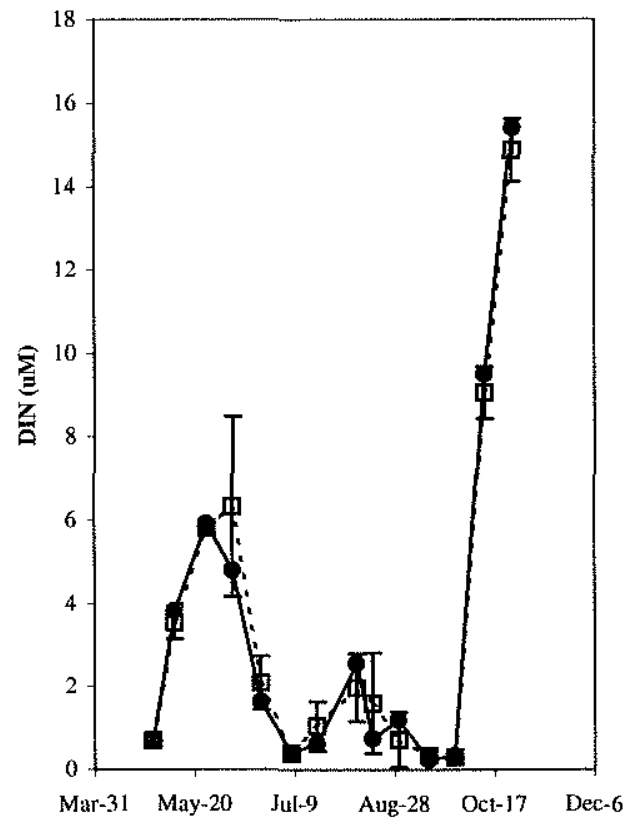


Figure 4.16: The seasonal trends of (a) Dissolved Inorganic Nitrogen (DIN) and (b) Dissolved Inorganic Phosphorus (DIP) for Deep Basin 0, 2, and $4 \mathrm{~m}$.

(a)

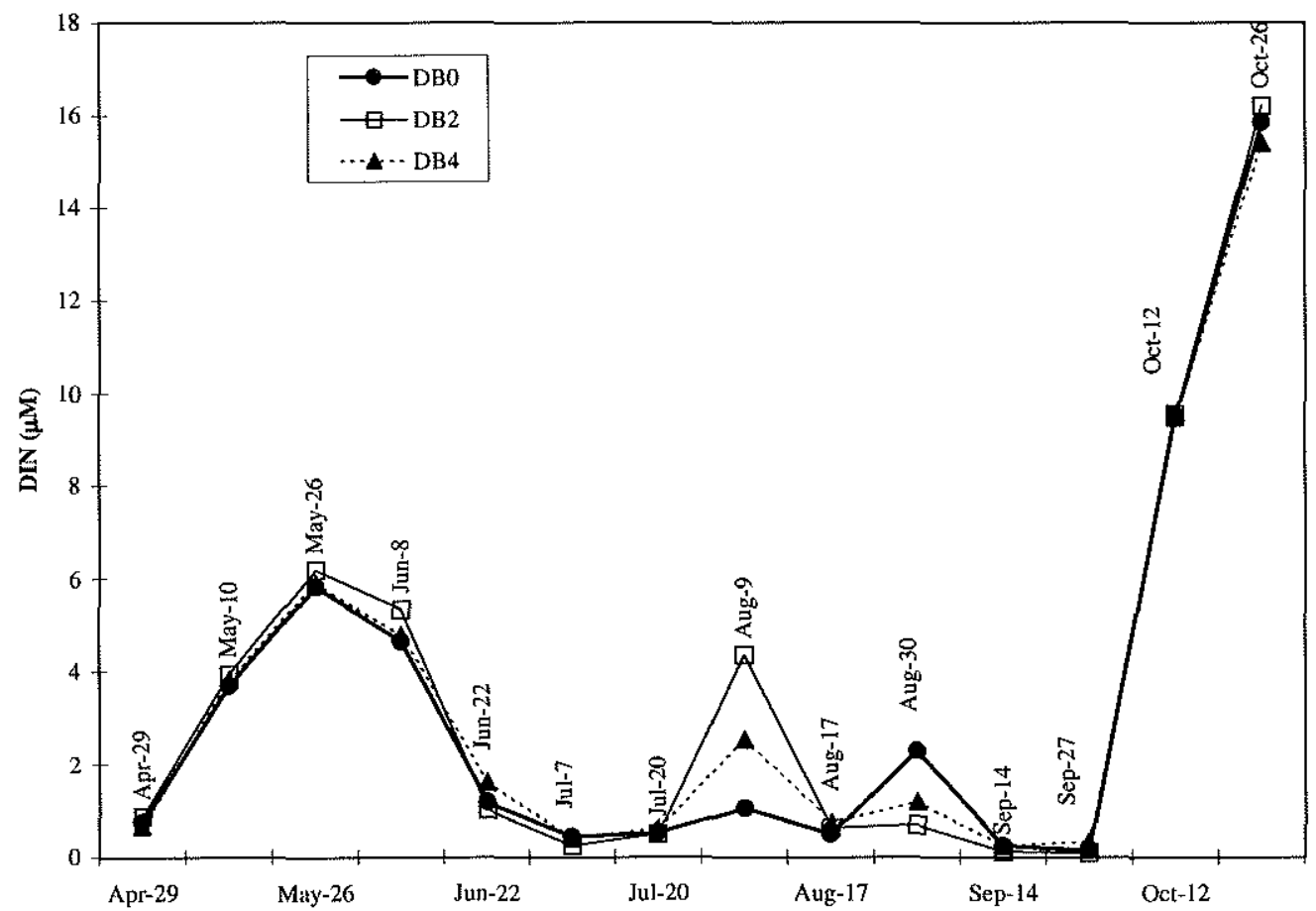

(b)

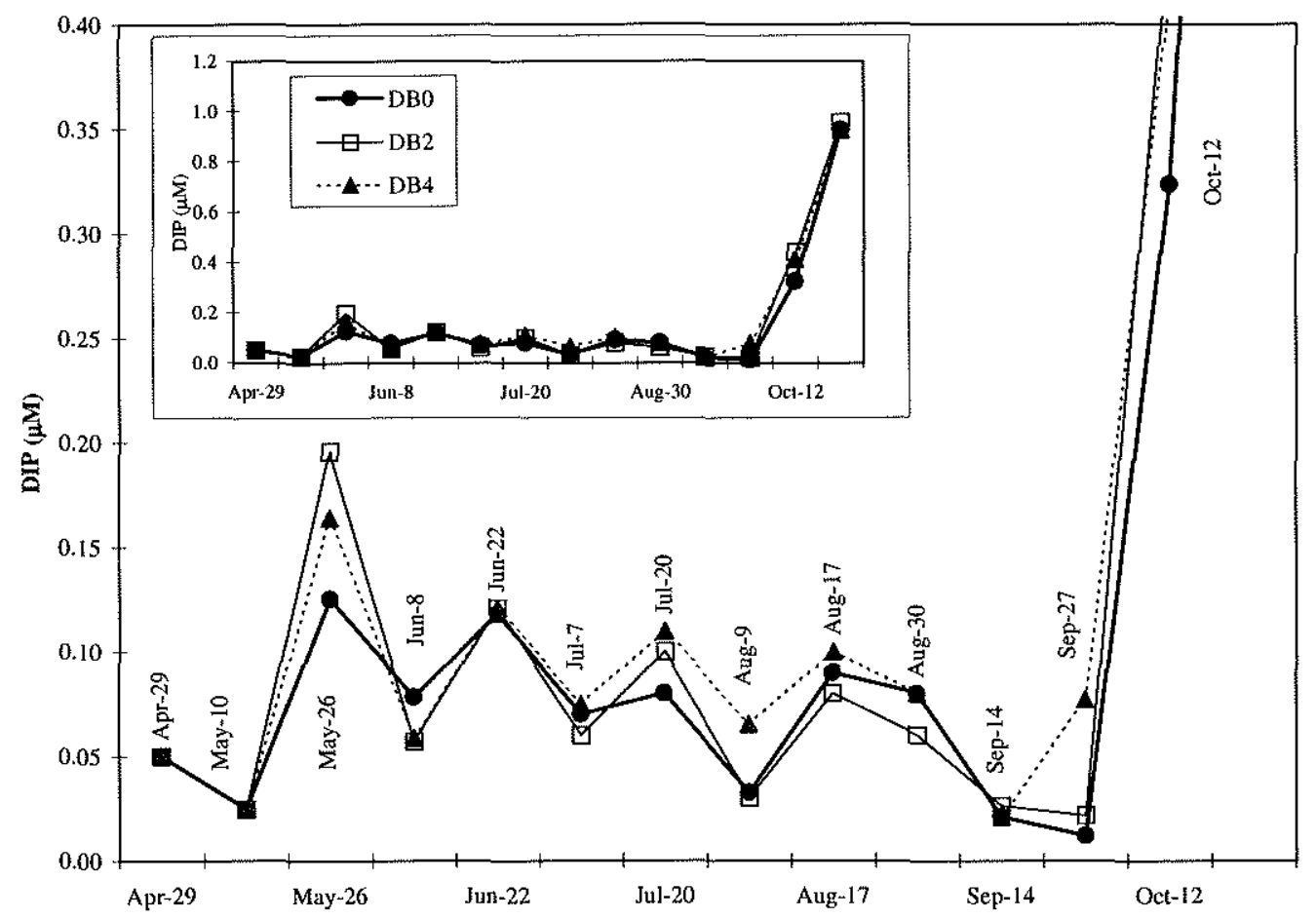


Figure 4.17: The seasonal trends of (a) Alkaline Phosphatase Activity (APA) and (b) Chlorophyll-a (Chl-a) for Deep Basin 0, 2, and $4 \mathrm{~m}$.

(a)

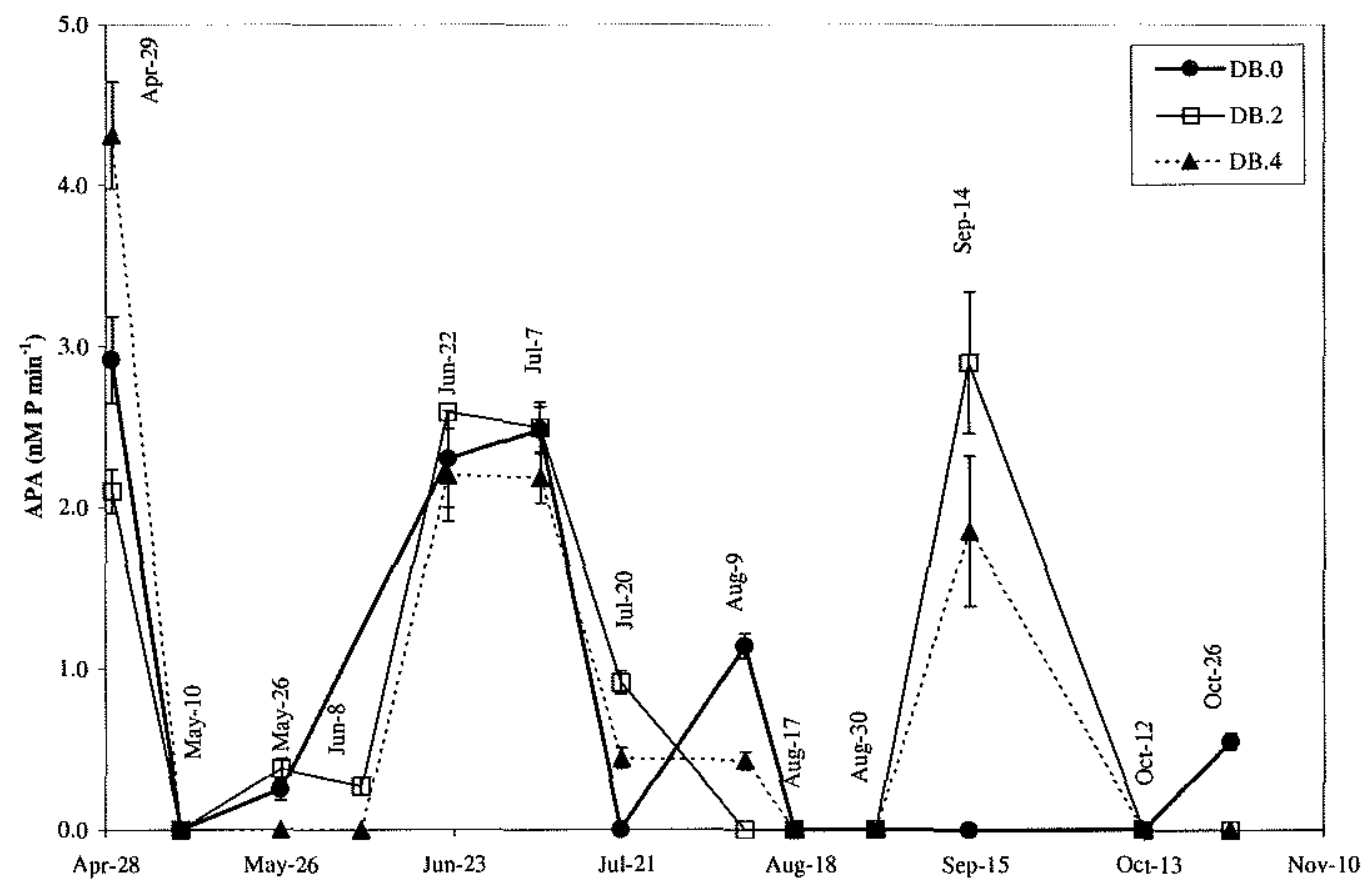

(b)

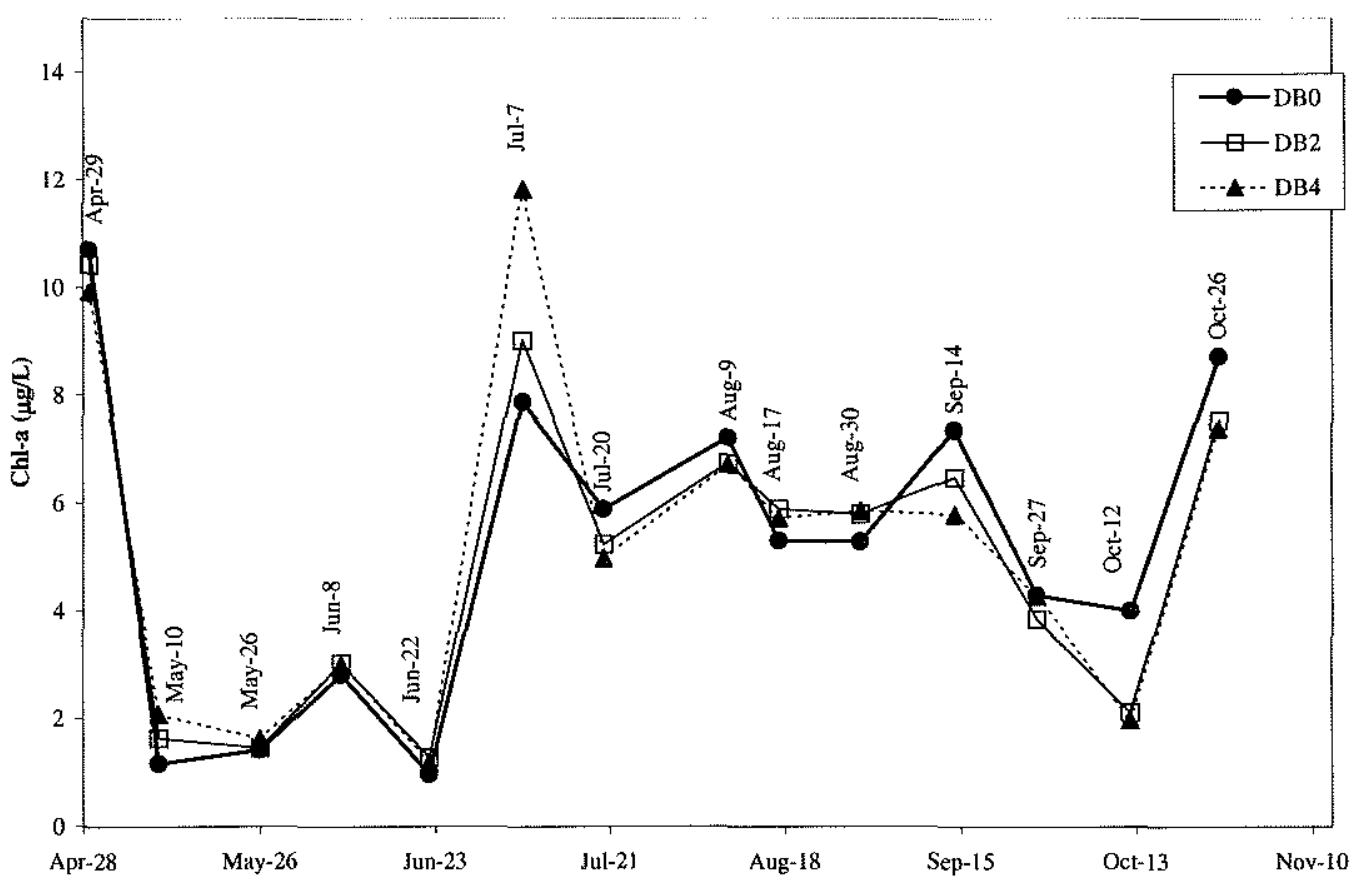


Figure 4.18: Dissolved inorganic and particulate nutrient ratios compared to alkaline phosphatase activity (APA) for Deep Basin $0 \mathrm{~m}$. (a) Ratio of dissolved inorganic nitrogen (DIN) to dissolved inorganic phosphorus (DIP) vs. APA. The dotted line represents the 16 N: 1 P Redfield Ratio. (b) Ratio of particulate carbon (POC) to particulate phosphorus (PP) vs. APA. The dotted line represents the 106 C: 1 P Redfieid Ratio (Redfield, 1958) and solid lines represent $129 \mathrm{C}$ : $1 \mathrm{P}$ and $258 \mathrm{C}$ : $1 \mathrm{P}$ ratios determined by Healey and Hendzel (H\&H) (1980). Arrows indicate the direction of limitation. Nutrient limitation indicated similarly is denoted by the star.
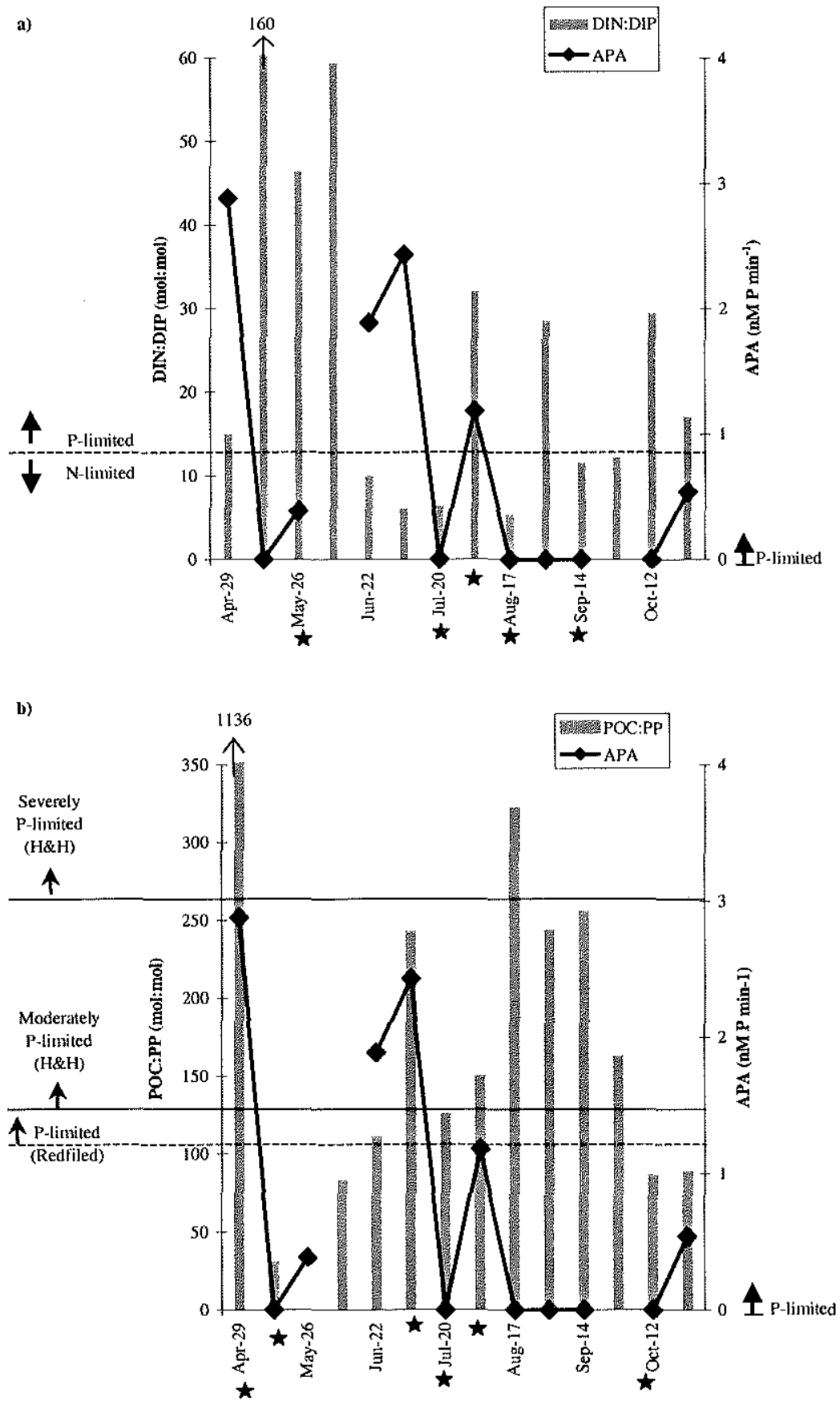
Figure 4.19: Dissolved inorganic and particulate nutrient ratios compared to alkaline phosphatase activity (APA) for Deep Basin $2 \mathrm{~m}$. (a) Ratio of dissolved inorganic nitrogen (DIN) to dissolved inorganic phosphorus (DIP) vs. APA. The dotted line represents the 16 N: 1 P Redfield Ratio. (b) Ratio of particulate carbon (POC) to particulate phosphorus (PP) vs. APA. The dotted line represents the 106 C: 1 P Redfield Ratio (Redfield, 1958) and solid lines represent $129 \mathrm{C}: 1 \mathrm{P}$ and $258 \mathrm{C}$ : $1 \mathrm{P}$ ratios determined by Healey and Hendzel (H\&H) (1980). Arrows indicate the direction of limitation. Nutrient limitation indicated similarly is denoted by the star.
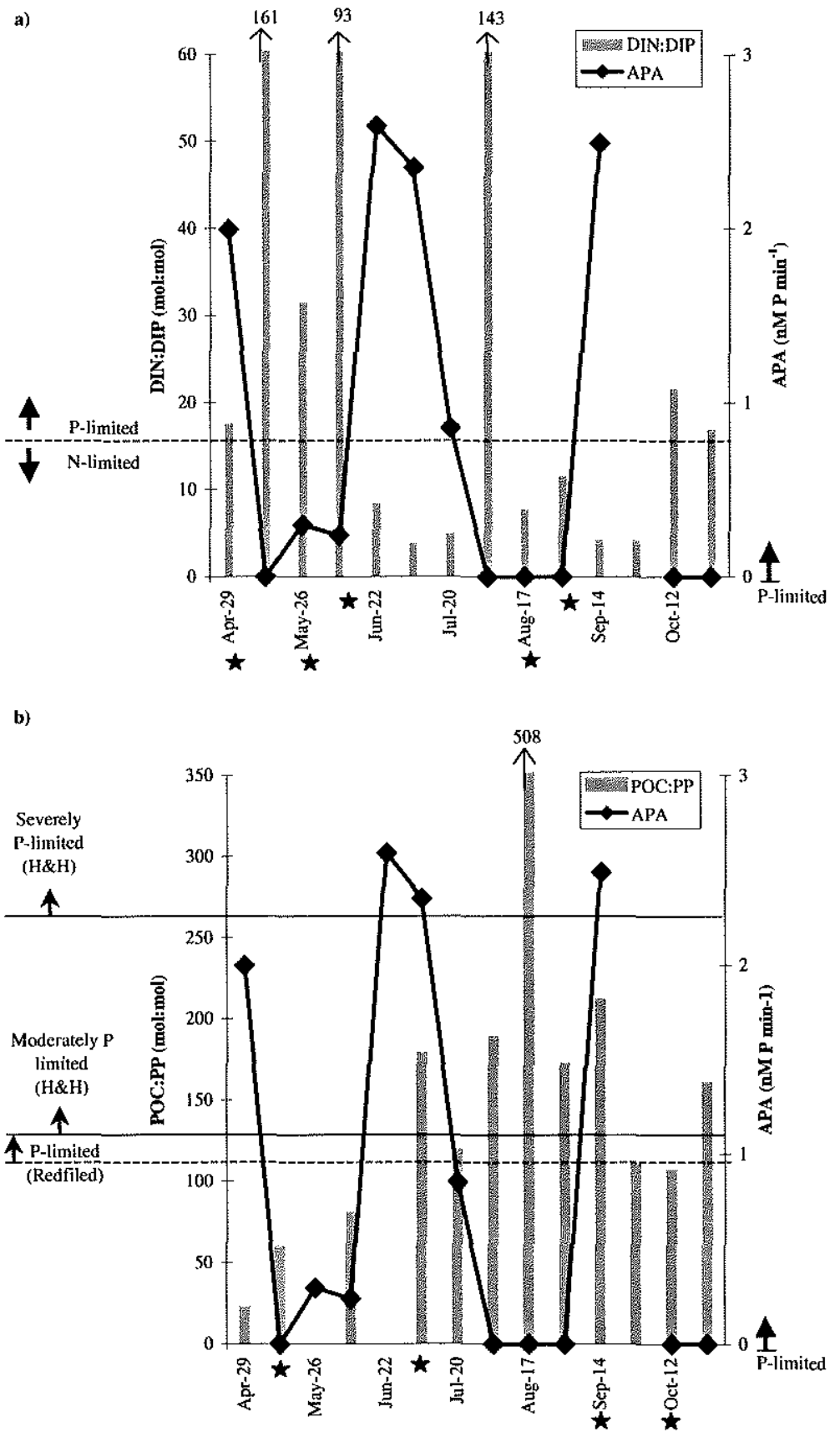
Figure 4.20: Dissolved inorganic and particulate nutrient ratios compared to alkaline phosphatase activity (APA) for Deep Basin $4 \mathrm{~m}$. (a) Ratio of dissolved inorganic nitrogen

(DIN) to dissolved inorganic phosphorus (DIP) vs. APA. The dotted line represents the $16 \mathrm{~N}: 1$ $P$ Redfield Ratio. (b) Ratio of particulate carbon (POC) to particulate phosphorus (PP) vs. APA. The dotted line represents the $106 \mathrm{C}: 1 \mathrm{P}$ Redfield Ratio (Redfield, 1958) and solid lines represent 129 C: $1 P$ and 258 C: 1 P ratios determined by Healey and Hendzel (H\&H) (1980). Arrows indicate the direction of limitation. Nutrient limitation indicated similarly is denoted by the star.
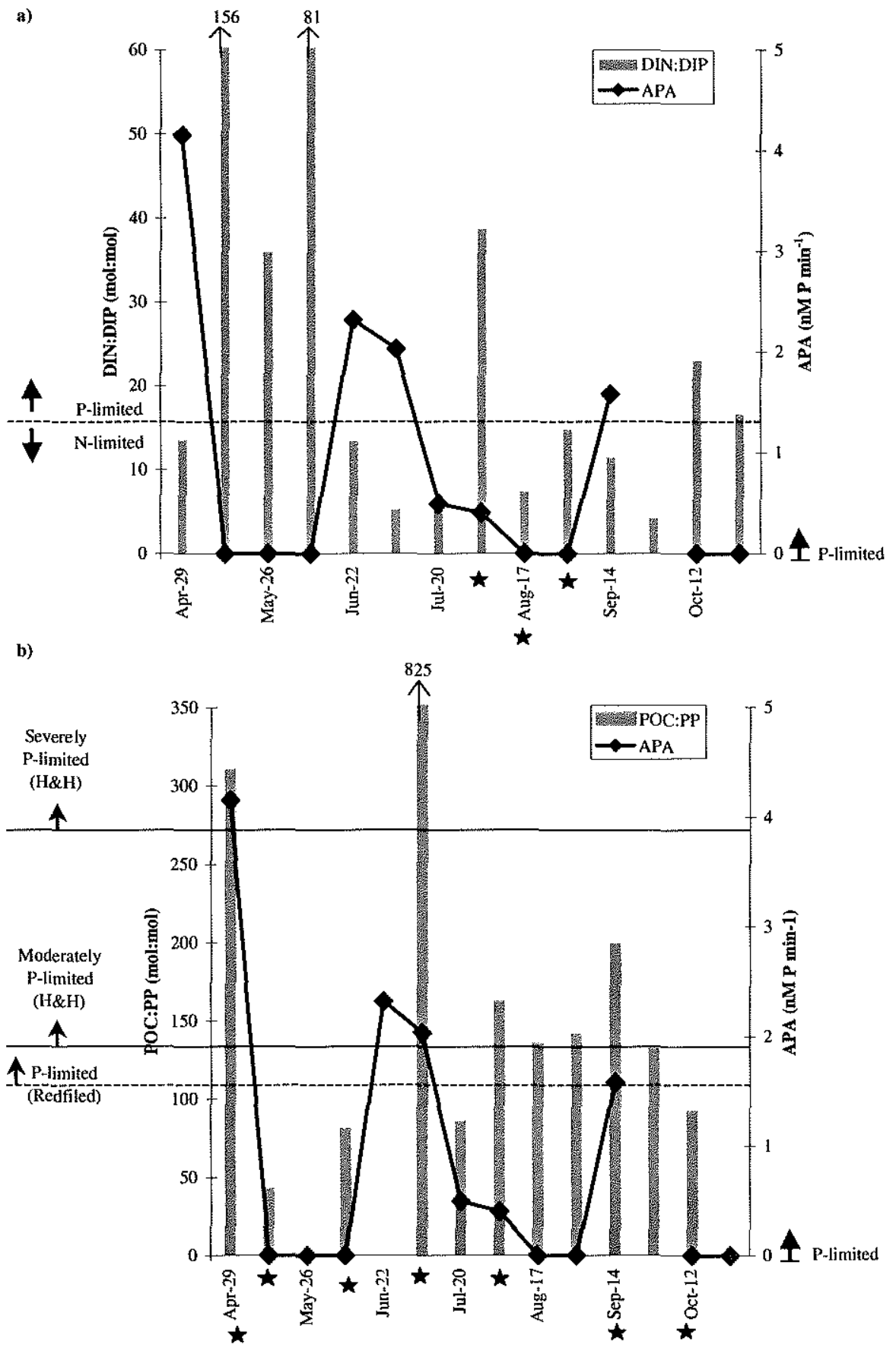
Figure 4.21: Additive amounts of the dominant phytoplankton classes in Ashumet Pond. The study period is sectioned off by dotted lines signifying major changes in the dominant class of phytoplankton. Cell counts are reported as biomass.

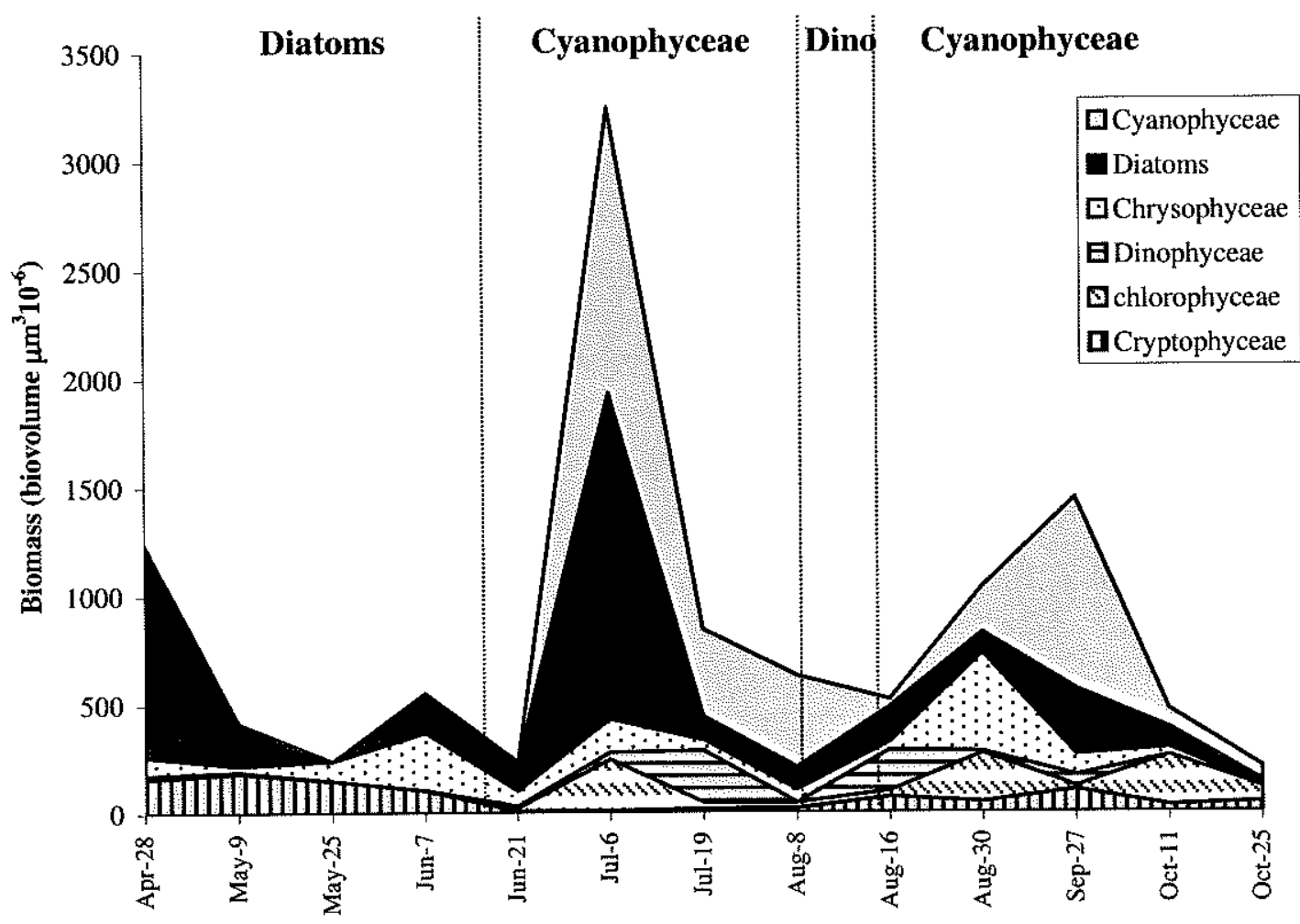


Figure 4.22: Deep Basin $0 \mathrm{~m}$ seasonal trends in alkaline phosphatase activity (APA) overlain on a) chlorophyll-a (Chl-a), b) dissolved inorganic phosphorus (DIP), and c) dissolved inorganic nitrogen (DIN). The dominant phytoplankton species are listed, with dotted lines signifying major changes in the dominant phytoplankton class.

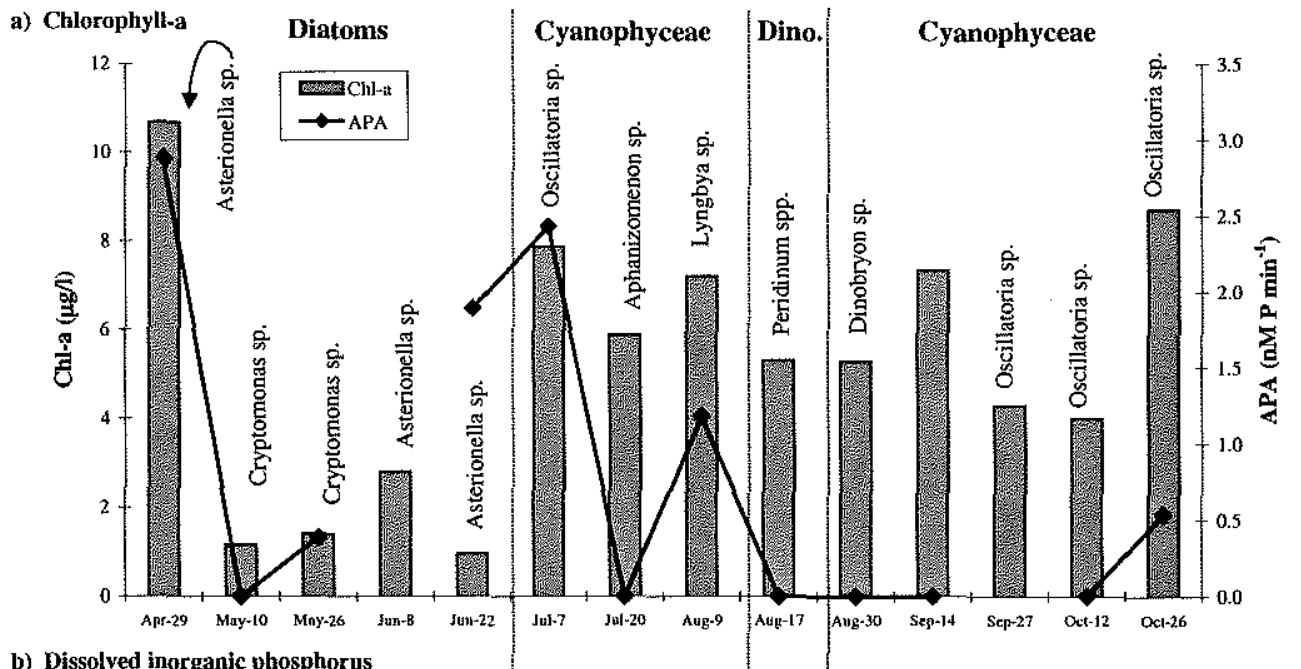

b) Dissolved inorganic phosphorus

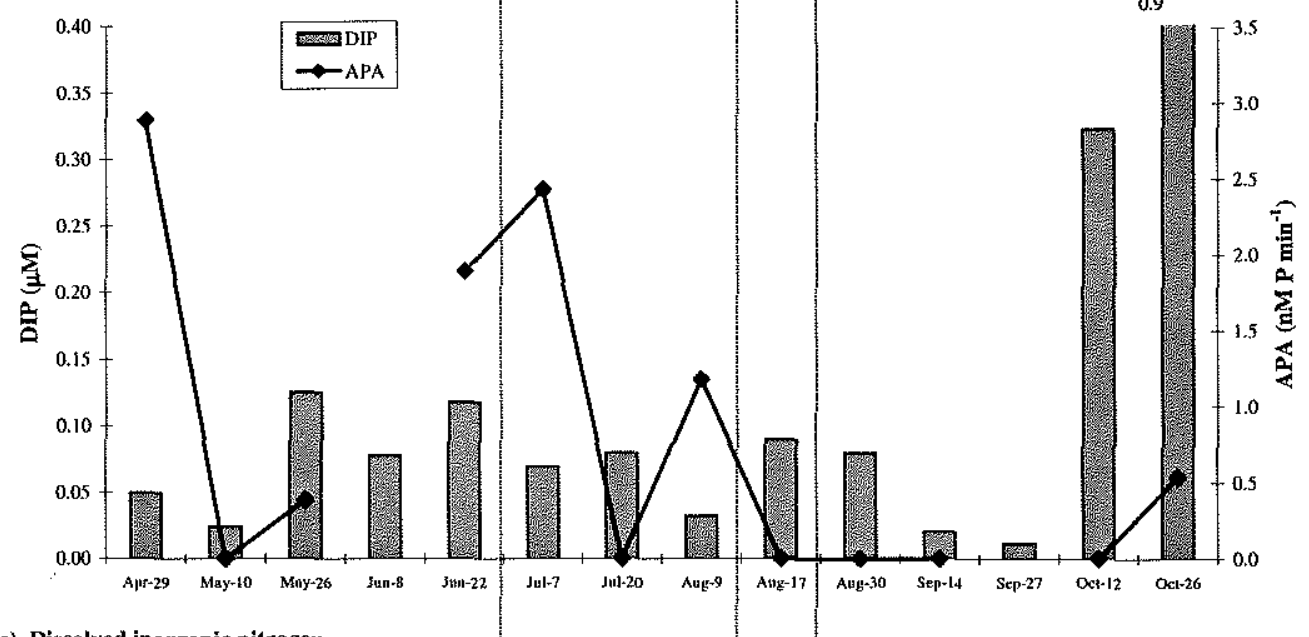

c) Dissolved inorganic nitrogen

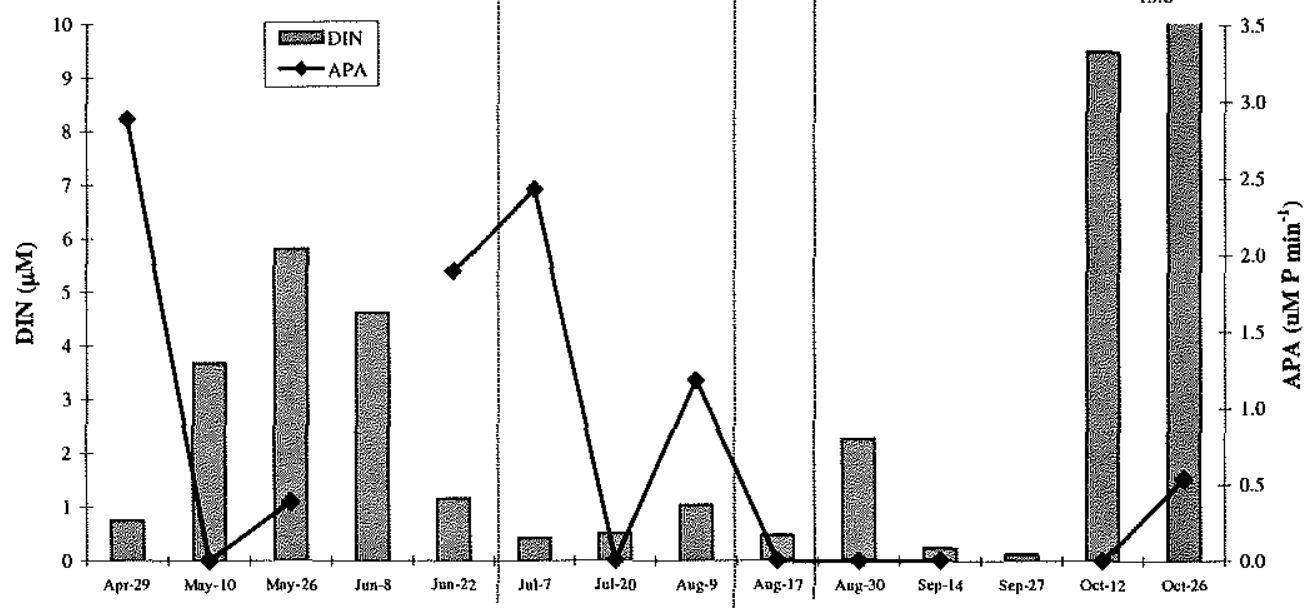


Figure 4.23: Dissolved inorganic phosphate (DIP) threshold for alkaline phosphatase activity (APA) in Ashumet Pond. All samples points from all sampling dates are plotted.

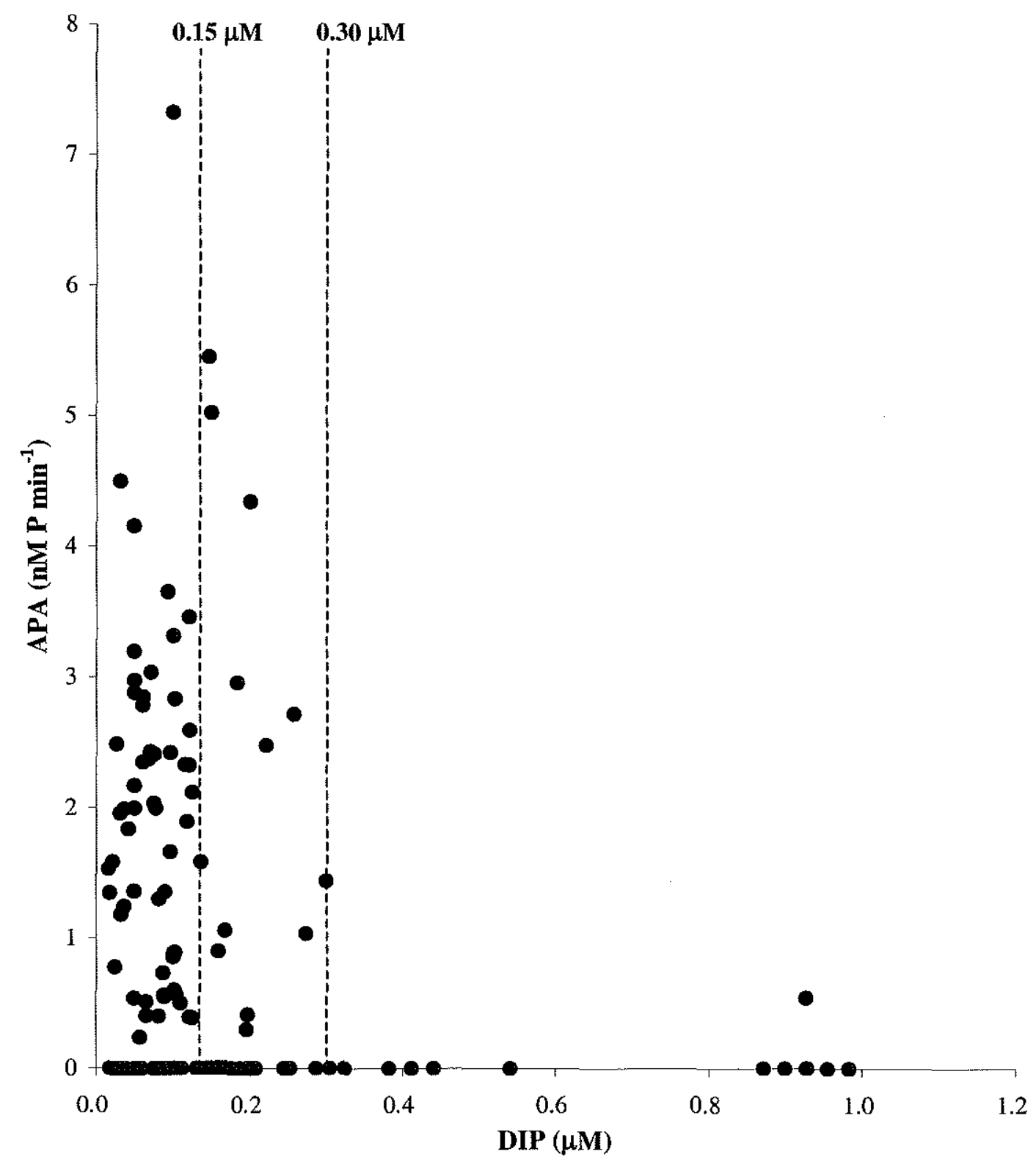




\section{REFERENCES}

AFCEE (U.S. Air Force Center for Environmental Excellence) (1994) Evaluation of the present and potential future health of Ashumet Pond. Prepared by Peter Shanahan, Hydro Analysis, Inc.

AFCEE (U.S. Air Force Center for Environmental Excellence) (1999) Ashumet Pond Well Field Design Report and Phosphorus Execution Plan. AFC-J23-35S18402M23-0001. Prepared by Jacobs Engineering.

AFCEE (U.S. Air Force Center for Environmental Excellence) (2000) Draft Ashumet Pond Trophic Health Technical Memorandum, Vol 1 and 2. AFC-J23-S18402M17-005. Prepared by Jacobs Engineering, including contributions from the University of Massachusetts Center for Marine Science and Technology, the United States Geological Survey, and the Woods Hole Oceanographic Institution.

Berman T. (1970) Alkaline phosphatases and phosphorus availability in Lake Kinneret. Limnology and Oceanography 15(5), 663-674.

Berman T. (1988) Differential uptake of orthophosphate and organic phosphorus substrates by bacteria and algae in Lake Kinneret. Journal of Plankton Research 10, 1239-1249.

Bjorkman K. and Karl D. M. (1994) Bioavailability of inorganic phosphorus compounds to natural assemblages of microorganisms in Hawaiian coastal waters. Marine Ecology-Progress Series 111, 265-273.

Bussey K. W. and Walter D. A. (1996) Spatial and temporal distribution of specific conductance, boron, and phosphorus in a sewage-contaminated aquifer near Ashumet Pond, Cape Cod, Massachusetts. U.S. Geological Survey. Open-File Report 96-472.

Canfield D. E. (1993) Organic matter oxidation in marine sediments. In Interactions of $C$, $N, P$ and $S$ Biogeochemical Cycles and Global Change, Vol. I 4 (ed. R. Wollast, F. T. Mackenzie, and L. Chou), pp. 333-363. Springer-Verlag.

Cembella A. D., Anita N. J., and Harrison P. J. (1984) The utilization of inorganic and organic phosphorous compounds as nutrients by eukaryotic microalgae: A multidisciplinary perspective: Part I. CRC Critical Reviews in Microbiology 10(4), 317-391. 
Chróst R. J. and Krambeck H. J. (1986) Fluorescence correction for measurements of enzyme activity in natural waters using methylumbelliferyl-substrates. Archiv fur Hydrobiologie 106(1), 79-90.

Chróst R. J. and Overbeck J. (1987) Kinetics of Alkaline Phosphatase Activity and Phosphorus Availability for Phytoplankton and Bacterioplankton in Lake Plußsee (North German Eutrophic Lake). Microbial Ecology 13, 229-248.

Dyhrman S. T. and Palenik B. P. (1997) The identification and purification of a cellsurface aklaline phosphatase from the dinoflagellate Prorocentrum Mimimum (Dinophyceae). Journal of Phycology 33, 602-612.

Eppley R. W. and Peterson B. J. (1979) Particulate organic matter flux and planktonic new production in the deep ocean. Nature 282, 677-680.

Feuillade J., Feuillade M., and Blanc P. (1990) Alkaline phosphatase activity fluctuations and associated factors in a eutrophic lake dominated by Oscillatoria rubescens. Hydrobiologia 207, 233-240.

Fitzgerald G. P. and Nelson T. C. (1966) Extractive and enzymatic analyses for limiting or surplus phosphorus in algae. Journal of Phycology 2, 32-37.

GraphPad. (2000) Nonlinear regression analysis program entitled GraphPad Prism ${ }^{\circledR}$ used to estimate $\mathrm{V}_{\max }$ and $\mathrm{K}_{\mathrm{m}}$ values from Michealis-Menten equation, available at www.graphpad.com/prism/.

Gonzalez-Gil S., Keafer B. A., Jovine R. V. M., Aguilera A., Lu S., and Anderson D. M. (1998) Detection and quantification of alkaline phosphatase in single cells of phosphorus-starved marine phytoplankton. Marine Ecology-Progress Series 164, 21-35.

Hantke B., Domany I., Fleischer P., Koch M., Pleb P., Wiendl M., and Melzer A. (1996) Depth profiles of the kinetics of phosphatase activity in hardwater lakes of different trophic level. Archiv fur Hydrobiologie 135(4), 451-471.

Healey F. P. and Hendzel L. L. (1979) Indicators of phosphorus and nitrogen deficiency in five algae in culture. J. Fish. Res. Board Can 36, 1364-1369.

Healey F. P. and Hendzel L. L. (1980) Physiological Indicators of Nutrient Deficiency in Lake Phytoplankton. Canadian Journal of Fisheries and Aquatic Sciences 37, $442-453$.

Hecky R. E., Campbell P. G., and Hendzel L. L. (1993) The stoichiometry of carbon, nitrogen, and phosphorus in particulate matter of lakes and oceans. Limnology and Oceanography 38(4), 709-724. 
Hecky R. E. and Kilham P. (1988) Nutrient limitation of phytoplankton in freshwater and marine environments: A review of recent evidence on the effects of enrichment. Limnology and Oceanography 33(4), 796-822.

Istvanovics V., Pettersson K., Pierson D., and Bell R. (1992) Evaluation of phosphorus deficiency indicators for summer phytoplankton in Lake Erken. Limnology and Oceanography 37(4), 890-900.

Jansson M., Olsson H., and Pettersson K. (1988) Phosphatases; origin, characteristics and function in lakes. Hydrobiologia 170, 157-175.

Jones G., Wortberg M., Kreissig S. B., Hammock B. D., and Rocke D. M. (1996) Application of the Bootstrap to Calibration Experiments. Analytical Chemistry 68, 763-770.

Karl D. M. (1999) A Sea of Change: Biogeochemical Variability in the North Pacific Subtropical Gyre. Ecosystems 2, 181-214.

Kim E. E. and Wyckoff H. W. (1991) Reaction Mechanism of Alkaline Phosphatase Based on Crystal Structures: Two-metal Ion Cayalysis. Journal of Molecular Biology 218, 449-464.

Kuenzler E. J. and Perras J. P. (1965) Phosphatases of marine algae. Biological Bulletin 128, 271-284.

LeBlanc D. R. (1984) Sewage Plume in a Sand and Gravel Aquifer, Cape Cod Massachusetts. Water-Supply Paper 2218, U.S. Geological Survey, Denver, Colorado.

MacTaggart D. L. and Farwell S. O. (1998) Realistic detection limits. American Environmental Laboratory 10.

McCarthy J. J. (1980) Nitrogen. In The physiological Ecology of Phytoplankton (ed. I. Morris), pp. 191-233. Blackwell.

McComb R. B., Bowers G. N., Jr., and Posen S. (1979) Alkaline Phosphatase. Plenum Press.

Monaghan E. J. and Ruttenberg K. C. (1999) Dissolved organic phosphorus in the coastal ocean: Reassessment of available methods and seasonal phosphorus profiles from the Eel River Shelf. Limnology and Oceanography 44(7), 1702-1714.

Mortimer C. H. (1941) The exchange of dissolved substances between mud and water in lakes (Parts I and II). Journal of Ecology 29, 280-329. 
Mortimer C. H. (1942) The exchange of dissolved substances between mud and water in lakes (Parts III and IV, summary, and references). Journal of Ecology 30, 147201.Oxtoby D. W. and Nachtrieb N. H. (1990) Principles of Modern Chemistry. Saunders College Publishing.

Nauwerck A. (1963) Die Beziehungen zwischen Zooplanton und Phytoplankton im See Eken. Sumbolae Botanicae Upsalienses 17, 1-163.

Oxtoby D. W. and Nachtrieb N. H. (1990) Principles of Modern Chemistry. Saunders College Publishing.

Parsons T. R., Takahashi M., and Hargrave B. (1984) Chemical Composition. In Biological Oceanographic Processes, pp. 37-60. Pergamon Press.

Perry M. J. (1972) Alkaline phosphatase activity in subtropical Central North Pacific waters using a sensitive fluorometric method. Marine Biology 15, 113-119.

Pettersson K. (1980) Alkaline phosphatase activity and algal surplus phosphorus as phosphorus-deficiency indicators in Lake Erken. Archiv fur Hydrobiologie 89(1/2), 54-87.

Pettersson K. and Jansson M. (1978) Determination of phosphatase activity in lake watera study of methods. Verh. Internat. Verein. Limnol. 20, 1226-1230.

Plummer C. C. and McGeary D. (1979) Physical Geology. Wm. C. Brown Publishers.

Redfield A. C. (1958) The biological control of chemical factors in the environment. American Scientist 46, 205-222.

Rengefors K. (2000): Performed phytoplankton species counts on all Ashumet Pond samples. WHOI Post Doctoral Fellow.

Rengefors K., Haupert C. L., Ruttenberg K. C., Taylor C., Howes B. L., and Anderson D. M. (2000) Species-specific response in alkaline phosphatase activity of freshwater phytoplankton in a nutrient enrichment experiment. submitted to Limnology and Oceanography (11/2000).

Reynolds C. S. (1984) The ecology of freshwater phytoplankton. Cambridge University Press.

Riegman R., Stolte W., Noordeloos A. A. M., and Slezak D. (2000) Nutrient Uptake and Alkaline Phosphatase (EC 3:1:3:1) Activity of Emiliania huxleyi (Prymnesiophyceae) during Growth under $\mathrm{N}$ and $\mathrm{P}$ Limitation in Continuous Cultures. Journal of Phycology 36, 87-96. 
Rivkin R. B. and Swift E. (1980) Characterization of Alkaline Phhosphatase and Organic Phosphorus Utilization in the Oceanic Dinoflagellate Pyrocystis noctiluca. Marine Biology 61, 1-8.

Rose C. and Axler R. P. (1998) Uses of alkaline phosphatase activity in evaluating phytoplankton community phosphorus deficeincy. Hydrobiologia 361, 145-156.

Rubin P. M., Zetooney E., and McGowan R. E. (1977) Uptake and Utilization of Sugar Phosphates by Anabaena flosaquae. Plant Physiology 60, 407-411.

Ruttenberg K. C., Monaghan E. J., and Keon N. E. (1998) Seasonal Cycle of dissolved organic phosphorus in a coastal marine system: The Eel River Shelf. EOS. Transactions- American Geophysical Union 79(1), OS52.

Schindler D. W. (1977) Evolution of Phosphorus Limitation in Lakes. Science 194, 260262.

Skoog D. A. and Leary J. J. (1992) Principles of instrumental analysis. Saunders College Publishing.

Smith R. E. and Kalff J. (1982) Size-dependent phosphorus uptake kinetics and cell quota in phytoplankton. Journal of Phycology 18(275-284).

Solow A. (2000): Author of bootstrap statistical analysis performed for $V_{\max }$ and $\mathrm{K}_{\mathrm{m}}$ estimates using a Line Weaver-Burk Plot. Director of Woods Hole Marine Policy Center.

Standard Methods. (1992) Standard Methods for the Examination of Water and Wastewater $18^{\text {th }}$ edition. American Public Health Association, American Water Works Association, Water Environment Federation.

Vincent W. F. (1981) Rapid physiological assays for nutrient demand by the plankton. II. Phosphorus. Journal of Plankton Research 3(4), 699-710.

Voet D. and Voet J. (1995) Biochemistry. John Wiley and Sons, Inc.

Wetzel R. G. (1975) Limnology. W.B. Saunders Co.

Whitton B. A. (1991) Use of phosphatase assays with algae to assess phosphorus status of aquatic environments. In Bioindicators and environmental management (ed. D. W. M. jeffrey, B.), pp. 295-310. Academic Press.

Whitton B. A., Grainger S. L. J., Hawley G. R. W., and Simon J. W. (1991) Cell-Bound and Extracellular phosphatase activities of cyanobacterial isolates. Microbial Ecology 21, 85-98. 
Yiyong Z. and Xinyu Z. (1997) Seasonal variation in kinetic parameters of alkaline phosphatase activity in a shallow chinese freshwater lake (Donghu Lake). Water Research 31(5), 1232-1235. 